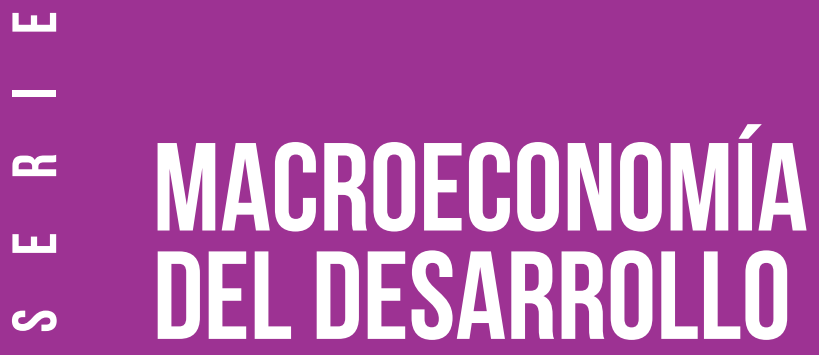

\title{
Políticas fiscales para el crecimiento y la igualdad
}

Ricardo Martner Andrea Podestá

Ivonne González 


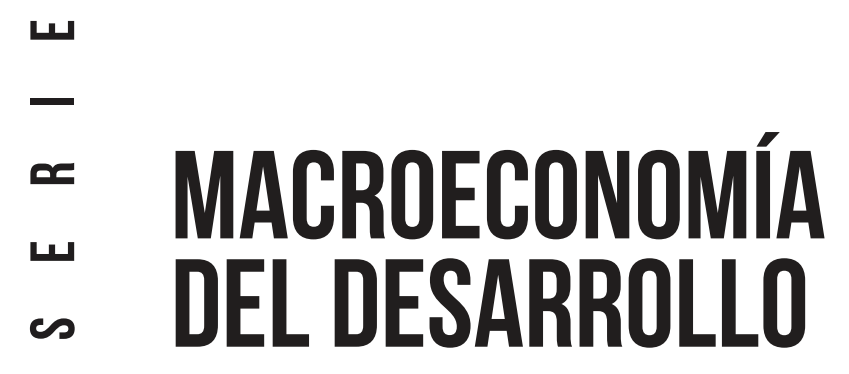

\section{Políticas fiscales para el crecimiento y la igualdad}

Ricardo Martner

Andrea Podestá

Ivonne González
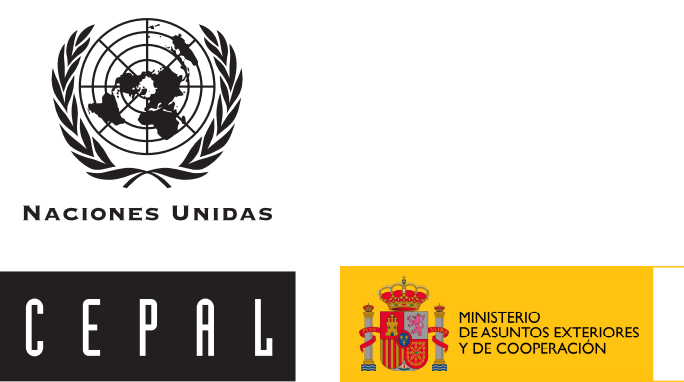

aecid

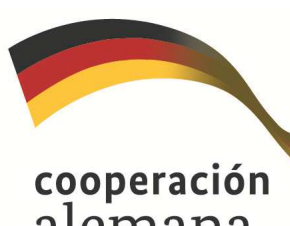

alemana

DEUTSCHE ZUSAMMENARBEIT 
Este documento ha sido preparado por Ricardo Martner, Andrea Podestá e Ivonne González, de la División de Desarrollo Económico de la CEPAL en el marco de las actividades de los proyectos CEPAL/GIZ: "Pacto fiscal para el crecimiento económico y la cohesión social" (GER/12/005), financiado por la cooperación alemana; y CEPAL/AECID: "Política fiscal para el crecimiento económico y la cohesión social" (AEC/11/003).

Se agradece la colaboración de Vianka Aliaga y Leandro Cabello en los cálculos y estimaciones. Se agradecen además los comentarios a una versión preliminar de este trabajo a Juan Alberto Fuentes, Claudio Hamilton, Ignacio Lozano y a los participantes del seminario "Macroeconomía para el crecimiento y la igualdad", organizado por la CEPAL en mayo de 2013. Los datos utilizados están disponibles en CEPALSTAT.

Las opiniones expresadas en este documento, que no ha sido sometido a revisión editorial, son de exclusiva responsabilidad de los autores y pueden no coincidir con las de la organización.

Publicación de las Naciones Unidas

ISSN 1680-8843

LC/L.3716

Copyright (C) Naciones Unidas, octubre de 2013. Todos los derechos reservados

Impreso en Naciones Unidas, Santiago de Chile

Los Estados miembros y sus instituciones gubernamentales pueden reproducir esta obra sin autorización previa. Solo se les solicita que mencionen la fuente e informen a las Naciones Unidas de tal reproducción. 


\section{Índice}

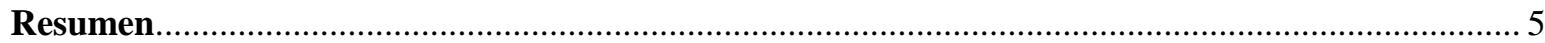

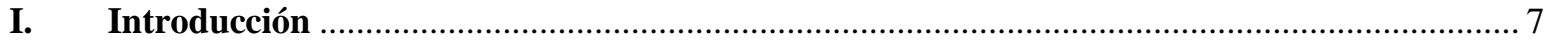

II. Aspectos conceptuales y evidencia empírica del vínculo entre política fiscal

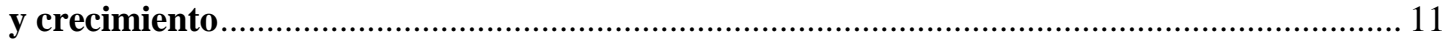

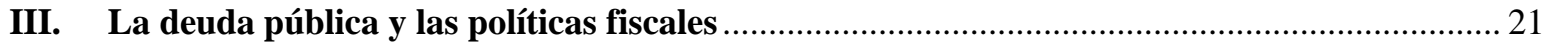

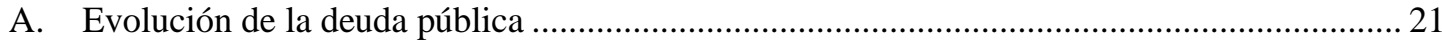

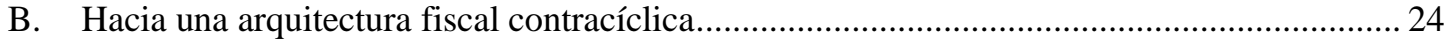

C. La necesidad de fortalecer las instituciones fiscales ................................................................ 42

1. Mayores grados de coordinación de las políticas monetarias y fiscales ......................... 43

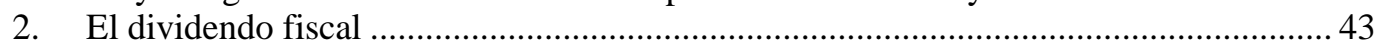

3. El fortalecimiento de la transparencia fiscal ......................................................... 43

4. La adopción de reglas estructurales de balance fiscal .................................................... 44

5. La constitución de fondos de estabilización de materias primas o de tributos ..................44

6. El fortalecimiento de instancias de coordinación con los gobiernos subnacionales ....... 44

IV. La incidencia de gastos e ingresos públicos sobre el crecimiento y la distribución

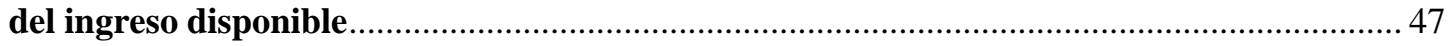

A. La clasificación económica: prioridad a la inversión .................................................................. 47

B. La clasificación funcional: preponderancia para el gasto social ............................................5 50

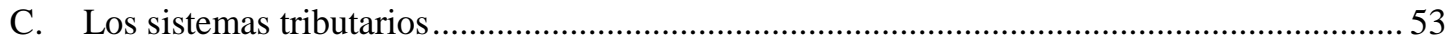

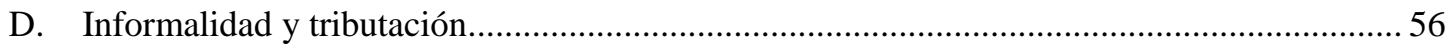

E. Un recuento de los determinantes de la distribución del ingreso ......................................... 57

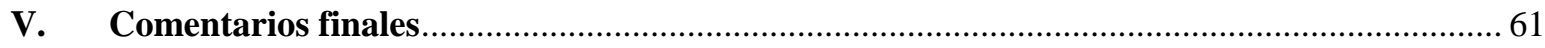

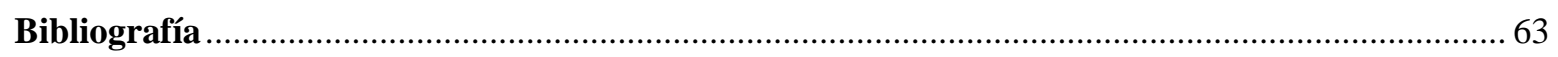

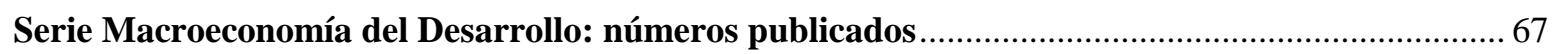




\section{Índice de cuadros}

\begin{tabular}{|c|c|}
\hline CUADRO 1 & $\begin{array}{l}\text { EFECTOS DE CORTO PLAZO DE LA POLÍTICA FISCAL SOBRE } \\
\text { EL CRECIMIENTO: MODELOS ALTERNATIVOS }\end{array}$ \\
\hline & EL CRECIMIENTO: MODELOS ALTERNATIVOS ............................ \\
\hline CUADRO 2 & LITERATURA EMPÍRICA SOBRE LA RELACIÓN ENTRE IMPUESTOS \\
\hline & Y CRECIMIENTO ECONÓMICO: PRINCIPALES RESULTADOS... \\
\hline CUADRO 3 & AUMENTOS DE IMPUESTOS, GASTOS Y DÉFICIT Y SU EFECTO \\
\hline & EN EL CRECIMIENTO . \\
\hline CUADRO 4 & EFECTOS DEL GASTO PÚBLICO SOBRE EL PRODUCTO \\
\hline & EN AMÉRICA LATINA: PANEL DE 20 PAÍSES, 1990-2010. \\
\hline CUADRO 5 & $\begin{array}{l}\text { MÁXIMOS Y MÍNIMOS DE LA BRECHA DEL PIB Y DEL SALDO CÍCLICO, } \\
1990-2012\end{array}$ \\
\hline CUADRO 6 & $\begin{array}{l}\text { AMÉRICA LATINA ( } 20 \text { PAIISES): DIFERENCIAL ENTRE LAS TASAS REALES } \\
\text { DE CRECIMIENTO DEL GASTO PRIMARIO Y DEL PIB }\end{array}$ \\
\hline CUADRO 7 & $\begin{array}{l}\text { EL CARIBE (13 PAÍSES): DIFERENCIAL DE LAS TASAS REALES DE } \\
\text { CRECIMIENTO DEL GASTO PRIMARIO Y DEL PIB }\end{array}$ \\
\hline CUADRO 8 & EJEMPLOS DE IMPACTOS ECONÓMICOS DE LAS FUNCIONES SOCIALES ..........51 \\
\hline CUADRO 9 & CLASIFICACIÓN CRUZADA DEL GASTO ..... \\
\hline CUADRO 10 & $\begin{array}{l}\text { CAMBIOS EN EL COEFICIENTE DE GINI Y EN SUS VARIABLES } \\
\text { EXPLICATIVAS } 2000-2011\end{array}$ \\
\hline
\end{tabular}

\section{Índice de gráficos}

\begin{tabular}{|c|c|}
\hline RÁFICO 1 & AMÉRICA LATINA (19 PAÍSES): DEUDA PÚBLICA EXTERNA (1970-2012) \\
\hline & E INTERNA (1990-2012). \\
\hline GRÁFICO 2 & DINÁMICA DE LA DEUDA PÚBLICA: FACTORES EXPLICATIVOS \\
\hline GRÁFICO 3 & DIFERENCIAS ENTRE BALANCE FISCAL EFECTIVO Y BFCA \\
\hline GRÁFICO 4 & VARIACIÓN DEL BALANCE GLOBAL CÍCLICAMENTE AJUST \\
\hline & Y DE LA BRECHA DEL PIB, 1990-2012 (18 PAÍSES). \\
\hline GRÁFICO 5 & AMÉRICA LATINA: CAMBIOS EN EL GASTO Y LA DEUDA PÚBLICA ........ \\
\hline GRÁFICO 6 & EL CARIBE: CAMBIOS EN EL GASTO Y LA DEUDA PÚBLICA... \\
\hline GRÁFICO 7 & $\begin{array}{l}\text { AMÉRICA LATINA (20 PAÍSES) Y EL CARIBE (13 PAÍSES): COMPOSICIÓN } \\
\text { DEL GASTO PÚBLICO }\end{array}$ \\
\hline GRÁFICO 8 & 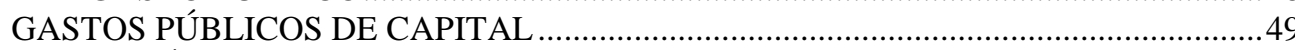 \\
\hline GRÁFICO 9 & GASTO PÚBLICO SOCIAL, 1990-2011 \\
\hline GRÁFICO 10 & COMPOSICIÓN DEL GASTO PÚBLICO SOCIAL. \\
\hline GRÁFICO 11 & $\begin{array}{l}\text { AMÉRICA LATINA (19 PAÍSES) Y EL CARIBE (13 PAÍSES): ESTRUCTURA } \\
\text { TRIBUTARIA (SIN SEGURIDAD SOCIAL) }\end{array}$ \\
\hline GRÁFICO 12 & $\begin{array}{l}\text { ÍNDICE DE GINI Y AÑOS DE EDUCACIÓN DE LA POBLACIÓN } \\
\text { ENTRE } 25 \text { Y } 64 \text { AÑOS, } 2011\end{array}$ \\
\hline
\end{tabular}

\section{Índice de diagramas}

DIAGRAMA 1 OBJETIVOS E INSTRUMENTOS DE LA POLÍTICA FISCAL ..........................................

\section{Índice de recuadros}

RECUADRO 1 MULTIPLICADORES DE POLÍTICA FISCAL 


\section{Resumen}

Resulta muy difícil evidenciar una relación causal entre las finanzas públicas y el crecimiento, dada la multiplicidad de interacciones mutuas, pero resulta interesante destacar la literatura reciente, que hace hincapié en los efectos complementarios - más que en los dilemas- de la política fiscal sobre los objetivos de desarrollo. Parece haber un consenso creciente de que es posible —en realidad, necesariogenerar ganancias de productividad mediante mejoras en la provisión de bienes públicos, e incrementar por esta vía el potencial de crecimiento de las economías en desarrollo.

A su vez, en América Latina la evolución de las finanzas públicas abre oportunidades inéditas para la construcción de una arquitectura fiscal contracíclica, que permita suavizar la excesiva volatilidad macroeconómica. Es menester finalmente enfatizar la relevancia del nivel y la composición de gastos e ingresos públicos en los objetivos de crecimiento económico, equidad distributiva, e inclusión social. 



\section{Introducción}

En la teoría económica clásica, se asume que existe un planificador benevolente y omnisciente, que puede definir las condiciones de eficiencia y por tanto la delimitación entre bienes públicos y privados, siendo los primeros aquellos bienes no rivales ni excluibles. Según esta tradición, al existir relativamente pocos bienes públicos "genuinos", el tamaño óptimo del Estado debería limitarse al costo de sus funciones esenciales, la defensa, la seguridad, la administración de justicia y la infraestructura, como describió Adam Smith lo que hoy se denomina el Estado Mínimo.

Es sólo durante la segunda mitad del siglo XX que la visión respecto del papel del Estado comienza a cambiar, principalmente con la introducción del concepto de bienes públicos meritorios. Un bien público meritorio puede definirse como un bien subconsumido en una economía de mercado, que crea externalidades positivas, en un marco de miopía de los agentes. Estas argumentaciones dieron espacio para legitimar la función pública en los más diversos ámbitos económicos y sociales. Los Gobiernos democráticos, esencialmente europeos, desarrollaron funciones sociales y redistributivas, dando nacimiento al Estado de Bienestar y sus cuatro pilares: educación, salud, pensiones universales e inclusión social.

La crisis financiera y de endeudamiento público en los países desarrollados ha reflotado una vez más la discusión sobre el papel del gasto público, pues grandes sumas han debido destinarse a los ámbitos productivo (incluyendo a grandes empresas) y bancario. Ante estas limitaciones, surgen periódicamente presiones para reducir el activismo fiscal. La idea subyacente es que se puede mejorar o mantener los indicadores de desarrollo humano con un gasto público mucho menor, apelando a la prestación privada de servicios de salud, educación y pensiones y a la sustitución progresiva de programas universales por esquemas focalizados en los más pobres (véase Tanzi, 2009).

Además del peso de la deuda pública, a menudo se argumenta que un tamaño elevado del propio gasto estatal es perjudicial para el crecimiento, pues, en términos marginales, el impacto positivo del gasto público sería menor que las distorsiones que introducen los impuestos requeridos para su financiamiento, o que dicho gasto desplazaría el gasto privado.

Ante estas aseveraciones, y en el contexto de países en desarrollo, el desafío es potenciar el papel catalizador del sector público con políticas de alta rentabilidad social, evitando los efectos de desplazamiento asociados a un inadecuado manejo financiero y a eventuales distorsiones del sistema tributario. 
Resulta muy difícil evidenciar una relación causal entre las políticas fiscales y el crecimiento económico, tanto por la complejidad de las interacciones mutuas como por la dificultad de establecer mediciones satisfactorias de la multiplicidad de acciones del Estado en la economía, pero es incuestionable sin embargo la influencia del nivel y la composición de gastos e ingresos públicos en el ciclo macroeconómico y en la tendencia de mediano plazo del PIB.

Por ello, es importante para el crecimiento y la igualdad diseñar políticas fiscales con capacidad contracíclica, amplia incidencia en la distribución del ingreso disponible, creciente calidad en el gasto y sistemas tributarios con capacidad recaudatoria, eficientes y equitativos.

Es bueno recordar en este contexto las tres funciones tradicionales de la política fiscal (Musgrave y Buchanan, 1999): proveer bienes públicos (esto es, impulsar el proceso político por el cual estos bienes están disponibles), proveer ajustes en la distribución del ingreso y contribuir a la estabilización macroeconómica. Como señala Tanzi (2009), concurren además en la política fiscal múltiples factores explicativos del potencial de crecimiento de las economías.

Para llevar a cabo estas funciones, que inciden fuertemente en los objetivos de desarrollo, el crecimiento, la equidad distributiva y la inclusión social, la política fiscal cuenta con diversos instrumentos como el gasto público, los impuestos y el déficit o endeudamiento, que a su vez requieren de instituciones para ser adecuadamente gestionados. Sin embargo, existen factores de economía política, de capacidad institucional, problemas de sostenibilidad fiscal y costos de eficiencia de los impuestos y del endeudamiento que pueden limitar la capacidad para implementar las políticas fiscales (véase el diagrama 1).

\section{DIAGRAMA 1 \\ OBJETIVOS E INSTRUMENTOS DE LA POLÍTICA FISCAL}

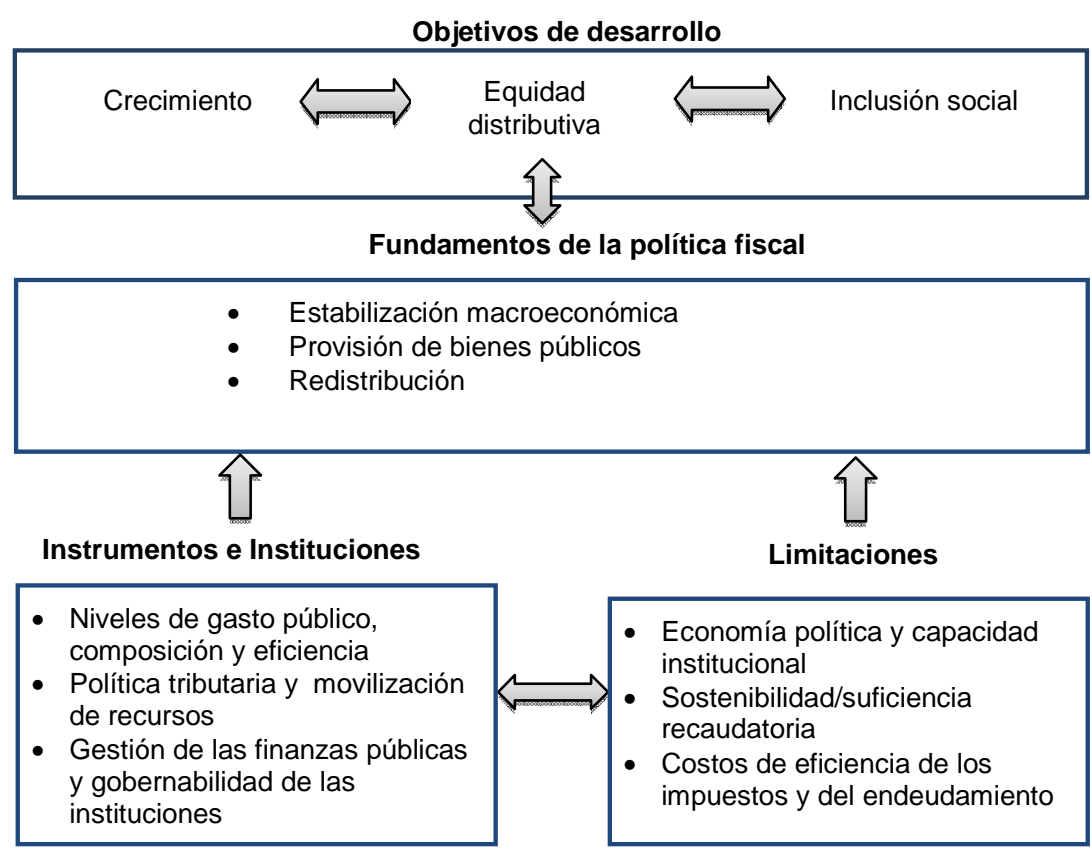

Fuente: Moreno-Dodson (ed.) 2012, con modificaciones.

Enfrentar estas limitaciones supone fortalecer la conexión entre las prioridades gubernamentales y la programación del gasto público, acelerando el tránsito de una gestión pública basada en insumos y procesos a otra orientada a objetivos de desarrollo e indicadores de desempeño, en sintonía con las 
demandas ciudadanas ${ }^{1}$. Avanzar aún más en este campo podría favorecer un pacto fiscal tendiente a reconocer una relación más directa entre la gestión pública de los recursos y la recaudación de esos recursos por la vía de la tributación.

En este documento, luego de efectuar una revisión de la literatura sobre el vínculo entre política fiscal y crecimiento (capítulo II), se describe la evolución reciente de las finanzas públicas en la región, enfatizando la importancia de una arquitectura contracíclica que permita enfrentar con éxito la excesiva volatilidad de ingresos y gastos públicos (capítulo III), y se ilustra la relevancia del nivel y la composición de gastos e ingresos públicos en los objetivos de crecimiento con igualdad (capítulo IV).

Para una discusión sobre estas materias, véase CEPAL/SEGIB, 2011. 



\section{Aspectos conceptuales y evidencia empírica del vínculo entre política fiscal y crecimiento}

Los efectos de la política fiscal sobre el crecimiento económico pueden ser muy diferentes a corto y mediano plazo. En general, los efectos en el corto plazo operan a través de la demanda agregada, mientras que los de mediano y largo plazo lo hacen a través de la oferta agregada. Existe abundancia de modelos teóricos antagónicos, pues keynesianos y neokeynesianos predicen que los estímulos físcales aumentan el consumo agregado, la demanda y por lo tanto el PIB o, por el contrario, los neoclásicos anticipan efectos nulos e incluso negativos. Los efectos de la política fiscal sobre el crecimiento (véase el cuadro 1) dependen del horizonte considerado, de los supuestos sobre el comportamiento de los agentes privados y de la credibilidad de las estrategias utilizadas, como se detalla a continuación.

La teoría neokeynesiana tradicional supone un horizonte de mediano plazo, con agentes miopes que no incorporan la restricción intertemporal del sector público en sus decisiones, y asume también la existencia de capacidad instalada ociosa en la economía y de precios y salarios rígidos. A pesar de que puedan existir efectos parciales de desplazamiento — por la vía de alguna representación IS-LM tradicional-, el multiplicador de gasto público es positivo, y superior o igual a uno en el corto plazo si el gasto público se financia con igual monto de impuestos. Así, el ajuste del sector público es recesivo; y el déficit expansivo ${ }^{2}$.

La teoría neoclásica, por el contrario, supone consumidores racionales y de horizonte infinito, que integran la restricción intertemporal del sector público a su propia restricción presupuestaria y toman las decisiones sobre consumo en función de las perspectivas de largo plazo (teoría del ciclo de la vida de Modigliani y teoría de la renta permanente de Friedman). El alza del gasto público presente conduciría inevitablemente a un aumento de impuestos futuros, y por lo tanto el ingreso disponible actualizado no cambiaría. Se comprende que los agentes anticipan esta situación, y que no van a modificar su consumo, ni presente ni futuro, ante cambios en el gasto público. Existe entonces neutralidad de la política fiscal o equivalencia ricardiana: independientemente de la forma de su financiamiento - ya sea por impuestos o por emisión de deuda—, un alza del gasto público no tiene ningún efecto ni sobre el PIB, ni sobre el consumo privado.

\footnotetext{
2 Véase Martner (2000) para una reseña sobre las principales teorías que explican los efectos de la política fiscal.
} 


\section{EFECTOS DE CORTO PLAZO DE LA POLÍTICA FISCAL SOBRE EL CRECIMIENTO: MODELOS ALTERNATIVOS}

\begin{tabular}{|c|c|c|c|}
\hline Modelo teórico & Supuestos principales & Mecanismos & Efecto neto sobre el PIB \\
\hline $\begin{array}{l}\text { Modelos neo- } \\
\text { keynesianos }\end{array}$ & $\begin{array}{l}\text { Horizonte de corto plazo; } \\
\text { expectativas adaptativas o } \\
\text { miopía de los agentes; } \\
\text { rigidez de precios y } \\
\text { recursos ociosos }\end{array}$ & $\begin{array}{l}\text { Multiplicador lineal de } \\
\text { gasto; eventuales efectos } \\
\text { de desplazamiento }\end{array}$ & $\begin{array}{l}\text { Ajuste fiscal es recesivo; } \\
\text { déficit expansivo }\end{array}$ \\
\hline Modelos Ricardianos & $\begin{array}{l}\text { Consumidores de } \\
\text { horizonte infinito y con } \\
\text { expectativas racionales }\end{array}$ & $\begin{array}{l}\text { Desplazamiento uno a } \\
\text { uno del consumo privado } \\
\text { por el consumo público }\end{array}$ & $\begin{array}{l}\text { Política fiscal neutra a corto } \\
\text { y largo plazo }\end{array}$ \\
\hline $\begin{array}{l}\text { Modelos neoclásicos } \\
\text { con impuestos } \\
\text { distorsionantes }\end{array}$ & $\begin{array}{l}\text { Efecto distorsionante de } \\
\text { los impuestos: su aumento } \\
\text { reduce la producción por } \\
\text { la menor oferta de trabajo }\end{array}$ & $\begin{array}{l}\text { Una disminución } \\
\text { permanente del gasto } \\
\text { público reduce los } \\
\text { impuestos esperados y } \\
\text { aumenta el consumo } \\
\text { privado }\end{array}$ & $\begin{array}{l}\text { Ajuste fiscal es recesivo } \\
\text { con alza de impuestos; } \\
\text { ajuste fiscal expansivo } \\
\text { con caída del gasto. } \\
\text { Déficit expansivo si se } \\
\text { reducen impuestos; } \\
\text { déficit contractivo si } \\
\text { aumentan los gastos }\end{array}$ \\
\hline $\begin{array}{l}\text { Modelos Keynesianos } \\
\text { con "puntos de } \\
\text { inflexión" }\end{array}$ & $\begin{array}{l}\text { Comportamiento } \\
\text { keynesiano mientras el } \\
\text { nivel de deuda pública es } \\
\text { sostenible; } \\
\text { comportamiento de } \\
\text { repudio de la deuda } \\
\text { pública cuando existe } \\
\text { posibilidad de no pago }\end{array}$ & $\begin{array}{l}\text { No linealidades } \\
\text { atribuibles a la } \\
\text { probabilidad de } \\
\text { insolvencia del sector } \\
\text { público }\end{array}$ & $\begin{array}{l}\text { Ajuste fiscal recesivo y } \\
\text { déficit expansivo en niveles } \\
\text { normales de deuda; Ajuste } \\
\text { expansivo y déficit recesivo } \\
\text { cuando la deuda es elevada }\end{array}$ \\
\hline
\end{tabular}

Fuente: Elaboración propia.

Si se introduce el supuesto de que los tributos son distorsionantes (Alesina y Perotti, 1995), un alza de impuestos implicaría una disminución de la producción. Si se cumple la restricción intertemporal del sector público, los consumidores son racionales y los impuestos distorsionantes, una caída del gasto público percibida como permanente supone una reducción de los impuestos futuros, lo que repercute en un aumento del ingreso disponible esperado, incrementando el consumo actual y produciendo efectos de oferta positivos que harían aumentar el PIB en el corto plazo. Los modelos de oferta con impuestos distorsionantes suponen entonces que el ajuste fiscal es expansivo, si se contraen los gastos, y contractivo, si se aumentan los impuestos.

Otra categoría de modelos incorpora no linealidades para explicar los cambios de régimen. Para Sutherland (1995), los agentes se comportan de manera keynesiana cuando el stock de deuda pública es bajo, y de manera anti keynesiana cuando el endeudamiento excesivo y la posibilidad de insolvencia amenazan no sólo a las generaciones futuras, sino a los propios agentes. En este caso las no linealidades se atribuyen a la probabilidad de insolvencia del sector público. Si ésta es baja, los agentes no se preocupan de los impuestos futuros. En cambio, si existe posibilidad de no pago de la deuda, los consumidores anticipan un alza futura de los impuestos y ahorran en consecuencia.

Los estudios posteriores a la Gran Recesión iniciada en 2008 en países de la $\operatorname{OCDE}^{3}$ señalan que el efecto de los estímulos fiscales sobre el crecimiento económico depende de las circunstancias de la economía, como la existencia de recursos ociosos; la efectividad de la política monetaria (por ejemplo, cuando la tasa de interés está próxima a cero); el porcentaje de población con restricciones crediticias; el carácter temporal o permanente de las medidas implementadas; el grado de confianza sobre las perspectivas económicas futuras; la competitividad, la apertura comercial y el régimen cambiario.

En el largo plazo, en los modelos neoclásicos de crecimiento económico la política fiscal puede afectar los incentivos a ahorrar e invertir y por lo tanto, el ratio capital-producto de equilibrio y el nivel

3 Véase Giavazzi y McMahon (2011), Auerbach y Gorodnichenko (2012), Roeger y in’t Veld (2012). 
del PIB, pero no puede influir en la tasa de crecimiento del estado estacionario ${ }^{4}$. En estos modelos, los impuestos y los gastos públicos pueden provocar cambios transitorios mientras la economía se mueve de un equilibrio a otro, pero la tasa de crecimiento volvería de nuevo a su situación inicial.

Sin embargo, la falta de convergencia de las tasas de crecimiento entre países debilita esas conclusiones. De esta forma surgen los modelos de crecimiento endógeno (como Barro 1990, Futagami et al. 1993 y Devarajan et al. 1996) que dan un mayor papel a la política fiscal, la cual puede afectar tanto al nivel del PIB como su tasa de crecimiento en el largo plazo. Estos modelos suponen la existencia de ciertos gastos públicos "productivos" que entran en la función de producción y afectan así la productividad del sector privado, mientras que hay otros gastos públicos "improductivos" que sólo afectan la función de utilidad de los hogares. Además, para financiar estos gastos se recurre a impuestos que distorsionan las decisiones de inversión.

Así, Barro (1990) analiza cómo la tributación y el gasto público afectan el crecimiento bajo el supuesto de no existencia de déficit financiero. Su modelo sugiere un rol positivo del gobierno para promover el crecimiento económico a través de la provisión de bienes públicos y servicios que elevan la productividad marginal del capital e incentivan una mayor inversión. No obstante, este efecto positivo depende del nivel inicial de los impuestos, dado que una carga tributaria excesiva reduce la tasa de crecimiento.

Loayza (1996) extiende el modelo de Barro e incorpora al sector informal. En particular, se centra en cómo las políticas gubernamentales influyen en el tamaño de este sector, y cómo esto afecta el crecimiento a largo plazo. La principal diferencia entre los dos modelos es que la tasa impositiva óptima es menor en la presencia del sector informal (Cornia et al, 2011).

Según Cornia et al (2011), los impuestos pueden afectar positivamente el crecimiento a través de diversos canales. El primero es mediante la provisión de bienes públicos, como carreteras, agua y saneamiento, salud y educación que aumenta la tasa de rendimiento de las inversiones privadas. Una segunda vía es la estabilidad macroeconómica, ya que los gobiernos que recaudan cantidades adecuadas de ingresos tienen menos probabilidades de monetizar el déficit fiscal o endeudarse en el extranjero, lo que reduce la probabilidad de crisis macroeconómicas. Una mayor estabilidad macroeconómica y una posición fiscal más fuerte posibilitan la adopción de políticas anticíclicas durante las crisis, lo que reduce la pérdida de producción durante los períodos difíciles. Un tercer canal a través del cual un incremento en los impuestos puede aumentar el crecimiento es una disminución en la desigualdad de los ingresos. Una alta desigualdad deprime el crecimiento, ya que causa efectos de economía política (Alesina y Rodrik, 1994); exacerba las imperfecciones del mercado de capitales (Aghion et al 1999); aumenta la inestabilidad política y las tasas de criminalidad que causan incertidumbre entre los inversionistas y reducen el crecimiento (Venieris y Gupta 1986, Bourguignon 1998); y además, erosiona los incentivos microeconómicos e incrementa los costos de mano de obra (Cornia 2005).

En suma, el efecto neto de la política fiscal sobre el crecimiento parece ser un asunto empírico, pues los argumentos abundan en ambos sentidos. La mayoría de los estudios empíricos proceden a la estimación con paneles de datos de ecuaciones del tipo ${ }^{5}$ :

$$
\mathrm{g}_{\mathrm{it}}=\mathrm{f}\left(\mathrm{pf}_{\mathrm{it}}, \mathrm{X}_{\mathrm{it}}\right)
$$

Donde: i denota el país y t refleja el año, g es la tasa de crecimiento, pf es la presión fiscal (agregada o por componentes) y X es un vector de variables de control, entre las que se incluye el nivel inicial de renta, el crecimiento de la población, el capital humano y otras variables relevantes. Además, otros estudios incorporan también al gasto en la ecuación:

$$
\mathrm{g}_{\mathrm{it}}=\mathrm{f}\left(\mathrm{pf}_{\mathrm{it}}, \mathrm{gp}_{\mathrm{it}}, \mathrm{X}_{\mathrm{it}}\right)
$$

Parte de esta revisión se extrae de Sanz-Sanz y Sanz (2013).

Véase Salinas y Delgado (2012). 
Parte de la evidencia empírica que analiza el impacto de los impuestos sobre el crecimiento económico no encuentra que estos efectos sean significativos. Por ejemplo, Mendoza et al. (1997), utilizando datos de panel de los países de la OCDE con medias de cinco años, no encuentran un efecto significativo de los impuestos en el crecimiento económico; solo hallan efectos limitados de los impuestos sobre la inversión (un incremento de 10 puntos de los impuestos disminuye en un 1-2\% la inversión). Únicamente encuentran un efecto negativo transitorio en el crecimiento económico cuando emplean datos anuales. Otros estudios como los de Angelopoulos et al. (2007) tampoco han encontrado efectos negativos de diversos impuestos en el crecimiento. En relación a los impuestos sobre las rentas del trabajo, Manski (2012) señala que al relajar los supuestos de modelos lineales y de relación similar entre impuestos y oferta de trabajo entre diferentes grupos demográficos no se encuentra ningún efecto significativo de los impuestos sobre la oferta de trabajo. En esta misma línea, Meghir y Phillips (2010) argumentan que en algunos casos, para aquellos individuos con muchas horas de trabajo, puede ser que excepcionalmente los impuestos aumenten las horas de trabajo. Piketty et al. (2011) analizan una muestra de 18 países de la OCDE y no encuentran evidencia de que los países que han disminuido estos gravámenes hayan experimentado un mayor crecimiento de la productividad y el PIB. Estos autores concluyen que las tasas máximas de impuestos sobre las rentas del trabajo pueden aumentarse sobre los niveles actuales sin perjudicar el crecimiento económico.

Gemmell et al. (2011) tampoco encuentran evidencia de efectos robustos de los tipos medios de las rentas del capital en la actividad económica empleando una muestra de 17 países de la OCDE. Estos autores sí hallan un impacto negativo y significativo del tipo impositivo medio y marginal de las rentas del trabajo sobre el crecimiento, así como del de sociedades. Sin embargo, también muestran evidencia de que disminuciones de los impuestos de sociedades de los países que disponen de tipos más bajos, afectan negativamente al crecimiento económico.

En cuanto a los efectos sobre el crecimiento económico de los distintos tipos de impuestos, Johansson et al. (2008) y Romero-Ávila y Strauch (2008) encuentran, a partir de una muestra de países de la OECD y de la UE, que el mayor efecto distorsionante corresponde al impuesto de sociedades, seguido del impuesto a la renta personal mientras que los del consumo son los menos perjudiciales. Harju y Kosonen (2012) señalan que cuanto mayor es la progresividad de los impuestos mayor es su efecto negativo sobre el esfuerzo de los emprendedores y el crecimiento económico. Según el estudio de Keane (2011), los impuestos sobre las rentas del trabajo reducen la oferta de horas de trabajo y también la inversión en capital humano. Las cotizaciones a la seguridad social perjudican la creación o mantenimiento del empleo (Bils and Klenow, 2008) mientras que Bennmarket et al. (2009) encuentran que disminuyen los salarios de los trabajadores pero no afecta al empleo. Arnold et al. (2011) argumentan que los aumentos de los impuestos al consumo óptimo son los que se basan en ampliaciones de la base imponible más que en incrementos de las tipos impositivos. En este sentido, Jorgenson y Yun (2001) estiman que la ampliación de las bases imponibles, aumentando los contribuyentes o las actividades que se gravan, podría llegar a incrementar hasta en un 6\% anual la renta, y generar más empleo en el corto plazo y mayores salarios en el largo plazo.

Del análisis de la literatura disponible, Salinas y Delgado (2012) sistematizan los principales resultados y extraen las siguientes conclusiones (véase el cuadro 2) para los estudios en países de la OCDE:

1) En general se observa un efecto negativo entre impuestos y crecimiento económico. La mayor parte de los estudios revisados concluyen una relación de signo negativo, aunque no es despreciable el número de trabajos que no alcanzan una conexión significativa, el 33,3\%.

2) Cuando se estudian las tasas medias, efectivas y marginales, la relación hallada con el crecimiento es también negativa. Aunque el número de trabajos analizados es reducido, 4 de los 6 estudios sostienen esa conclusión, mientras que los dos restantes no llegan a un resultado estadísticamente significativo.

3) Sí hay consenso en las repercusiones del grado de progresividad del sistema tributario sobre el crecimiento económico. Los 6 trabajos en esta materia coinciden en una relación negativa, es decir, a mayor progresividad de los sistemas tributarios, menor crecimiento. 
4) También hay unanimidad en los estudios que analizan el impacto de un cambio en la estructura tributaria (o tax mix) consistente en el incremento del peso de la imposición indirecta (impuestos que gravan el consumo) en detrimento de la directa (impuestos sobre la renta de empresas e individuos). Los 5 trabajos revisados prevén mejoras de crecimiento económico con este cambio.

\section{CUADRO 2}

LITERATURA EMPÍRICA SOBRE LA RELACIÓN ENTRE IMPUESTOS Y CRECIMIENTO ECONÓMICO: PRINCIPALES RESULTADOS

\begin{tabular}{lccc}
\hline Número de trabajos & $\begin{array}{c}\text { Número y porcentaje de } \\
\text { trabajos que concluyen } \\
\text { relación positiva }\end{array}$ & $\begin{array}{c}\text { Número y porcentaje de } \\
\text { trabajos que concluyen } \\
\text { relación negativa }\end{array}$ & $\begin{array}{c}\text { Número y porcentaje de } \\
\text { trabajos que concluyen } \\
\text { relación no significativa }\end{array}$ \\
\hline $\begin{array}{l}\text { Impuestos (21) } \\
\text { Tipos medios, efectivos y } \\
\text { marginales (6) }\end{array}$ & $0(0 \%)$ & $13(61,9 \%)$ & $7(33,3 \%)$ \\
$\begin{array}{l}\text { Progresividad (6) } \\
\begin{array}{l}\text { Cambio de tax mix: más } \\
\text { impuestos indirectos en } \\
\text { detrimento de directos }(5)\end{array}\end{array}$ & $0(0 \%)$ & $4(66,7 \%)$ & $2(33,3 \%)$ \\
\hline
\end{tabular}

Fuente: Salinas y Delgado (2012).

Respecto de la evidencia empírica para América Latina, Cornia et al (2011) evalúan econométricamente el impacto de los impuestos sobre la tasa de crecimiento del PIB per cápita para 18 países de esta región en el periodo 1990-2008, controlando por diversas variables (inversión, educación, déficit presupuestario, términos del intercambio, coeficiente de gini) y aplicando cuatro modelos. Los resultados sugieren que el 3-4\% de aumento promedio en el ratio impuestos/PIB observado entre 2002 y 2009 elevó la tasa de crecimiento del PIB per cápita entre el 0,3 y el 1\%, contradiciendo, según los autores, las afirmaciones de la teoría neoclásica sobre los costos de eficiencia de "impuestos distorsivos", tales como los impuestos directos.

En definitiva, la evidencia empírica disponible sobre el efecto de los impuestos en el crecimiento económico no es concluyente y muestra la necesidad de incorporar los gastos en las estimaciones. En efecto, el gasto público puede contribuir al crecimiento económico al afectar el nivel de los factores de producción y aumentar su productividad. Por ejemplo, los gobiernos pueden proveer ciertos tipos de bienes y servicios (como infraestructura, investigación y desarrollo, educación, etc.) que elevan la productividad marginal del capital y del trabajo en el proceso de producción. Además, el aumento de la productividad incrementa los rendimientos de la inversión privada, lo que resulta en un mayor stock de capital privado y mayor producción.

Sin embargo, financiar estos gastos tiene costos que pueden superar los beneficios. En el caso de los impuestos, las distorsiones y costos de eficiencia afectan negativamente el crecimiento. La emisión de deuda pública implica mayores impuestos en el futuro y también puede afectar el crecimiento, por ejemplo, desplazando al sector privado en el acceso a financiamiento o afectando el grado de confianza que tienen los inversores sobre la sostenibilidad de las finanzas públicas.

De aquí la importancia de considerar el efecto conjunto de los gastos públicos y de su forma de financiamiento a la hora de evaluar el impacto de un cambio en el gasto público sobre el crecimiento. En última instancia, el efecto neto de la política fiscal sobre el crecimiento económico depende del nivel y composición de los gastos e impuestos. En el siguiente cuadro se presentan los efectos sobre el crecimiento de las distintas combinaciones posibles de ejecución del gasto público (productivos, no productivos y déficit) y su financiación (impuestos distorsionantes, no distorsionantes y déficit). 


\section{AUMENTOS DE IMPUESTOS, GASTOS Y DÉFICIT Y SU EFECTO EN EL CRECIMIENTO}

\begin{tabular}{|c|c|c|c|c|}
\hline \multirow{2}{*}{ Financiado por } & & \multicolumn{2}{|c|}{ Gasto público } & \multirow{2}{*}{ Déficit públicc } \\
\hline & & Productivo & No productivo & \\
\hline \multirow{2}{*}{ Impuestos } & Distorsionantes & $\begin{array}{c}\text { Negativo/ positivo } \\
\text { (elevados /bajos gastos) }\end{array}$ & Negativo & Ambiguo \\
\hline & No distorsionantes & Positivo & Cero & Positivo \\
\hline Déficit público & & Ambiguo & Negativo & - \\
\hline
\end{tabular}

Fuente: Gemmell, Kneller y Sanz (2011b).

De esta forma, el efecto sobre el crecimiento de un aumento de los impuestos distorsionantes destinado a financiar gastos públicos productivos dependerá del tamaño del sector público. Si el país dispone ya de un nivel de tipos impositivos y stock de capital público elevados, por encima del umbral óptimo, entonces el efecto sobre el crecimiento será negativo y, en caso contrario, será positivo. En cambio, la financiación de gastos públicos no productivos mediante impuestos distorsionantes tendrá efectos claramente negativos mientras que el impacto de un incremento de impuestos distorsionantes para disminuir el déficit público es ambiguo, dado que se crean nuevas distorsiones en la economía para disminuir otras ya existentes.

Por otro lado, cuando los impuestos no distorsionantes se destinan a gastos públicos productivos o a reducir el déficit fiscal, los efectos sobre el crecimiento económico serán positivos; en tanto que si financian gastos públicos no productivos el impacto sobre la actividad económica no será significativo. Finalmente, el efecto sobre el crecimiento de un mayor déficit fiscal para incrementar los gastos públicos productivos dependerá del stock de capital público existente (mientras más elevado, mayor será la probabilidad de un efecto negativo). En el caso que el aumento del déficit se destine para financiar gastos públicos no productivos, el impacto sobre el crecimiento económico será negativo.

En cuanto a la evidencia empírica sobre la relación entre el gasto público y el crecimiento económico, esta puede agruparse en dos generaciones según se considere o no la restricción presupuestaria del gobierno (véase Gemmell, 2010). Los estudios de primera generación, realizados hasta mediados de la década de los 90, no consideran esta restricción presupuestaria, es decir, no tienen en cuenta que todo aumento de gasto público debe financiarse con mayores impuestos u otros ingresos, aumento del déficit fiscal o reasignación de partidas de gastos. Además, varios de estos estudios consideran solo el gasto público total, donde hay componentes que influyen de manera positiva sobre la actividad económica (como transportes, comunicaciones y educación) y otros que lo hacen de manera neutral o negativamente. Como consecuencia de estas limitaciones, generalmente los resultados de estos estudios no son robustos ${ }^{6}$.

Por otra parte, los estudios de segunda generación, realizados a partir de la segunda mitad de los noventa, tienen en cuenta la restricción presupuestaria del gobierno y por lo tanto sus resultados son más robustos.

En estos modelos, para considerar la restricción presupuestaria del gobierno se incluye entre las variables explicativas del crecimiento económico a los gastos $(\mathrm{E})$, los ingresos totales $(\mathrm{R})$ y el déficit o superávit presupuestario (D), además de otras variables de control que tienen efectos sobre el crecimiento. A su vez, se tiene en cuenta que el crecimiento puede verse afectado no solo por el nivel de los gastos totales (E) sino también por la participación de cada categoría de gasto en el total $\left(\mathrm{e}_{\mathrm{j}} / \mathrm{E}\right)$.

6 Nijkamp y Poot (2004) revisan 93 artículos de esta primera generación de estudios sobre la relación entre gasto público y crecimiento económico y encuentran que los componentes del gasto que más positivamente influyen en la actividad económica son infraestructuras (transportes y comunicaciones) y educación. 
Gemmell et al. (2012) expresan la siguiente ecuación del crecimiento del PIB en el país i en el momento $\mathrm{t}\left(\mathrm{g}_{\mathrm{it}}\right)$, donde se centran solo en las variables fiscales (expresadas como proporción del PIB):

$$
g_{i t}=\cdots \gamma_{1}\left(\frac{E}{P I B}\right)_{i t}+\sum_{j=1}^{n-1} \gamma_{2 j}\left(\frac{e_{j}}{E}\right)_{i t}+\gamma_{3}\left(\frac{R}{P I B}\right)_{i t}+\gamma_{4}\left(\frac{D}{P I B}\right)_{i t}+\cdots
$$

Sin embargo, dado que la restricción presupuestaria del gobierno especifica que $D_{i t} \equiv R_{i t}-E_{i t}$, las tres variables son perfectamente colineales. Si arbitrariamente se elige omitir una variable (por ejemplo, $\mathrm{D}_{\mathrm{it}}$ ), la ecuación (3) puede escribirse como:

$$
g_{i t}=\cdots\left(\gamma_{1}-\gamma_{4}\right)\left(\frac{E}{P I B}\right)_{i t}+\sum_{j=1}^{n-1} \gamma_{2 j}\left(\frac{e_{j}}{E}\right)_{i t}+\left(\gamma_{3}+\gamma_{4}\right)\left(\frac{R}{P I B}\right)_{i t}+\cdots
$$

La ecuación anterior muestra la importancia de una correcta interpretación de los efectos de los gastos e ingresos sobre el crecimiento. Los parámetros de la ecuación (4) capturan el efecto del aumento en el gasto total o de una disminución de los impuestos financiados por un cambio en el déficit presupuestario (la variable omitida en este caso). Por ejemplo $\left(\gamma_{1-} \gamma_{4}\right)$ mide el efecto neto de un aumento del gasto, es decir, descontando el efecto de ser financiado mediante un aumento del déficit. Estos efectos dependen de los signos y tamaños relativos de $\gamma_{1}, \gamma_{3}$ y $\gamma_{4}$. Por otra parte, la interpretación de los coeficientes de los componentes del gasto, $\gamma_{2 j}$, no se ve afectada por la forma de financiamiento, ya que mide el efecto sobre el crecimiento de un cambio en la participación de cada categoría en el gasto total, manteniendo constantes las otras variables de la ecuación (4), incluyendo los gastos totales. Además la ecuación (4) puede ser derivada a partir de la ecuación (3), omitiendo cualquiera de los tres elementos de la restricción presupuestaria $\left(\mathrm{E}_{\mathrm{it}}, \mathrm{R}_{\mathrm{it}}, \mathrm{o} \mathrm{D}_{\mathrm{it}}\right)$ y la interpretación de los parámetros dependerá de las variables incluidas y la omitida.

Si bien la gran mayoría de los estudios recurren a datos de panel de distintos países para realizar las estimaciones, algunos autores han comenzado a utilizar datos fiscales subnacionales para estimar los efectos del gasto público sobre el crecimiento económico, como es el caso de Rocha y Giuberti (2007) para 27 estados de Brasil; Hong y Ahmed (2009) para 14 estados de la India o Yan y Gong (2009) para 31 provincias chinas.

Algunos de los estudios empíricos sobre la materia dividen los gastos del gobierno en productivos e improductivos a partir de la clasificación funcional del gasto, utilizando una definición a priori de gasto productivo común en esta literatura que incluye educación, salud, vivienda, transporte y comunicaciones, servicios generales y defensa. En términos generales, estos estudios encuentran que los gastos más productivos tienen un impacto positivo sobre el crecimiento, ya sea que se financien a través de reducciones en gastos menos productivos o mediante la generación de déficit fiscales relativamente pequeños, o una combinación de ambos ${ }^{7}$.

Entre los estudios para países en desarrollo que hallan estos resultados están Adam y Bevan (2005), Bayraktar y Moreno-Dodson (2010), López y Miller (2007) y Hong y Ahmed (2009). Según cuál sea la forma de financiamiento, encuentran que un aumento de 1 punto porcentual del gasto productivo en términos del PIB, aumenta la tasa de crecimiento entre 0,1 y 1,1 puntos porcentuales. Adam y Bevan (2005) muestran que, como excepción, el gasto productivo tiene efectos negativos para el crecimiento si se financia con déficit y si este es superior al 1,5\% del PIB.

En cuanto a los efectos sobre el crecimiento, en países en desarrollo, de los gastos desglosados por sector o función, Bose, Haque, y Osborn (2007) cruzan información entre el sector o función del gasto (educación, sanidad, transportes y comunicaciones, etc.) y su naturaleza económica (inversión, consumo o transferencias) y encuentran que la inversión pública en educación y el gasto total en educación son los únicos gastos que están positiva y significativamente asociados con el crecimiento. En esta misma línea, Rocha y Giuberti (2007) concluyen que existe una relación positiva entre los gastos de

Véase Gemmell, Misch y Moreno-Dodson (2012). 
defensa, educación, transporte y comunicaciones y el crecimiento económico en los estados de Brasil. En cambio, Ghosh y Gregoriou (2008), utilizando datos de panel para 15 países en desarrollo, muestran que el gasto en operaciones y mantenimiento tiene un mayor impacto en el crecimiento que el gasto en salud o educación.

Otros estudios empíricos descomponen el gasto público según la clasificación económica, es decir, entre gasto corriente y gasto en capital. Los efectos de los gastos de capital sobre el crecimiento dependen de la forma en que se financien y no hay ganancia de crecimiento si se sustituye gasto corriente por gasto en capital. Por ejemplo, para el caso de países en desarrollo, Ghosh y Gregoriou (2008), Rocha y Giuberti (2007), Devarajan, Swaroop y Zou (1996) y Haque (2004) muestran que la reasignación de partidas de gasto corriente hacia gasto de capital implica efectos negativos del crecimiento (un aumento de 1 punto porcentual de la participación del gasto de capital en el gasto total reduce la tasa de crecimiento entre 0,01 y 0,36 puntos porcentuales). Esto estaría indicando la complementariedad entre ambos tipos de gastos. Por el contrario, Bose, Haque y Osborn (2007) encuentran efectos positivos sobre el crecimiento si las inversiones se financian con ingresos no tributarios mientras que Gupta et al. (2005) hallan ese resultado cuando el gasto en capital se financia mediante endeudamiento o también a través de mayores ingresos.

Por otra parte, M'Amanja y Morrisey (2005), a partir de datos de series de tiempo para Kenia en el periodo 1964-2002, hallan que la inversión pública aumenta el crecimiento pero los gastos en educación, sanidad, asuntos económicos y los gastos corrientes influyen de forma negativa. En cambio, Muinelo-Gallo y Roca-Sagalés (2011), utilizando datos de panel para 43 países de rentas medias y altas, no encuentran un efecto significativo de la inversión pública en el crecimiento económico, pero sí en la reducción de la desigualdad.

En cuanto a la evidencia para países desarrollados, Mendoza et al. (1997), De la Fuente (1997), y Schuknecht y Tanzi (2005) hallan que el gasto público total afecta negativamente al crecimiento económico en una muestra de países de la OCDE. De manera similar, Miller y Russek (1997) muestran que el gasto público total financiado con impuestos tiene un impacto negativo en el crecimiento mientras que si se financia mediante deuda es neutral. Sin embargo, estos autores revelan que el gasto en educación tiene un efecto positivo sobre el crecimiento, mientras que las erogaciones en sanidad, seguridad social y servicios económicos influyen negativamente.

Respecto de la composición de los gastos, Gemmell et al. (2009) concluyen que un aumento del gasto en infraestructura y educación financiado con disminuciones proporcionales del resto de las partidas tiene un impacto positivo para el crecimiento económico en una muestra de 17 países de la OCDE en el periodo 1970-2004. Lo mismo ocurre si se restan recursos del consumo público para financiar más inversiones. A partir de esta misma muestra de países, Gemmell et al. (2011) estiman que un aumento de los gastos públicos productivos en un 1\% del PIB incrementa la tasa de crecimiento en 0,12 puntos si se financia con déficit y en 0,26 si es a través de aumentos en los impuestos no distorsionantes o disminuciones de gastos no productivos.

En síntesis, la evidencia empírica es mixta, pero sugiere que tanto en los países desarrollados como en desarrollo la política fiscal en su conjunto tiende a afectar positivamente el crecimiento de largo plazo, lo que confirma ampliamente las predicciones de los modelos de crecimiento endógeno con finanzas públicas (Gemmell, Misch y Moreno-Dodson, 2012).

Lo anterior también se ve documentado en las regresiones de panel del cuadro 4, donde se verifica que el gasto público ha tenido en un impacto positivo sobre el PIB per cápita, en el período 1990-2010, para 20 países de América Latina. Ante las dificultades de colinealidad reseñadas entre el gasto público, los ingresos fiscales y el déficit, se optó por privilegiar en las estimaciones las variables de gasto, distinguiéndose entre el gasto corriente primario y el gasto de capital. Implícitamente, al incluir como variable explicativa a la deuda pública se están considerando los déficit acumulados y por lo tanto se puede diferenciar la forma de financiamiento del gasto.

La elasticidad del gasto público primario con relación al PIB per cápita es positiva y significativa, como también lo son las de la inversión total y del tipo de cambio real. A su vez, tanto la deuda pública 
como la inflación tienen un impacto negativo sobre el crecimiento. Las variables de capital humano, de estabilidad política y de derechos civiles son fuertemente relevantes, corroborando la importancia de los "determinantes profundos" del nivel y del crecimiento del PIB per cápita en la región, así como el tipo de cambio real (véase Rodrik, 2008). Vale la pena notar que el coeficiente rezagado del PIB per cápita también es significativo, indicando un fuerte componente inercial y un impacto mucho mayor a mediano plazo de las variables explicativas.

\section{CUADRO 4 \\ EFECTOS DEL GASTO PÚBLICO SOBRE EL PRODUCTO EN AMÉRICA LATINA: PANEL DE 20 PAÍSES, 1990-2010 ${ }^{a}$}

(Variables valoradas a precios constantes y expresadas en logaritmos)

\begin{tabular}{|c|c|c|c|}
\hline \multicolumn{4}{|c|}{ Variable explicada: producto interno bruto por habitante } \\
\hline Regresiones & $(1)$ & $(2)$ & (3) \\
\hline \multicolumn{4}{|l|}{ Variables explicativas } \\
\hline \multicolumn{4}{|l|}{ Fiscales } \\
\hline \multirow{2}{*}{ Gasto público primario } & $0,05^{* * *}$ & $0,10^{* * *}$ & $\ldots$ \\
\hline & $(0,01)$ & $(0,03)$ & \\
\hline \multirow{2}{*}{ Gasto corriente primario } & $\cdots$ & $\cdots$ & $0,12 * * *$ \\
\hline & & & $(0,03)$ \\
\hline \multirow{2}{*}{ Deuda pública } & $-0,017$ * & $-0,005$ & $-0,035$ * \\
\hline & $(0,006)$ & $(0,01)$ & $(0,01)$ \\
\hline \multicolumn{4}{|l|}{ Macroeconómicas } \\
\hline \multirow{2}{*}{ Formación bruta de capital fijo } & $0,13^{* \star *}$ & $\ldots$ & $\ldots$ \\
\hline & $(0,01)$ & & \\
\hline \multirow[t]{2}{*}{ Formación bruta de capital fijo (sector público) } & $\cdots$ & $\cdots$ & $0,07^{* * *}$ \\
\hline & & & $(0,01)$ \\
\hline \multirow{2}{*}{ Formación bruta de capital fijo (sector privado) } & $\cdots$ & $0,084^{\star \star \star}$ & $0,083^{* * *}$ \\
\hline & & $(0,01)$ & $(0,01)$ \\
\hline \multirow{2}{*}{ Tipo de cambio real } & $0,05^{* * *}$ & 0,08 ** & 0,079 * \\
\hline & $(0,01)$ & $(0,02)$ & $(0,03)$ \\
\hline \multirow{2}{*}{$\Delta$ Índice de precios al consumidor (IPC) } & $-0,003$ & $-0,005$ & $-0,06$ * \\
\hline & $(0,002)$ & $(0,01)$ & $(0,02)$ \\
\hline \multirow{2}{*}{ Producto por habitante $(-1)$} & $0,65 * * *$ & $0,70 * * *$ & $0,36 * * *$ \\
\hline & $(0,09)$ & $(0,10)$ & $(0,06)$ \\
\hline \multicolumn{4}{|l|}{ Logros en educación } \\
\hline Indicador de Capital humano & $0,026^{* * *}$ & 0,06 * & 0,06 ** \\
\hline $\begin{array}{l}\text { (población adulta con educación terciaria y secundaria/adultos con } \\
\text { educación primaria) }\end{array}$ & $(0,006)$ & $(0,02)$ & $(0,01)$ \\
\hline \multicolumn{4}{|l|}{ Institucionales } \\
\hline \multirow{2}{*}{ Estabilidad política } & $0,02^{* *}$ & 0,018 & 0,024 * \\
\hline & $(0,005)$ & $(0,01)$ & $(0,009)$ \\
\hline \multirow{2}{*}{ Derechos civiles } & $0,04^{* * *}$ & 0,06 ** & $0,045^{* *}$ \\
\hline & $(0,01)$ & $(0,02)$ & $(0,02)$ \\
\hline Número de observaciones & 310 & 218 & 218 \\
\hline
\end{tabular}

Fuente: Cálculos propios.

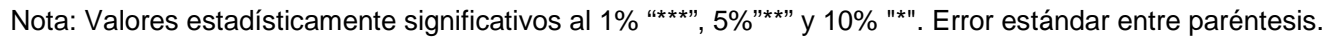

a Modelo de datos de panel, incluidos efectos fijos y corrección de sección cruzada.

Si se desagrega el efecto del gasto, incluyendo las variables de control mencionadas, se observa que tanto el gasto corriente primario como la formación bruta de capital fijo del sector público inciden positiva y significativamente sobre el PIB per cápita (ecuaciones 2 y 3 ). Dado el período considerado y la cantidad de países en la estimación de panel, parece notable recoger un efecto tan significativo de las variables fiscales sobre el crecimiento. Probablemente debido al bajo nivel del período inicial, la recuperación de los gastos públicos corrientes y de inversión han tenido un impacto retroalimentador sobre el crecimiento económico. Vale recordar que la evidencia empírica muestra que los efectos del 
gasto público varían según su composición; son positivos en rangos moderados, y pueden tornarse negativos si se exceden ciertos límites (véase European Commission, 2002, para una discusión detallada de esta tipología).

Como lo muestran estas regresiones de panel, para la inmensa mayoría de los países de la región, el nivel de gasto público es inferior al óptimo, aún si su único objetivo fuese el crecimiento económico. En otras palabras, todo tipo de gastos públicos, corrientes, de capital, transferencias o gasto directo, pueden aumentar la eficiencia macroeconómica, en la medida en que favorecen la oferta laboral y la formación de capital físico y humano. Ello no obsta por supuesto a la posibilidad de mejoras en su productividad. 


\section{La deuda pública y las políticas fiscales}

En la historia moderna de América Latina, una restricción recurrente al crecimiento ha sido el efecto de arrastre de la deuda pública, cuyo peso en la economía deteriora las expectativas y aumenta el costo financiero de los proyectos públicos y privados. Numerosos trabajos recientes ponen en evidencia un vínculo negativo entre la deuda pública como porcentaje del PIB y el crecimiento (aunque la causalidad es discutible), tanto en los países de la OCDE (véase por ejemplo Panizza, Presbitero, 2012) como en la región (CEPAL, 2012a).

\section{A. Evolución de la deuda pública}

Aunque ya en la década de los 70 se observa un crecimiento de la deuda externa pública como porcentaje del PIB (véase el gráfico 1), en la década de 1980 la combinación de un escaso crecimiento económico, de escasez de capitales y de grandes depreciaciones de las monedas domésticas en un marco de pasivos dolarizados jugó un papel preponderante en la ampliación de los déficit fiscales y de la deuda pública. Así, entre 1980 y 1989 la deuda pública externa trepó de menos de 35 puntos del PIB a un máximo de 78 puntos del PIB como promedio, alcanzando valores superiores a $100 \%$ del PIB en Bolivia (Estado Plurinacional de), Ecuador, Nicaragua, Panamá y Perú.

Gran parte de esta bola de nieve puede explicarse por el denominado "pecado original", definido como la dificultad para un país emergente de endeudarse externamente en su propia moneda o de endeudarse a largo plazo, incluso en el mercado doméstico. En varios países, el presupuesto fiscal se vio envuelto en una dinámica explosiva de crecimiento de la deuda en la que de manera típica una proporción creciente de los ingresos fiscales fue absorbida por el servicio de la deuda.

En la década de 1990 se redujo fuertemente el peso de la deuda pública externa, gracias al recobrado crecimiento económico, a los procesos de renegociación y a significativas reestructuraciones en algunos países, si bien incidió en otros la mantención de tipos de cambio fijos o revaluados (lo que redujo los pasivos externos en moneda nacional).

Luego de la crisis de 2002, que se tradujo en una nueva contracción del financiamiento externo, varios países de la región lograron activar a partir de 2003 un proceso combinado de generación sistemática de superávit primarios (apoyado por el fortalecimiento de sus sistemas tributarios y por la 
generación de ingresos extraordinarios provenientes de la exportación de productos básicos), de mecanismos de autoseguro (como los fondos de estabilización o los esquemas de prepago de deuda durante las fases de auge o de reducción de las tasas de interés), y de mejoramiento de la gestión de pasivos y activos públicos.

\section{GRÁFICO 1 \\ AMÉRICA LATINA (19 PAÍSES): DEUDA PÚBLICA EXTERNA (1970-2012) E INTERNA (1990-2012)}

(Porcentajes del PIB)

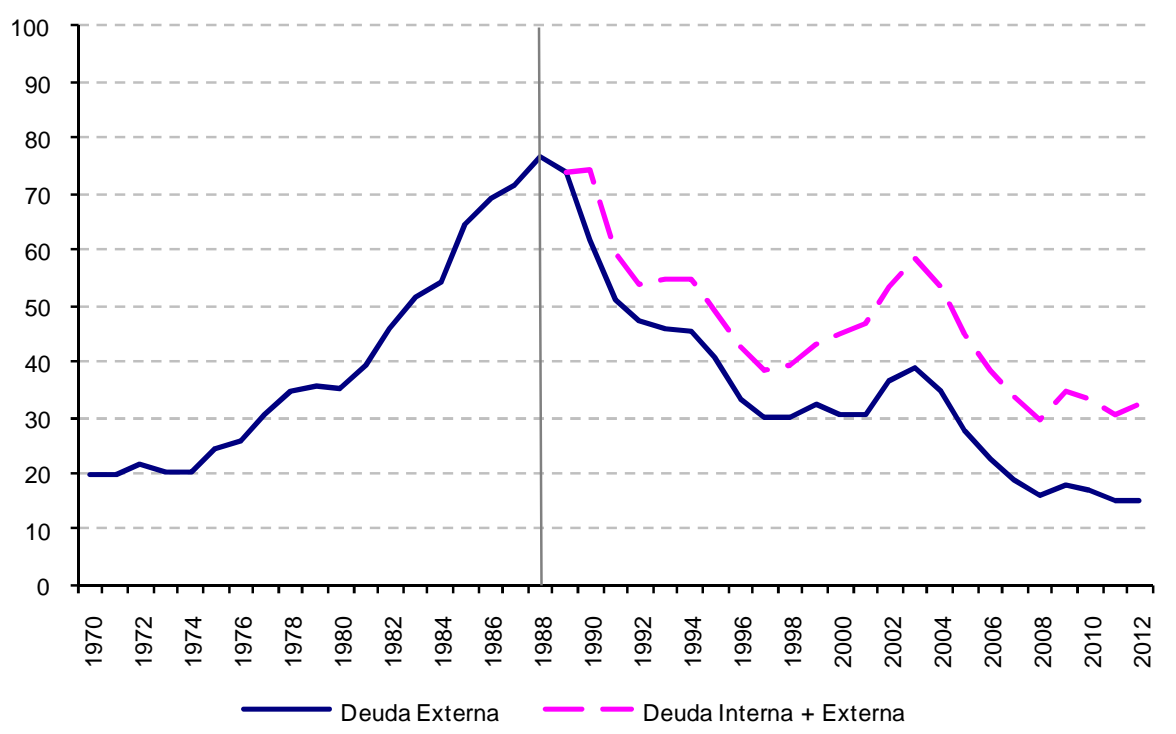

Fuente: Elaboración propia, sobre la base de cifras oficiales.

En tal sentido, es de destacar que, además de reducir en pocos años (entre 2003 y 2007) el nivel, se modificó considerablemente la composición de la deuda pública a favor de una extensión de los plazos, de una mayor participación de la deuda a tasa fija, de un aumento de la participación de residentes y de un incremento de la importancia de las deudas en moneda local (a partir de 2010, la deuda interna tiene una mayor participación en el total del endeudamiento público que la deuda externa).

Así, la deuda pública pasó de valores promedios cercanos a 60 puntos del PIB en 2003 a sólo 32 en 2008. A su vez, su componente externo se contrajo a valores cercanos a 16 puntos del PIB. Como se señaló, parte importante de esta reducción se dio en el período 2003-2007, y a pesar del deterioro del saldo primario a partir de 2008, el coeficiente de deuda se ha mantenido más bien constante desde entonces (31,2 puntos del PIB en 2012), pues el diferencial entre la tasa de interés y la tasa de crecimiento de la economía (o efecto "bola de nieve") ha sido poco significativo, exceptuando en algunos países de Centroamérica y en el Caribe.

La descomposición de los factores explicativos de la dinámica de la deuda pública muestra la fuerte exposición al aumento del tipo de cambio hasta 2002. La posterior caída como porcentaje del PIB se debió a la reversión de dicha tendencia, pero también a saldos primarios positivos, al crecimiento económico y a menores tasas de interés externa y doméstica (véase el gráfico 2). También se ilustra la importancia de factores discrecionales y de composición (ajuste "stock-flow"), probablemente asociados a las decisiones de varios países de pre-pagar deuda externa durante dicho período ${ }^{8}$.

8 En este tipo de ejercicios es habitual encontrar un residuo elevado, el denominado ajuste stock-flow, que da cuenta de las inconsistencias entre los balances fiscales y la evolución de la deuda pública. Puede deberse a razones de cobertura y de registro contable, efectos de valuación de activos y pasivos y también a renegociaciones o directamente "quitas" de deuda. 


\section{DINÁMICA DE LA DEUDA PÚBLICA: FACTORES EXPLICATIVOS}

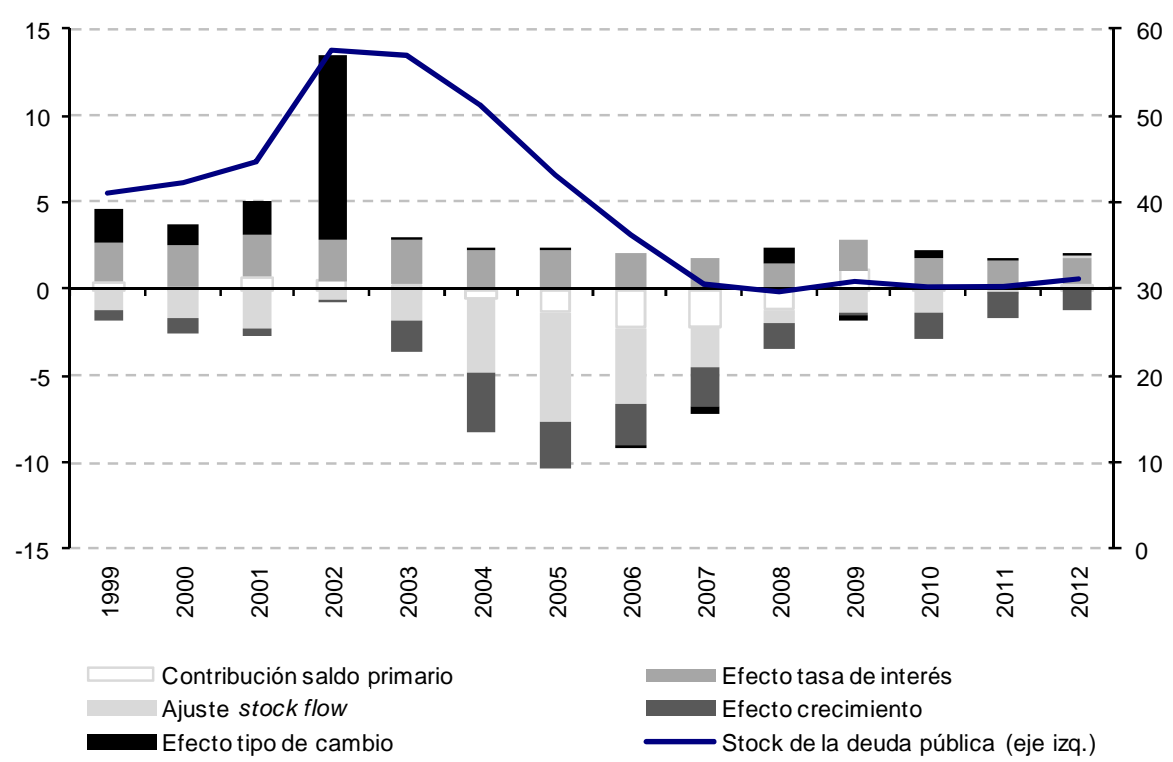

Descomposición dinámica de la deuda pública

$\Delta \mathrm{d}(\mathrm{t})=-$ saldo primario $(\mathrm{t})+\mathrm{d}(\mathrm{t}-1){ }^{*}(\mathrm{r}-\mathrm{g} / 1+\mathrm{g})+$ stock flow $(\mathrm{t})$

\begin{tabular}{|c|c|c|c|}
\hline \multicolumn{2}{|c|}{ Contribuciones al cambio de la deuda pública } & \multicolumn{2}{|l|}{ Descripción de variables } \\
\hline & & 1. Tasa de crecimiento del PIB (\%) & $g(t)$ \\
\hline $\begin{array}{l}\text { (a) Contribución del saldo } \\
\text { primario (déficit) }\end{array}$ & $-(b f(t)+(r(t) \times d(t-1)))$ & 2. Balance fiscal global (en $\%$ del PIB) & $b f(t)$ \\
\hline (b) Efecto crecimiento & $-(\mathrm{d}(\mathrm{t}-1) \times \mathrm{g}(\mathrm{t}) /(1+\mathrm{g}(\mathrm{t})))$ & 3. Pago de intereses (en \% de PIB) & $r(t) \times d(t-1)$ \\
\hline (c) Efecto tasa de interés & $d(t-1) \times r(t) /(1+g(t))$ & 4. Tasa de interés real (\%) & $r(t)=f\left(r^{D}(t), r^{*}(t)\right)$ \\
\hline (d) Efecto tipo de cambio & $\begin{array}{l}\mathrm{d}(\mathrm{t}-1) \times \operatorname{dev}(\mathrm{t}) \times(\mathrm{dx}(\mathrm{t}-1) \\
/ \mathrm{d}(\mathrm{t}-1)) \times\left(1+\mathrm{r}^{*}(\mathrm{t})\right) /(1+\mathrm{g} \\
(\mathrm{t}))\end{array}$ & 5. Tasa de interés real interna (\%) & $r^{D}(t)$ \\
\hline \multirow{6}{*}{ (e) Ajuste stock flow } & $\Delta d(t)-(a)-(b)-(c)-(d)$ & 6. Tasa de interés real externa (\%) & $r^{*}(t)$ \\
\hline & & Supuesto: & $r^{D}(t)=r^{*}(t)$ \\
\hline & & 7. Tasa de devaluación nominal & $\operatorname{dev}(\mathrm{t})$ \\
\hline & & $\begin{array}{l}\text { 8. Participación de la deuda externa } \\
\text { en la deuda total (\%) }\end{array}$ & $d x(t) / d(t)$ \\
\hline & & $\begin{array}{l}\text { 9. Saldo de la deuda pública (final de } \\
\text { año) }\end{array}$ & $d(t)$ \\
\hline & & 10. Cambio en la deuda pública & $\Delta d(t)=d(t)-d(t-1)$ \\
\hline
\end{tabular}

Fuente: Cálculos propios, sobre la base de cifras oficiales.

En contraste con lo que sucede en otras partes del mundo, y con lo que aconteció en el pasado en la región, se logró una reducción de la deuda pública que constituye un factor estabilizador de las expectativas de los agentes económicos. El control de las finanzas públicas es hoy un activo significativo para América Latina en su conjunto.

Cabe apuntar, sin embargo, que la situación sigue siendo muy diversa. Algunos países de Centroamérica continúan con niveles de endeudamiento relativamente altos; en el Caribe, por su parte, muchos países exhiben coeficientes muy elevados de deuda como porcentaje del PIB; y en algunos países de América del Sur es menester reducir aún más los niveles de endeudamiento en el mediano plazo, dadas las aún elevadas tasas de interés de la deuda pública.

Este conjunto de factores determina que la región siga disponiendo de espacios (si bien acotados) para enfrentar escenarios adversos, debido principalmente a que los niveles de deuda pública son menores con respecto a los registrados previo a la crisis. En efecto, en Argentina, Bolivia (Estado Plurinacional de), Brasil, Chile, Colombia, Ecuador, Haití, Guatemala, Nicaragua, Panamá, Paraguay, 
Perú y Uruguay la deuda pública (bruta o neta, según los países) se ha reducido o mantenido como porcentaje del PIB entre 2008 y 2012 (véase CEPAL, 2013).

Por el contrario, en Costa Rica, El Salvador, Honduras y República Dominicana la deuda pública ha aumentado como porcentaje del PIB, aunque en niveles acotados. Lo mismo ha sucedido en nueve de los trece países del Caribe, pero con niveles iniciales mucho más altos.

\section{B. Hacia una arquitectura fiscal contracíclica}

Las políticas fiscales contra-cíclicas generan ganancias en términos de bienestar, pues estabilizan el consumo, reducen la volatilidad del PIB y minimizan las distorsiones producidas por cambios impositivos continuos, además de otorgar protección social en momentos de alto desempleo. Idealmente, las políticas fiscales deben asegurar excedentes en situaciones de bonanza y aceptar déficit en recesiones, con un saldo promedio fijo a lo largo dell ciclo económico.

El balance fiscal cíclicamente ajustado (BFCA) es el indicador que permite evaluar la orientación de la política en una perspectiva de mediano plazo. Bajo el supuesto de que el producto real fluctúa en torno a una tendencia, calcula el efecto cíclico que la actividad económica y la variación de precios relevantes tienen en el resultado fiscal, mostrando el balance que resultaría si el PIB estuviese en su nivel de tendencia y si los precios fueran los del mediano plazo.

Los cálculos muestran que las cuentas fiscales en la región son muy sensibles a la fluctuación del PIB y de los precios de productos básicos (cuadro 5), y por ello es fundamental disponer de indicadores estructurales. Estos efectos cíclicos dependen de tres factores: el tamaño de las brechas entre las series efectivas y la tendencia, el valor de la elasticidad de la fuente de ingresos relevante (respecto del PIB o del precio de materias primas) y la ponderación de dicha fuente en los ingresos totales. Se observa que, con la excepción de Guatemala y México, las elasticidades brutas han sido superiores a uno en el período de estimación.

En los países cuyos ingresos fiscales dependen más de las fluctuaciones del PIB que de las variaciones de los precios de productos básicos, los efectos cíclicos son más bien pequeños, pues el peso de los impuestos es en promedio de 19 puntos del PIB en la región (véase CEPAL, 2013a), por lo que los estabilizadores automáticos son relativamente menores (la semi-elasticidad del balance fiscal con respecto al PIB es de 0,2 en promedio, en contraste con 0,5 en los países OCDE). Sin embargo, las amplias brechas (recesivas) entre el crecimiento efectivo y el de tendencia, como las que surgieron a inicios de la década del 2000, provocaron mínimos superiores a 3 puntos del PIB en el saldo cíclico en países como Argentina, Bolivia (Estado Plurinacional de), Costa Rica, Ecuador, Panamá, República Dominicana, Uruguay y Venezuela (República Bolivariana de).

\section{CUADRO 5}

MÁXIMOS Y MÍNIMOS DE LA BRECHA DEL PIB Y DEL SALDO CÍCLICO, 1990-2012

(Porcentaje del PIB potencial y porcentaje del PIB)

\begin{tabular}{|c|c|c|c|c|c|c|c|c|c|c|}
\hline \multirow[b]{3}{*}{ Argentina } & \multicolumn{4}{|c|}{$\begin{array}{c}\text { Brecha del PIB } \\
\text { (en porcentajes del PIB potencial) }\end{array}$} & \multicolumn{4}{|c|}{$\begin{array}{c}\text { Saldo cíclico } \\
\text { (en porcentajes del PIB) }\end{array}$} & \multicolumn{2}{|c|}{$\begin{array}{l}\text { Elasticidades } \\
\text { de largo plazo }\end{array}$} \\
\hline & \multicolumn{2}{|c|}{ Mínimo } & \multicolumn{2}{|c|}{ Máximo } & \multicolumn{2}{|c|}{ Mínimo } & \multicolumn{2}{|c|}{ Máximo } & \multirow{2}{*}{$\begin{array}{l}\text { PIB } \\
1,22\end{array}$} & \multirow[t]{2}{*}{$\begin{array}{c}\text { Recursos no } \\
\text { renovables }\end{array}$} \\
\hline & $-27,9$ & $(2001)$ & 21,6 & (1994) & $-3,3$ & & 2,1 & & & \\
\hline $\begin{array}{l}\text { Bolivia (Estado } \\
\text { Plurinacional de) }\end{array}$ & $-11,0$ & (2003) & 9,2 & (1998) & $-9,8$ & (1999) & 7,7 & (2008) & 1,23 & 2,44 \\
\hline Brasil & $-3,7$ & (2003) & 3,1 & (1997) & $-0,8$ & & 0,6 & (2011) & 1,30 & \\
\hline Chile & $-10,3$ & (2002) & 9,8 & (1995) & $-2,0$ & $(2002)^{a}$ & 7,3 & $(2007)^{a}$ & 1,09 & 1,32 \\
\hline Colombia & $-6,2$ & (2003) & 15,1 & (1991) & $-1,0$ & & 1,3 & & 1,17 & 1,76 \\
\hline Costa Rica & $-18,7$ & (2002) & 18,2 & (1997) & $-3,3$ & & 2,9 & (1998) & 1,06 & \\
\hline
\end{tabular}


Cuadro 5 (conclusión)

\begin{tabular}{|c|c|c|c|c|c|c|c|c|c|}
\hline \multirow[b]{3}{*}{ Ecuador } & \multicolumn{4}{|c|}{$\begin{array}{c}\text { Brecha del PIB } \\
\text { (en porcentajes del PIB potencial) }\end{array}$} & \multicolumn{3}{|c|}{$\begin{array}{c}\text { Saldo cíclico } \\
\text { (en porcentajes del PIB) }\end{array}$} & \multicolumn{2}{|c|}{$\begin{array}{l}\text { Elasticidades } \\
\text { de largo plazo }\end{array}$} \\
\hline & \multicolumn{2}{|c|}{ Mínimo } & \multicolumn{2}{|c|}{ Máximo } & \multirow{2}{*}{$\begin{array}{l}\text { Mínimo } \\
-7,2\end{array}$} & \multicolumn{2}{|c|}{ Máximo } & \multirow{2}{*}{$\frac{\mathrm{PIB}}{1,75}$} & \multirow{2}{*}{$\begin{array}{c}\text { Recursos no } \\
\text { renovables }\end{array}$} \\
\hline & $-44,3$ & $(2000)$ & 22,0 & (1994) & & 2,5 & & & \\
\hline EI Salvador & $-7,1$ & (1992) & 6,2 & (2008) & $-1,0$ & 1,2 & & 1,41 & \\
\hline Guatemala & $-5,3$ & $(2005)$ & 12,2 & (1991) & $-0,5$ & 0,9 & & 0,88 & \\
\hline México & $-29,6$ & (1994) & 11,4 & (1992) & $-3,2$ & 2,6 & (2008) & 0,99 & 1,40 \\
\hline Nicaragua & $-11,0$ & $(2003)$ & 21,9 & (1992) & $-2,1$ & 3,1 & & 1,24 & \\
\hline Panamá & $-15,5$ & (2003) & 9,5 & (1998) & $-4,9$ & 2,4 & & 1,70 & \\
\hline Perú & $-23,2$ & (1991) & 12,5 & (1997) & $-3,2$ & 2,1 & & 1,20 & \\
\hline $\begin{array}{l}\text { República } \\
\text { Dominicana }\end{array}$ & $-35,8$ & (2002) & 11,4 & (1995) & $-5,3$ & 1,3 & & 1,08 & \\
\hline Uruguay & $-18,7$ & $(2002)$ & 18,2 & (1997) & $-3,4$ & 3,0 & (1998) & 1,09 & \\
\hline $\begin{array}{l}\text { Venezuela (República } \\
\text { Bolivariana de ) }\end{array}$ & $-58,7$ & (2003) & 84,9 & (1995) & $-10,6$ & 7,2 & (1995) & 1,01 & 1,81 \\
\hline
\end{tabular}

Fuente: Cálculos propios. Se indican los años de máximo y mínimo.

a Proyecciones oficiales.

En el gráfico 3 se ilustra la diferencia entre el balance fiscal efectivo y el BFCA (es decir, el saldo cíclico) de los gobiernos centrales de dieciocho países de la región, para cuya estimación se ha utilizado información anual procedente de la base de datos de la CEPAL ${ }^{9}$. De los resultados obtenidos se observa que en términos generales los países han tenido una posición similar en el ciclo macroeconómico. Para el periodo 1990-2011, es posible distinguir al menos tres sub periodos, comenzando por los años previos a 1999 donde la mayoría de los países presentaba una brecha de PIB positiva, para luego dar lugar a un período de aproximadamente 7 u 8 años en que las economías se situaron por debajo del PIB potencial. Posteriormente, la brecha tiende a ser positiva, aunque con un claro quiebre para el año 2009.

Así los países que presentan una mayor diferencia entre ambos balances son Bolivia (Estado Plurinacional de), Chile, México, Perú, Ecuador, Trinidad y Tabago y Venezuela (República Bolivariana de), donde se registran desviaciones por sobre los 4 puntos porcentuales del PIB. Es posible apreciar que en estos países, que tienen significativos ingresos por recursos no renovables ${ }^{10}$, el efecto cíclico está directamente relacionado con la posición de los precios frente a la tendencia de los mismos.

9 La metodología para el cálculo del BFCA incluye la estimación del producto potencial por el filtro Hodrick-Prescott, y se asume que sólo los ingresos tienen un componente cíclico. En el caso de que existan ingresos provenientes de la explotación de materias primas, generalmente afectados por los movimientos de los precios internacionales, se determina el precio de referencia por el filtro de tendencia Hodrick-Prescott. Las elasticidades fueron estimadas por el método de corrección de errores.

10 En Ecuador, México, Venezuela (República Bolivariana de), Trinidad y Tobago y Bolivia (Estado Plurinacional de), alrededor del $30 \%$ o más del total de los ingresos fiscales se originan en la producción de petróleo en el caso de los cuatro primeros y en la explotación de gas en el último. Los ingresos fiscales provenientes de la explotación de recursos naturales son también significativos en Chile, Colombia y Perú, donde su participación se ubica en torno al 15\%, en promedio, para 2011. 


\section{GRÁFICO 3}

DIFERENCIAS ENTRE BALANCE FISCAL EFECTIVO Y BFCA

(En puntos del PIB y en moneda corriente local)
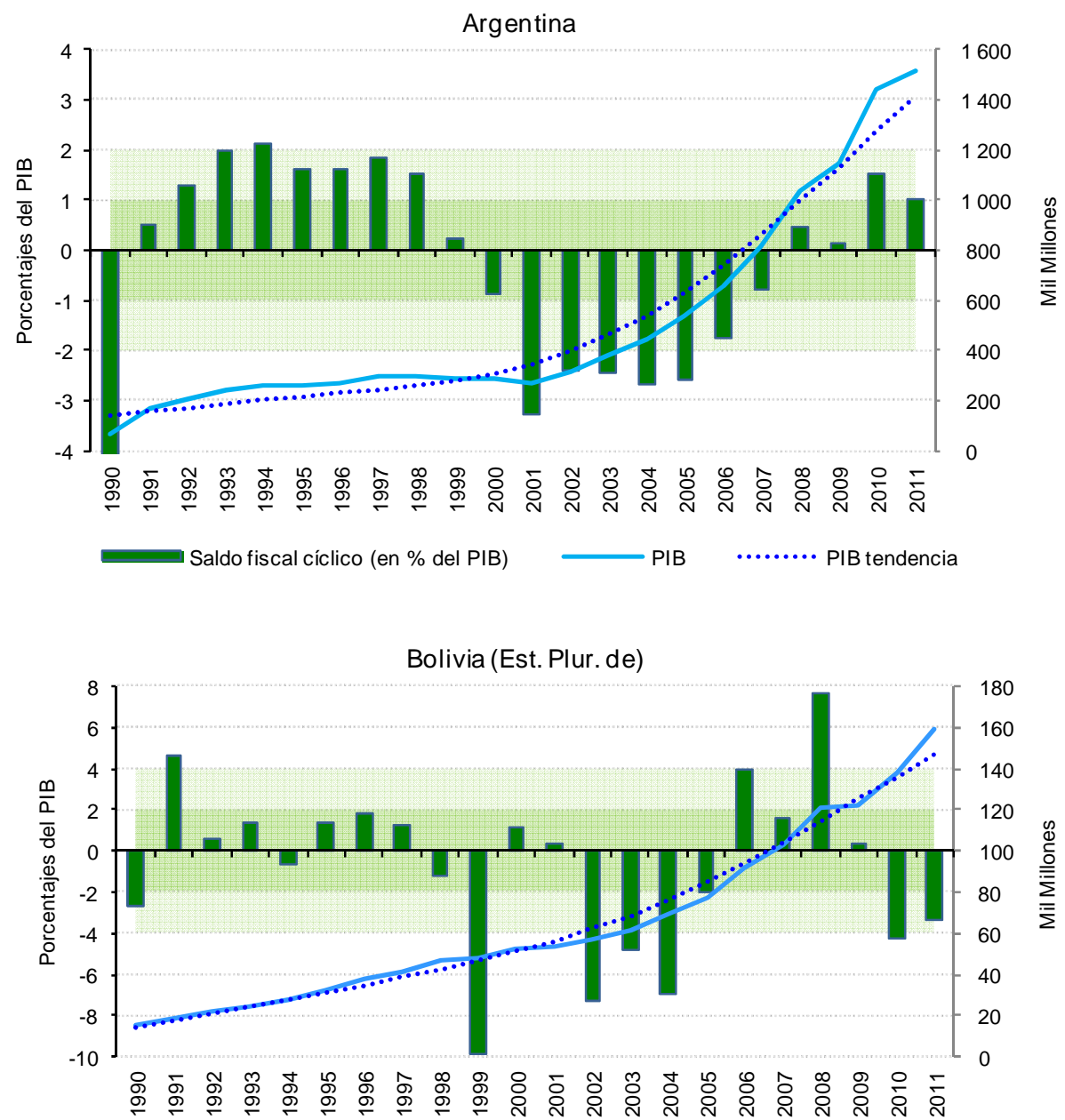

Saldo fiscal cíclico (en \% del PIB) — PIB $\quad$ …..... PIB tendencia

Bolivia (Est. Plur. de)

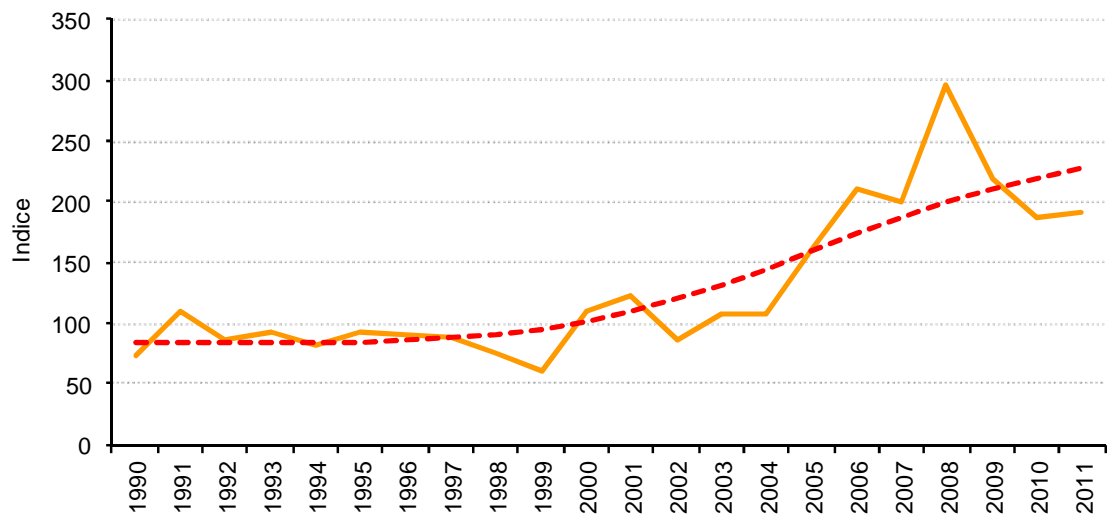

Precio recursos no renovables

- - - Precio recursos no renovables tendencia 
Gráfico 3 (continuación)

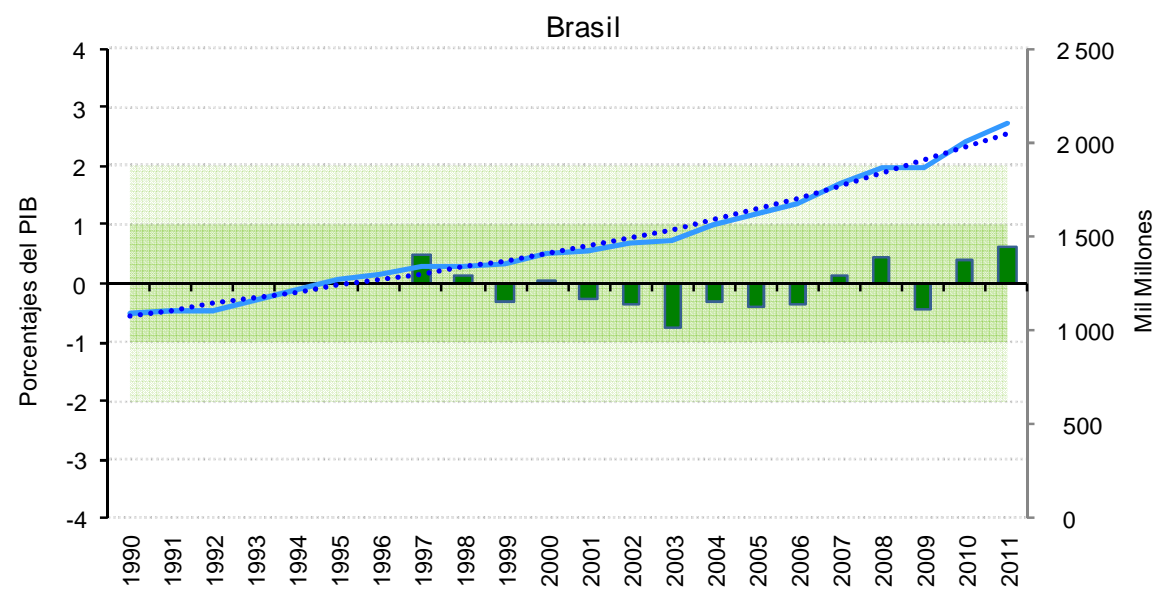

Saldo fiscal cíclico (en \% del PIB) — PIB _....... PIB tendencia

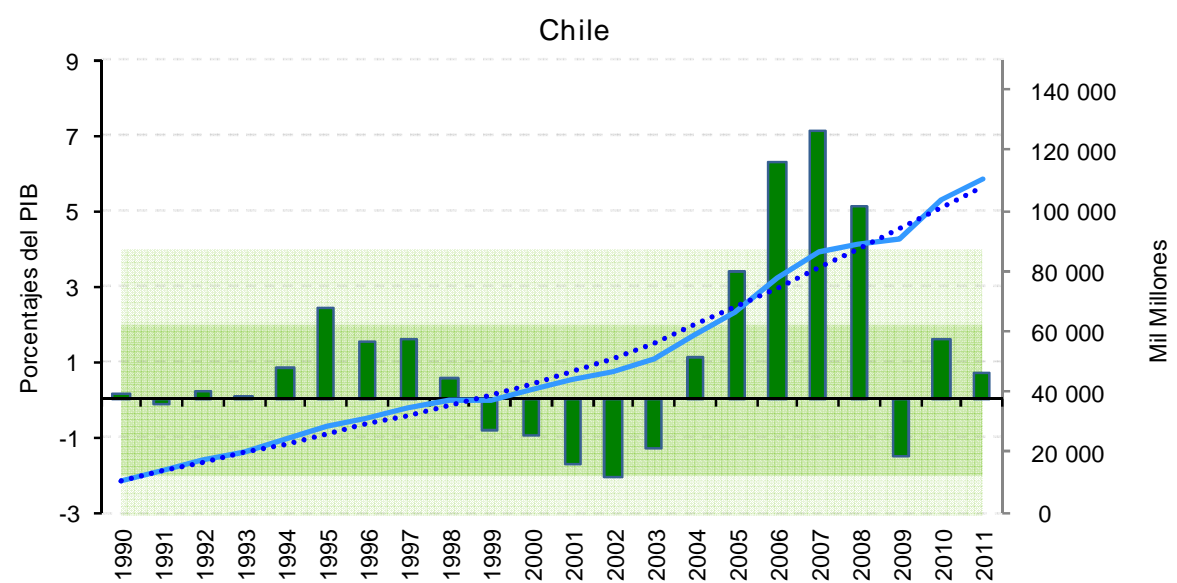

Saldo fiscal cíclico (en \% del PIB) $\quad$ PIB $\quad$ …..... PIB tendencia

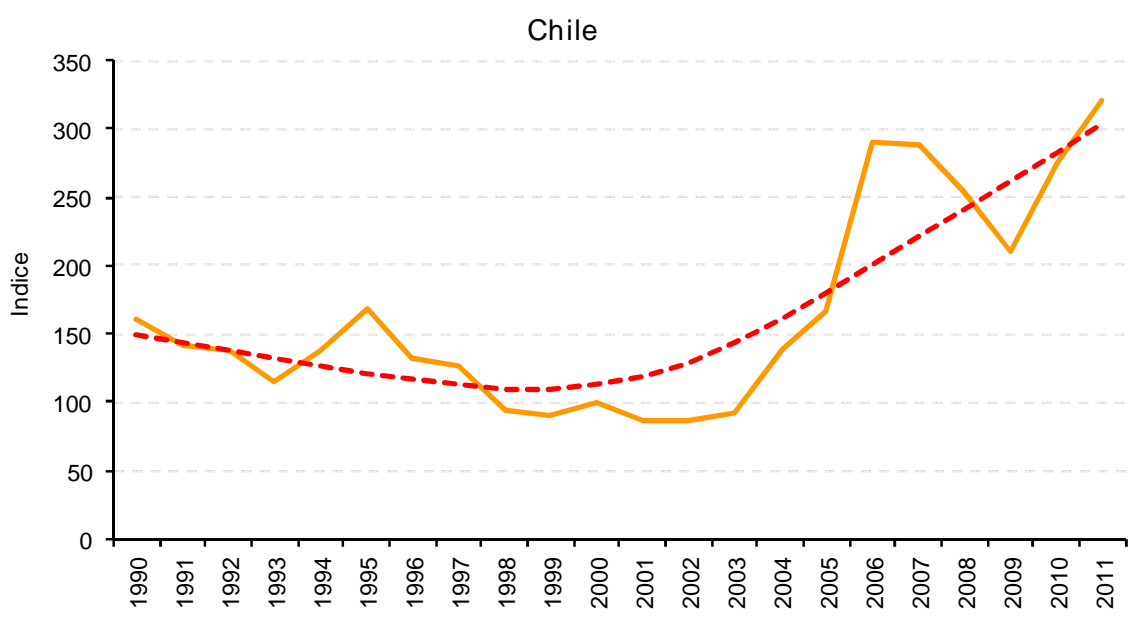

Precio recursos no renovables

- Precio recursos no renovables tendencia 
Gráfico 3 (continuación)

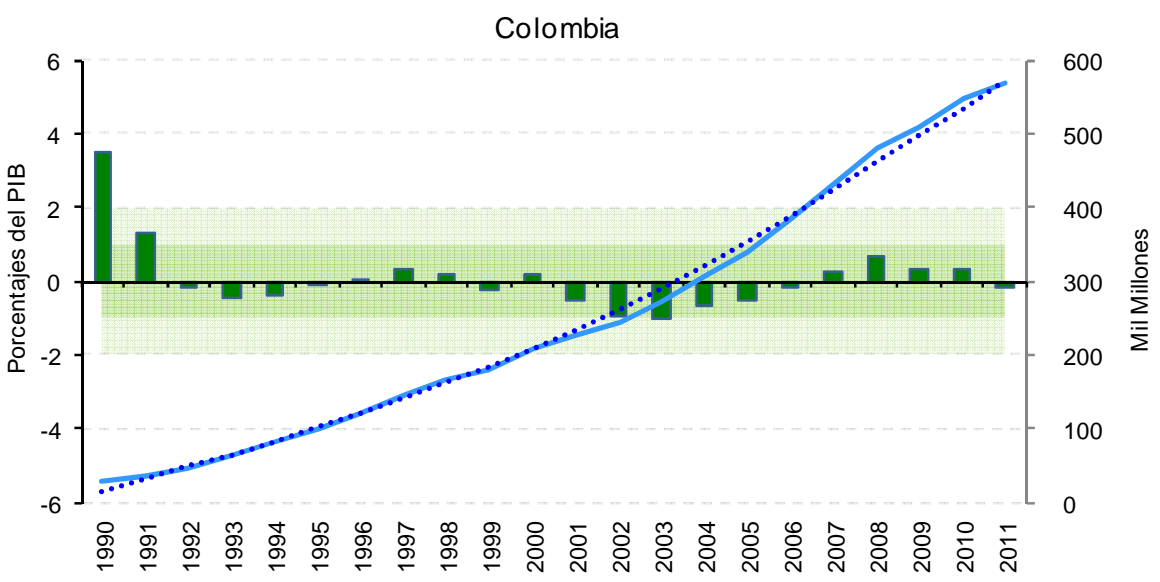

Saldo fiscal cíclico (en \% del PIB) $\quad$ PIB $\quad \cdots . . .$. PIB tendencia

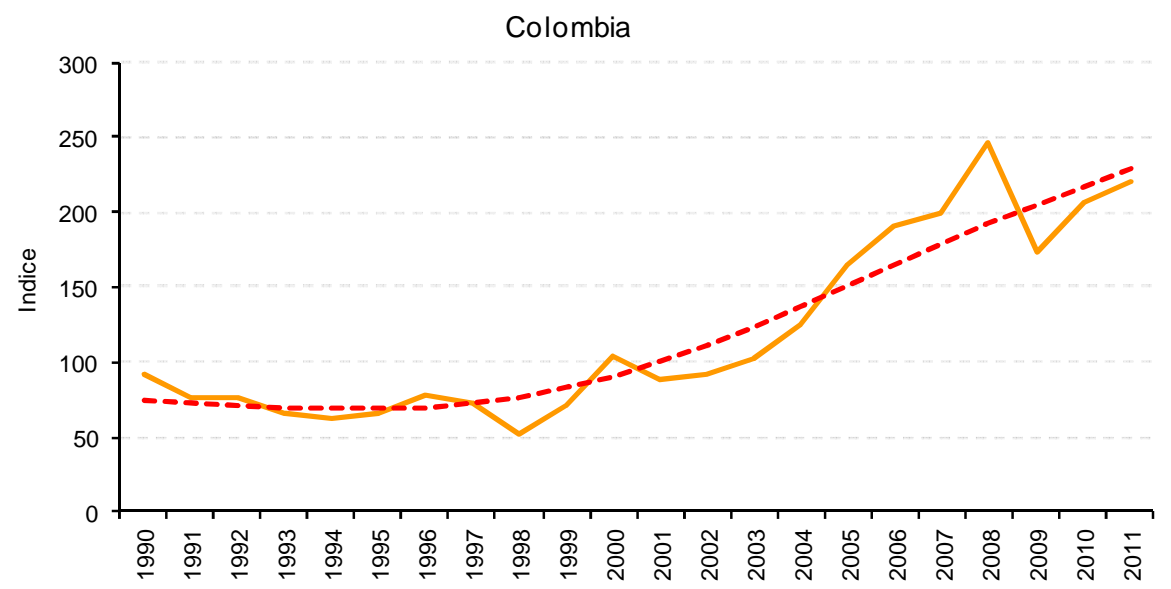

Precio recursos no renovables _- - - - Precio recursos no renovables tendencia

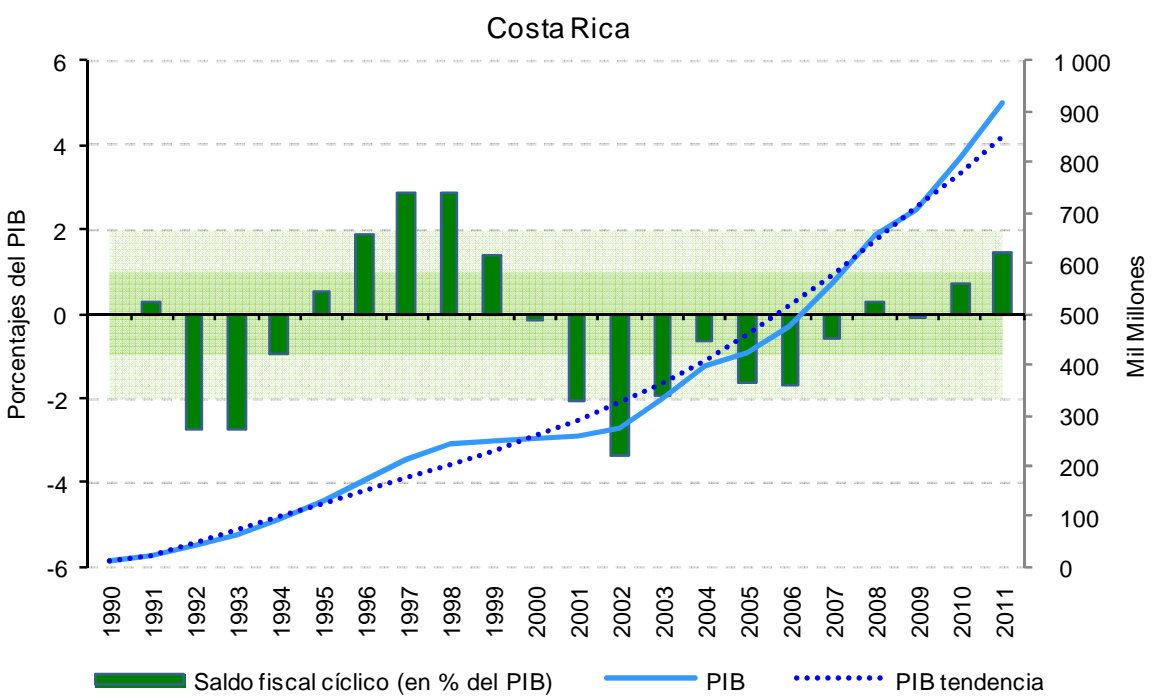


Gráfico 3 (continuación)
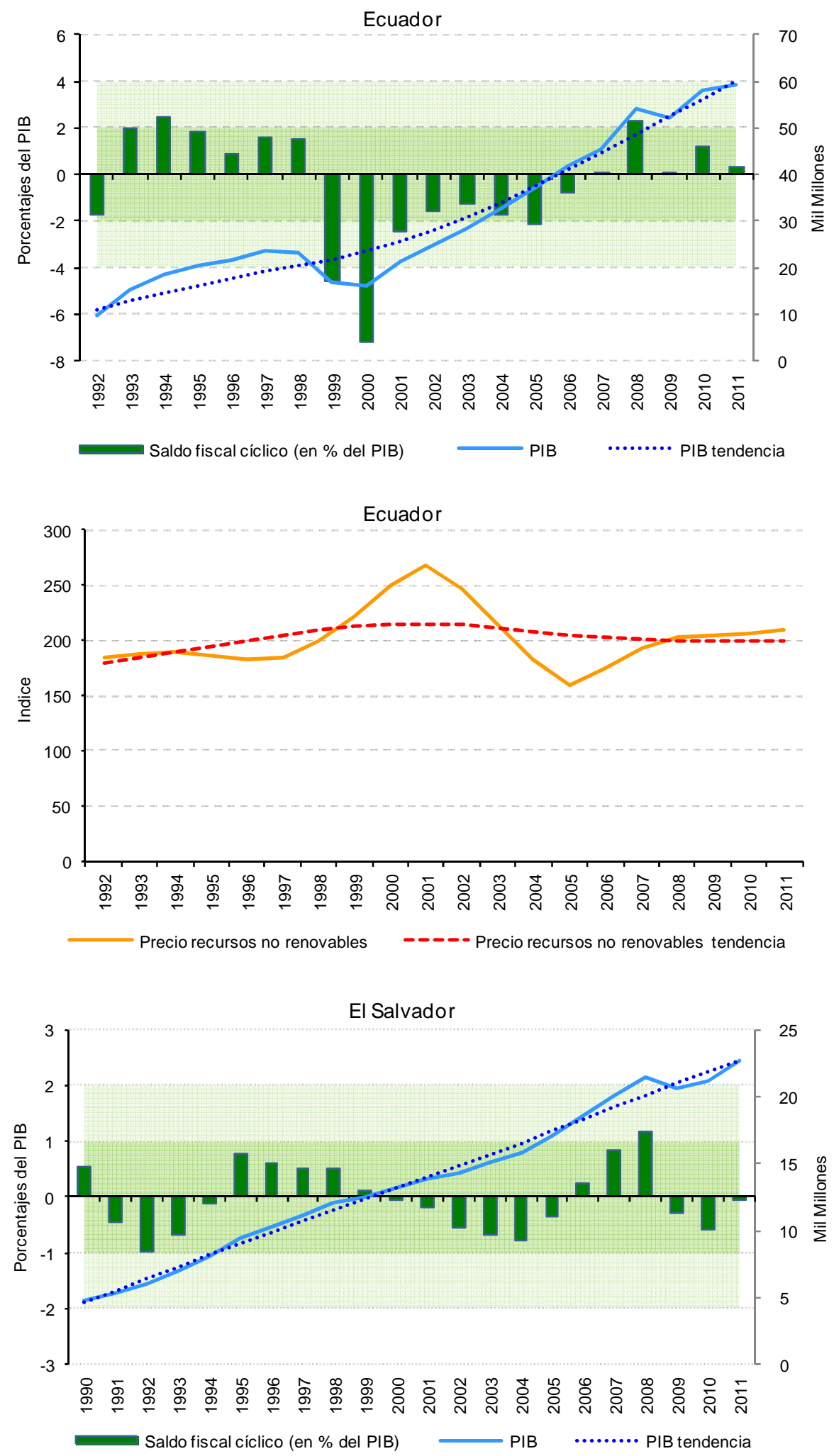
Gráfico 3 (continuación)
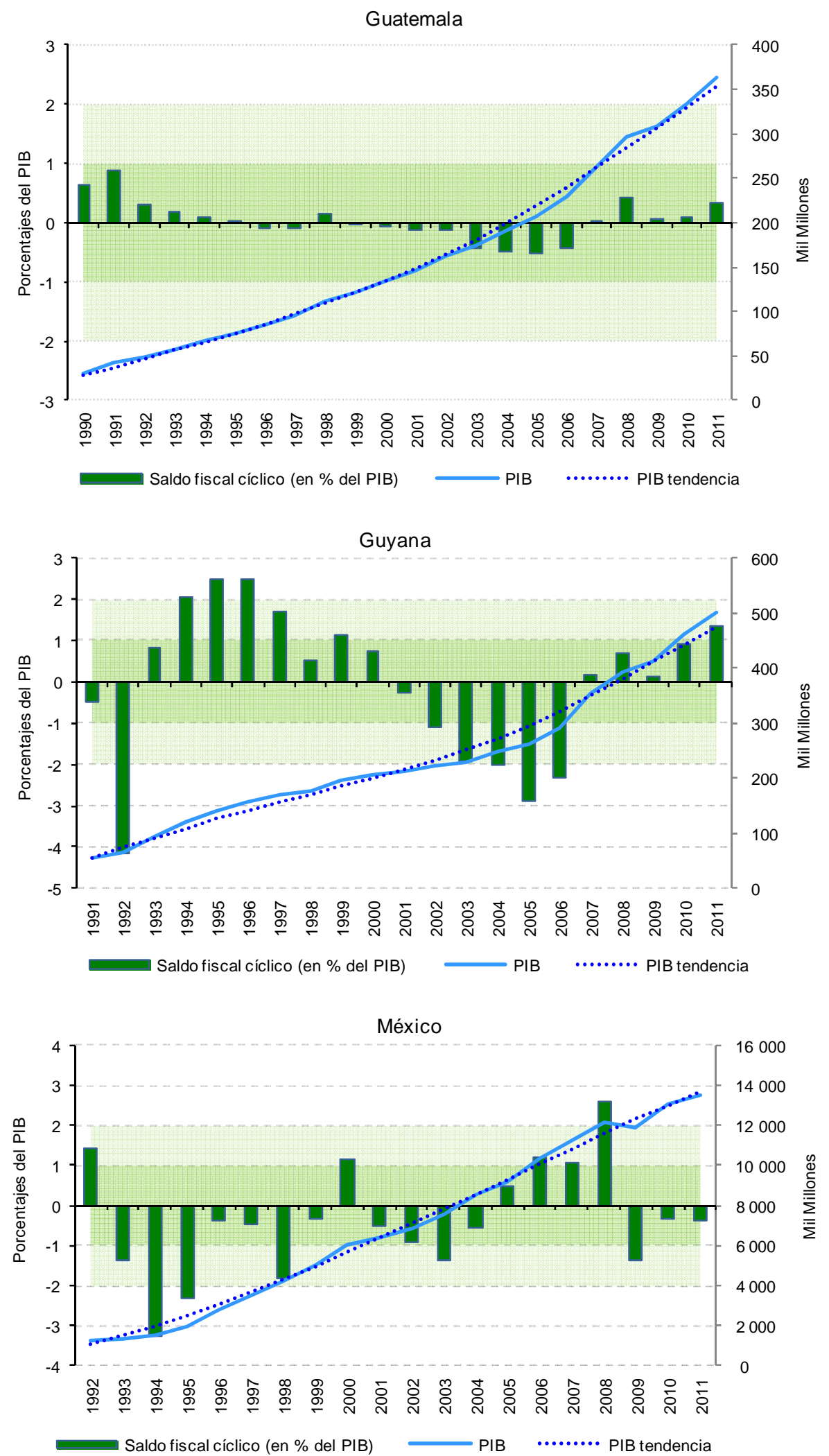
Gráfico 3 (continuación)
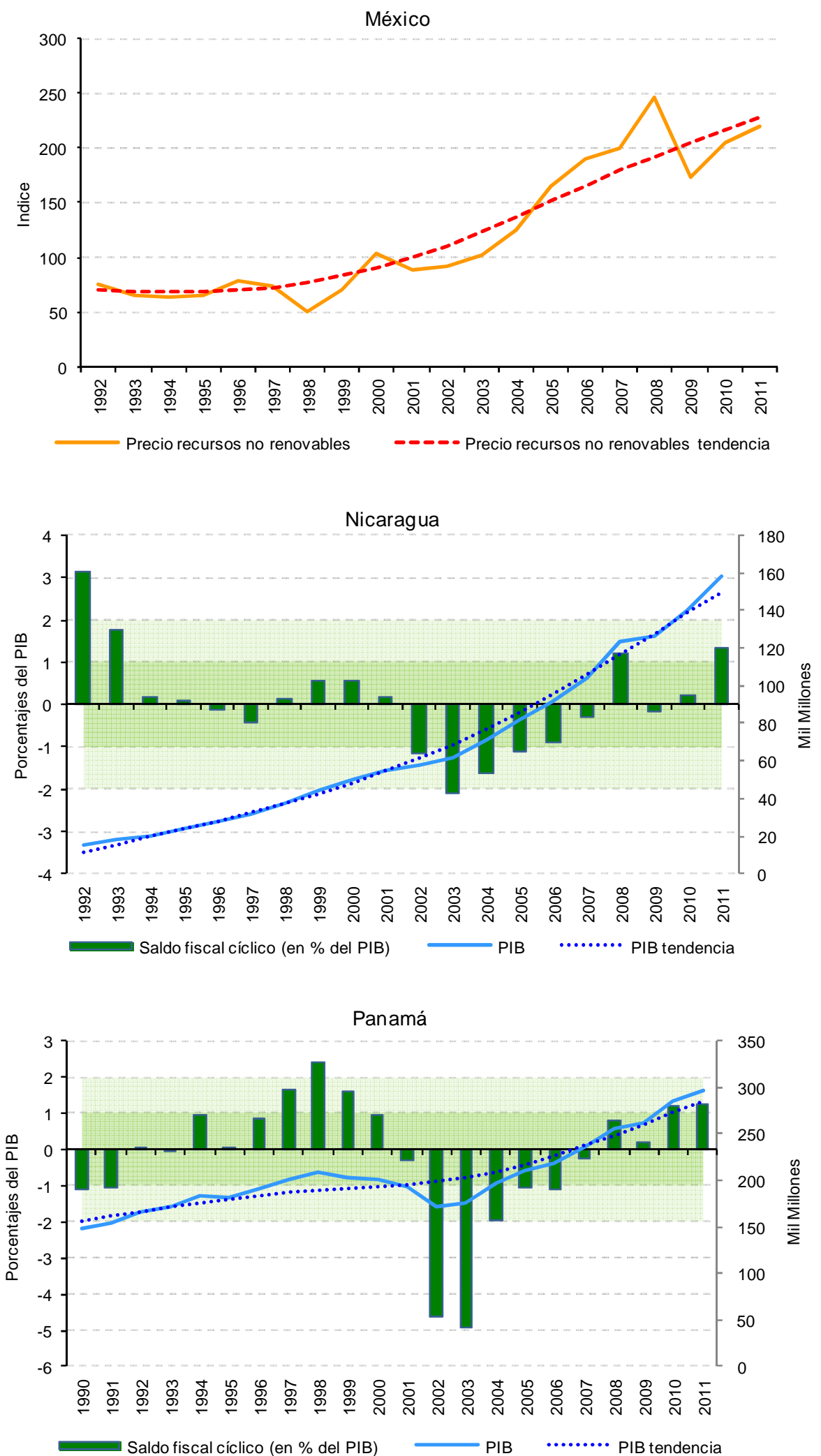
Gráfico 3 (continuación)

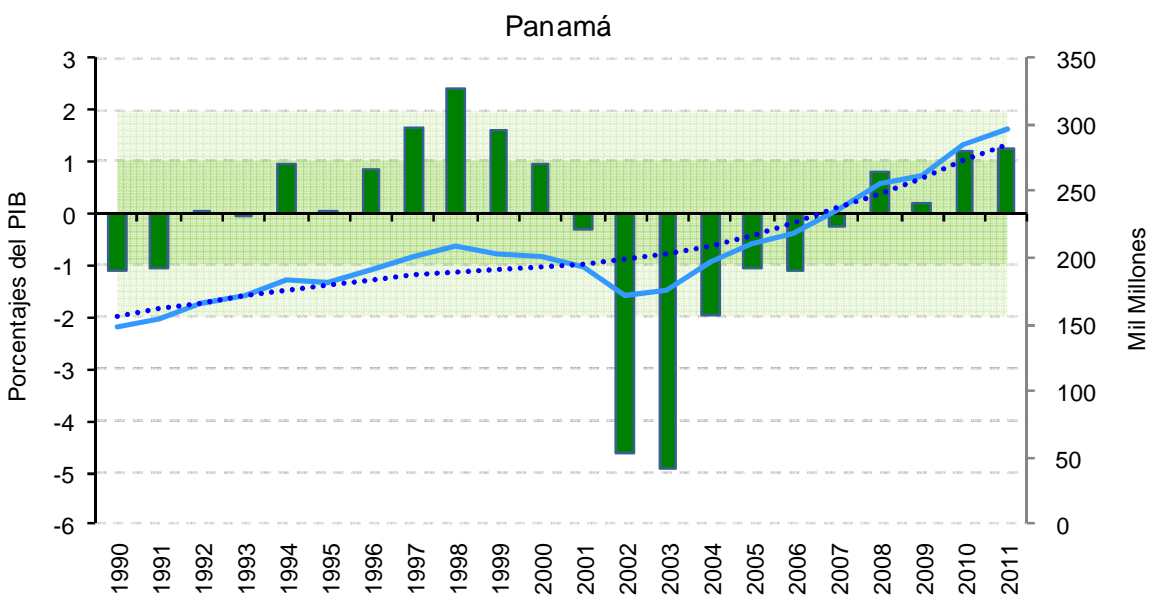

Saldo fiscal cíclico (en \% del PIB) — PIB $\quad$ …..... PIB tendencia

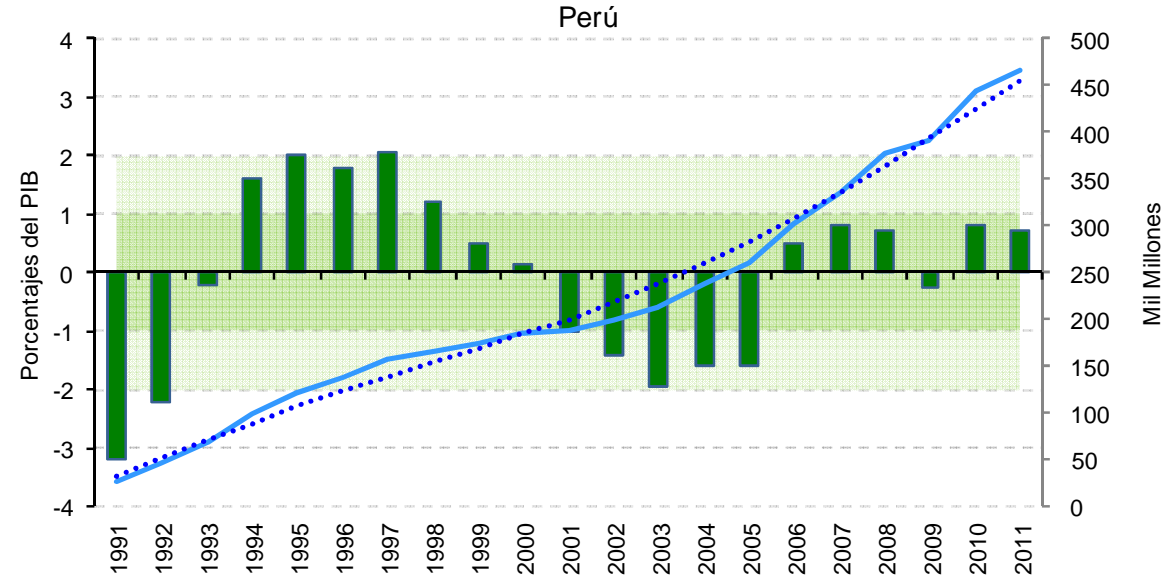

Saldo fiscal cíclico (en \% del PIB) $\quad$ PIB $\quad$ …..... PIB tendencia

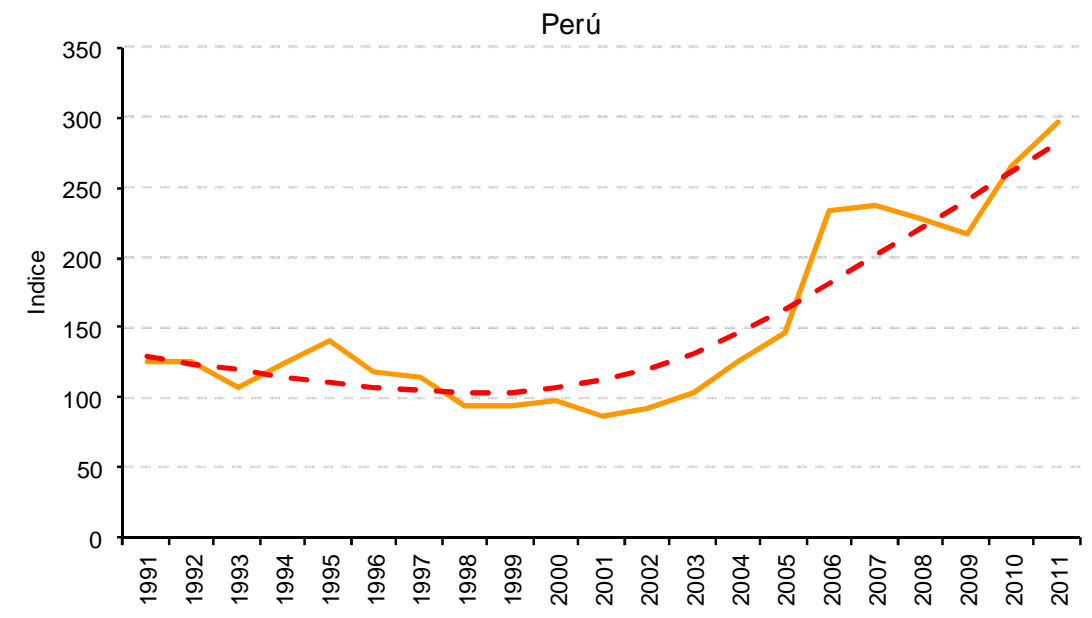

- Precio recursos no renovables $\quad$ - - Precio recursos no renovables tendencia 
Gráfico 3 (continuación)
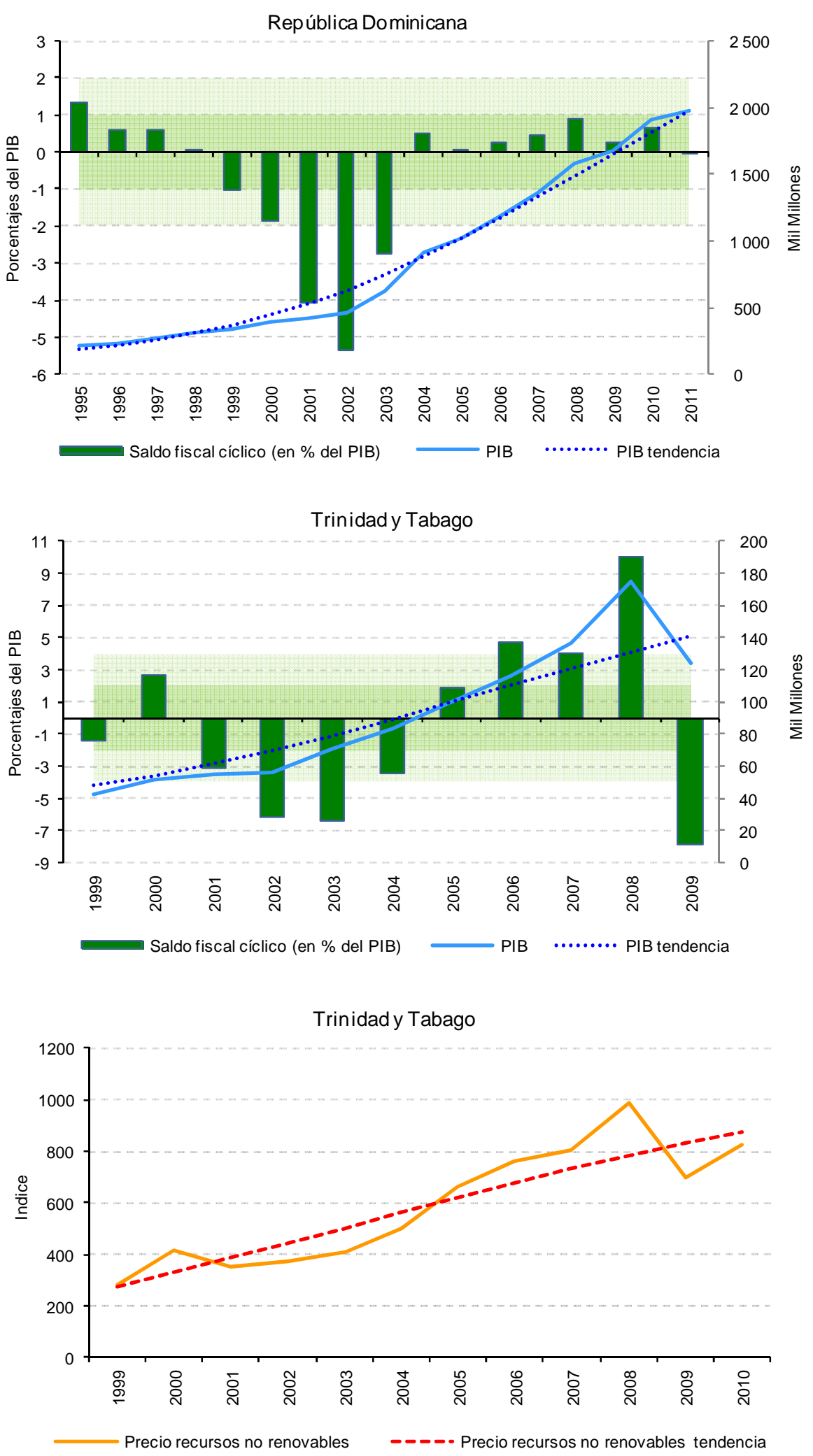
Gráfico 3 (conclusión)

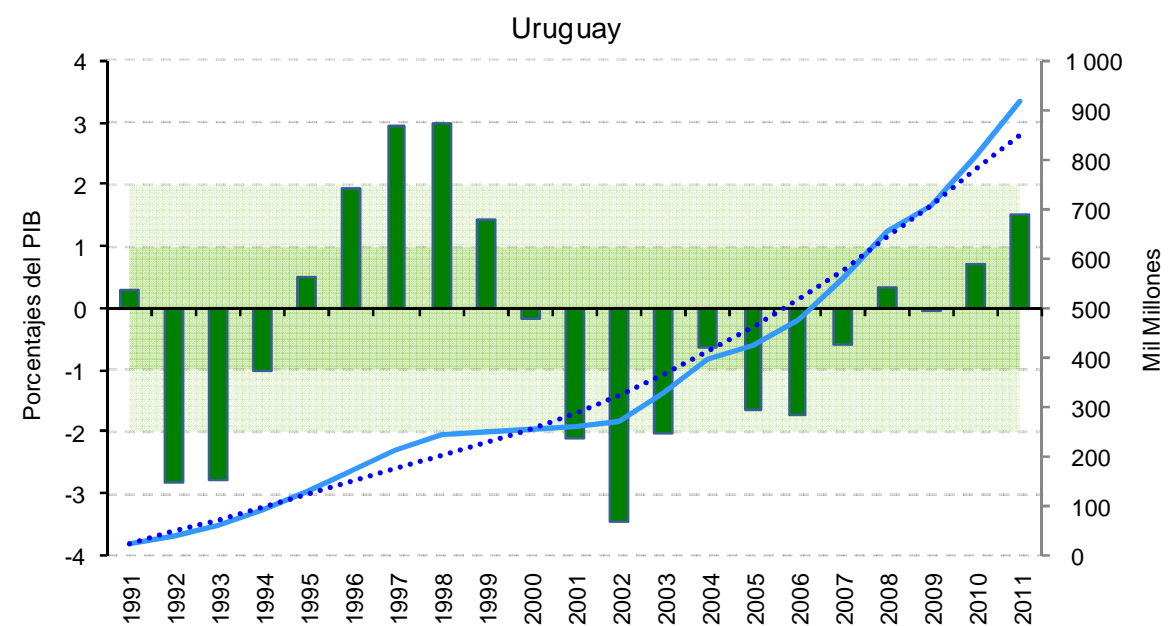

Saldo fiscal cíclico (en \% del PIB) _ PIB $\quad$ …..... PIB tendencia
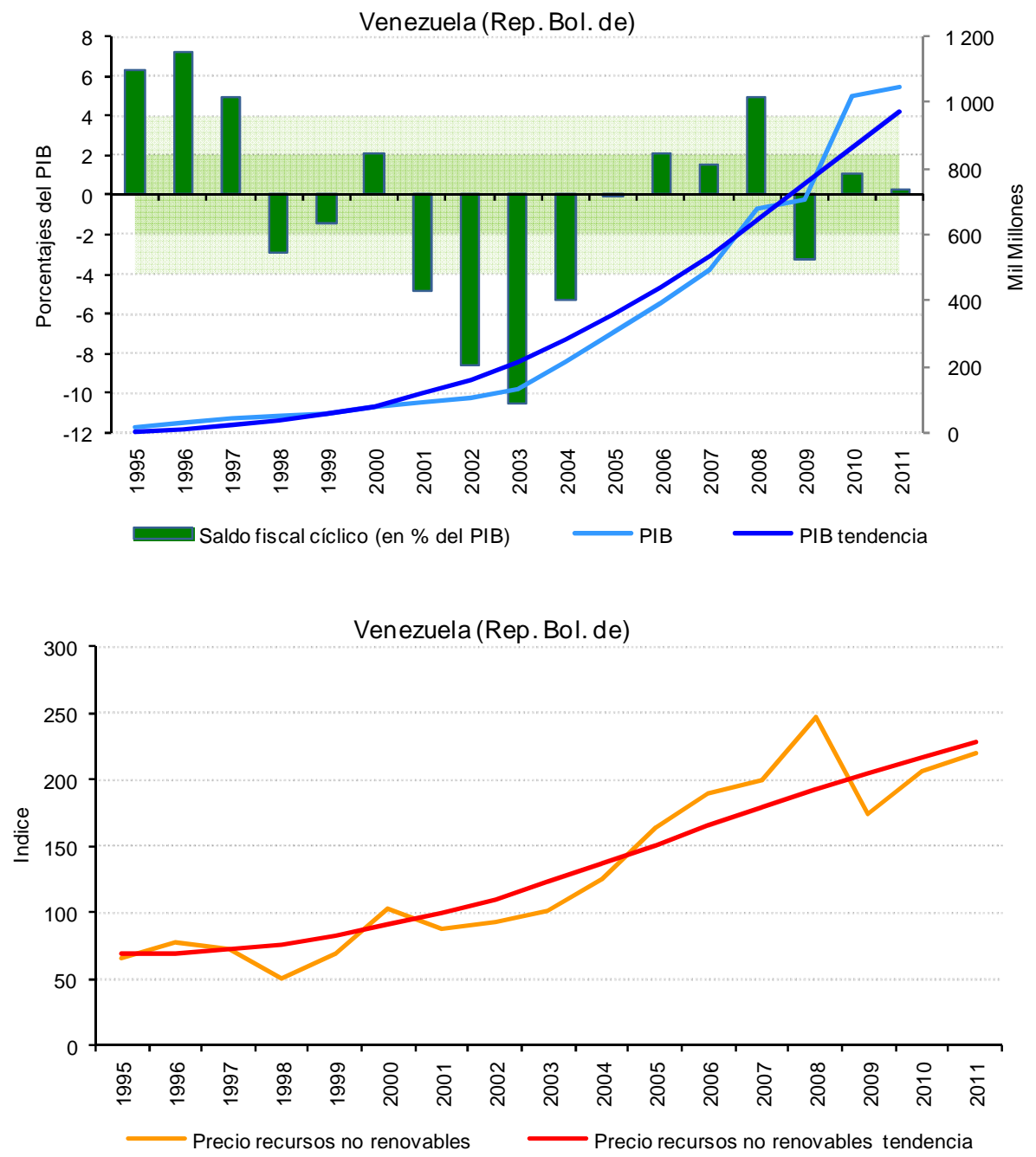

Fuente: Cálculos propios. BFCA: Balance cíclicamente ajustado por el PIB y el precio de las materias primas. 
Una forma de identificar lo que fue la orientación de la política fiscal en ciertos períodos es comparar las variaciones del balance fiscal cíclicamente ajustado (BFCA) con la brecha de PIB. La idea es que los cambios en el BFCA reflejan las decisiones discrecionales de las autoridades de cambiar las tasas tributarias o los niveles de gasto. Por ejemplo. una política fiscal procíclica (contracíclica), si la brecha del PIB es positiva, se caracteriza por una reducción (aumento) en el BFCA, lo que indica una medida discrecional expansiva (contractiva). En Martner (2007) se analizan 267 episodios para 18 países de América Latina en el período 1990-2005, y se obtiene que un 55\% ha resultado procíclico, y el $45 \%$ contracíclico o neutro. Ello se contrapone con la idea generalizada de que en América Latina las políticas han sido siempre procíclicas, pues en varios países de la región se aplicaron medidas restrictivas en fases de bonanza, durante la década de 1990 y luego de 2003. Además, existe un cierto grado de asimetría: cuando la brecha de PIB es positiva, existió una tendencia a la prociclicidad. Resultaría según estos resultados más difícil hacer políticas contracíclicas en tiempos de bonanza. Con la misma metodología, para este estudio se compararon 364 episodios entre 1990 y 2012. El gráfico a continuación ilustra los resultados: no es posible detectar un padrón generalizado en América Latina ${ }^{11}$.

\section{VARIACIÓN DEL BALANCE GLOBAL CÍCLICAMENTE AJUSTADO Y DE LA BRECHA DEL PIB, 1990-2012 (18 PAÍSES)}

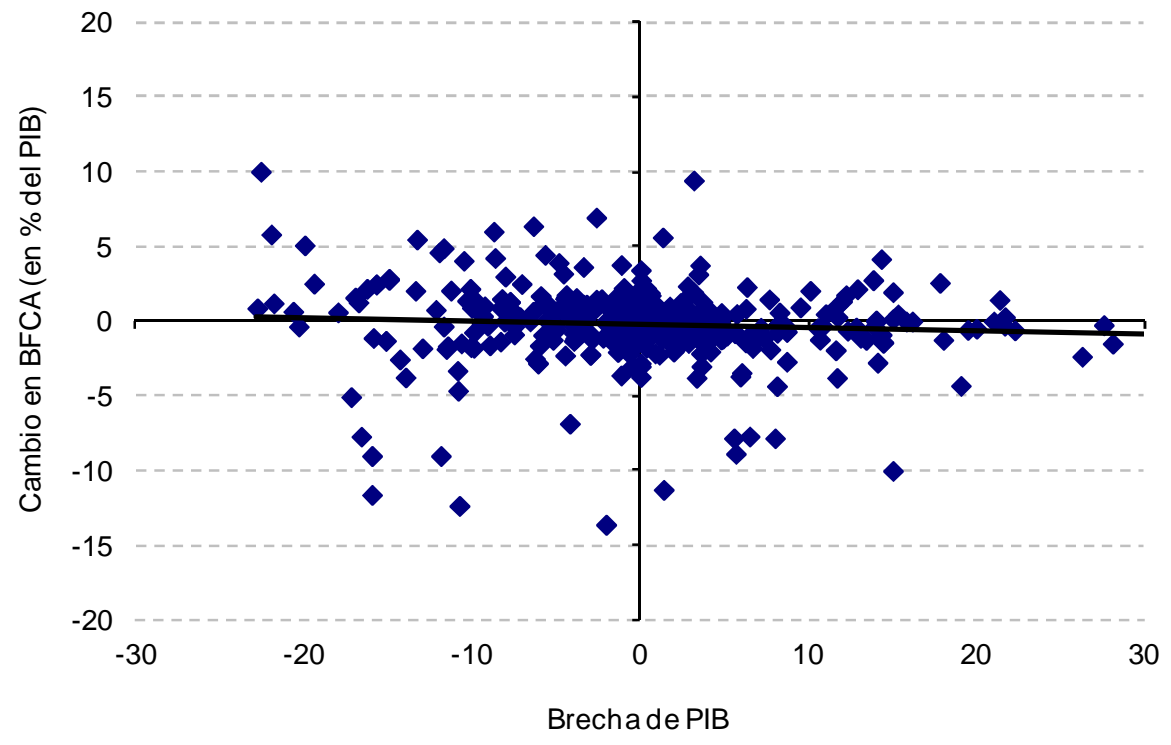

Fuente: Cálculos propios, sobre la base de cifras oficiales.

En parte debido a la volatilidad de los ingresos fiscales, en América Latina la tendencia del gasto público ha sido más bien pro-cíclica en las últimas décadas. El cuadro 6 muestra que, en general y en promedio, en las fases de auge el diferencial ha sido positivo, evidenciando la propensión de las autoridades a gastar más que el crecimiento del PIB en bonanza, reduciendo la capacidad de reacción ante eventos adversos.

11 Los estudios disponibles a nivel de país sí muestran comportamientos más definidos; véase por ejemplo Lozano (2009) para el caso de Colombia. 


\section{AMÉRICA LATINA (20 PAÍSES): DIFERENCIAL ENTRE LAS TASAS REALES DE CRECIMIENTO DEL GASTO PRIMARIO Y DEL PIB}

\begin{tabular}{lccrrr}
\hline & $1990-1996$ & $1997-2002$ & $2003-2008$ & 2009 & $2010-2012$ \\
\hline Argentina & 4,0 & $-1,8$ & 5,2 & 18,0 & 6,0 \\
Bolivia (Estado Plurinacional de) & 4,8 & 5,1 & 1,0 & 4,2 & 0,4 \\
Brasil & $-0,1$ & 3,8 & 1,6 & 1,5 & 1,7 \\
Chile & 2,6 & 2,3 & 0,0 & 15,8 & $-3,2$ \\
Colombia & 5,9 & 9,9 & 1,1 & 9,9 & $-1,0$ \\
Costa Rica & 1,1 & 1,6 & 0,4 & 13,1 & 3,6 \\
Cuba & $\ldots$ & $-0,9$ & 7,7 & $-3,3$ & $-8,4$ \\
Ecuador & 1,4 & 4,0 & 10,2 & 0,9 & 10,5 \\
El Salvador & 0,1 & 1,2 & $-0,7$ & 12,2 & 1,1 \\
Guatemala & $-3,5$ & 4,6 & 0,1 & 4,0 & $-0,3$ \\
Haití & $\ldots$ & 5,1 & 2,3 & 8,5 & 3,5 \\
Honduras & $-2,7$ & 5,8 & 2,5 & 5,7 & $-6,6$ \\
México & 0,6 & 1,1 & 2,6 & 1,5 & $-0,8$ \\
Nicaragua & 0,5 & $-0,6$ & 3,8 & 0,9 & $-0,4$ \\
Panamá & 1,1 & 1,9 & 2,3 & 3,8 & $-0,9$ \\
Paraguay & 7,8 & 1,0 & $-2,8$ & 33,7 & 6,5 \\
Perú & 5,3 & $-0,6$ & 0,1 & 8,0 & $-0,5$ \\
República Dominicana & 3,1 & 4,4 & 3,3 & $-17,1$ & 4,5 \\
Uruguay & 5,1 & 3,4 & $-1,9$ & 5,2 & 0,7 \\
Venezuela (República Bolivariana de) & $-3,5$ & 3,6 & 2,6 & 2,9 & 3,2 \\
América Latina & 1,9 & 2,7 & 2,1 & 6,5 & 1,0 \\
\hline
\end{tabular}

Fuente: Cálculos propios sobre la base de cifras oficiales.

Por ello, en plena crisis global, en 2009, en algunos países, el menor espacio fiscal obligó a disminuir el ritmo de expansión del gasto público, a pesar de las expectativas de recesión o de desaceleración económica según el caso. Por el contrario, en otros, el aumento del gasto fue notable, como en Argentina, Chile, Colombia, Costa Rica, El Salvador, Paraguay y Perú, mostrando capacidad de gasto ante el entorno recesivo (aunque no siempre dicho aumento puede atribuirse a políticas contracíclicas explícitas). Entre 2010 y 2012 el diferencial promedio es mucho menor, por el retiro de algunos estímulos fiscales en varios de los países recién reseñados. Aunque se verifica una alta volatilidad de las tasas de crecimiento del gasto público cuando se comparan con las tasas de crecimiento del PIB, se advierte una aceleración en 2012, probablemente asociada a una reacción contracíclica ante los efectos adversos de la profundización de la crisis de la economía mundial.

En los países del Caribe (véase el cuadro 7) el gasto público primario aumentó menos o igual que el PIB entre 2003-2008 en cinco países (Antigua y Barbuda, Belice, Granada, Saint Kitts y Nevis y Santa Lucía), y se incrementó fuertemente durante 2009 en seis de ellos (Antigua y Barbuda, Barbados, Guyana, Saint Kitts y Nevis, Suriname y Trinidad y Tabago). Al mismo tiempo, las erogaciones se redujeron en Dominica, Granada y Jamaica, países en que el espacio fiscal es muy reducido, por el significativo peso de la deuda pública en sus economías. Entre 2010 y 2012, el patrón general parece tener poca correlación con la posición de la economía en el ciclo, verificándose una alta volatilidad de las tasas de crecimiento del gasto público, aunque en promedio ha aumentado más en los 13 países del Caribe que en los 20 de América Latina. 


\begin{tabular}{|c|c|c|c|c|}
\hline \multicolumn{5}{|c|}{$\begin{array}{c}\text { CUADRO } 7 \\
\text { EL CARIBE (13 PAÍSES): DIFERENCIAL DE LAS TASAS REALES DE CRECIMIENTO } \\
\text { DEL GASTO PRIMARIO Y DEL PIB }\end{array}$} \\
\hline & $1997-2002$ & $2003-2008$ & 2009 & $2010-2012$ \\
\hline Antigua y Barbuda & 7,2 & 0,2 & 7,1 & $-4,8$ \\
\hline Bahamas & $-1,8$ & 4,0 & 4,1 & 7,1 \\
\hline Barbados & 3,4 & 0,7 & 6,4 & $-3,5$ \\
\hline Belice & 4,0 & $-2,6$ & 4,8 & $-0,1$ \\
\hline Dominica & $-20,2$ & 7,1 & $-4,0$ & 6,6 \\
\hline Granada & 17,0 & $-2,5$ & $-10,8$ & $-3,6$ \\
\hline Guyana & $-1,2$ & 2,6 & 6,4 & 3,6 \\
\hline Jamaica & 0,6 & 4,1 & $-3,8$ & 4,3 \\
\hline Saint Kitts y Nevis & 15,8 & $-3,8$ & 7,4 & 4,4 \\
\hline San Vicente y las Granadinas & $-0,9$ & 2,2 & 4,5 & $-2,1$ \\
\hline Santa Lucía & 1,4 & $-1,5$ & 6,0 & 6,2 \\
\hline Suriname & $-14,5$ & 1,4 & 30,2 & 0,3 \\
\hline Trinidad y Tabago & 1,3 & 2,7 & 40,6 & $-1,0$ \\
\hline El Caribe & 0,9 & 1,1 & 7,6 & 1,3 \\
\hline
\end{tabular}

Fuente: Cálculos propios sobre la base de cifras oficiales.

Cuando se afirma que en la región las políticas fiscales son procíclicas porque el gasto público crece más que el PIB en épocas de bonanza, surge un problema metodológico de causalidad inversa (véase Jaimovich y Panizza, 2007) pues es perfectamente posible que una variable explicativa del crecimiento sea el propio gasto público.

Por tanto, es necesario disponer de un conjunto más amplio de indicadores para calificar la orientación global de la política fiscal. En efecto, a pesar del crecimiento del gasto, la política fiscal ha podido orientarse a la generación de superávit primarios y a la reducción de la deuda pública durante las fases de bonanza (CEPAL, 2012b).

El hecho de que el gasto público crezca más que el PIB en épocas de bonanza no es suficiente argumento entonces para calificar de procíclica una política fiscal. Durante la década de los 2000 en América Latina los ingresos (inclusive los tributarios, véase Cornia et al., 2011) crecieron más rápidamente que el PIB y que los gastos, por lo que mejoró el superávit primario y se redujo la deuda pública. $\mathrm{Al}$ aumentar su patrimonio y mejorar su hoja de balance, la política fiscal ha ejercido más bien un efecto neto de estabilización del gasto del sector privado.

En este documento diferenciamos, para fines ilustrativos y para reafirmar el punto anterior, cuadrantes de política fiscal según las variaciones de gasto y de deuda. En bonanza, la política fiscal sería entonces contracíclica (procíclica) en sentido estricto cuando al mismo tiempo se contraen (aumentan) el gasto público y la deuda pública como porcentajes del PIB, y contracíclica (procíclica) en sentido débil cuando crece (disminuye) el gasto público y disminuye (aumenta) la deuda pública, siempre como porcentajes del PIB. En épocas de crisis, la política fiscal es contracíclica (procíclica) en sentido estricto cuando aumenta (se reduce) simultáneamente el gasto y la deuda, y contracíclica (procíclica) en sentido débil cuando crece (se reduce) el gasto y disminuye la deuda ${ }^{12}$. Por supuesto, como ya se mostró, el cambio en la deuda no es enteramente una decisión de política, pero su dinámica y/o costo tiene una fuerte influencia en las decisiones de gasto.

Por ello, resulta interesante entonces ilustrar simultáneamente las evoluciones del gasto público y de la deuda pública, según épocas de bonanza y de recesión (véanse los gráficos 5 y 6). En la década de 1990 se produjeron episodios pro-cíclicos (en sentido estricto) en algunos países, pues en fase de bonanza aumentó al mismo tiempo el gasto y la deuda pública, con los consiguientes efectos negativos de mediano plazo.

12 Esta definición es sólo parcial, al no incluir la evolución de los ingresos. Implícitamente, se asume entonces que el efecto multiplicador del gasto público es mayor al de los ingresos, como se discute más adelante. 
En cambio, en la gran mayoría de los países de América Latina en el período 2003-2007 se redujo la deuda pública, y en algunos se contrajo al mismo tiempo el peso del gasto público, dando lugar a políticas contracíclicas estrictas. Lo mismo sucedió en el Caribe (gráfico 6), destacando el caso de Guyana que obtuvo una condonación de su deuda externa equivalente a 100\% del PIB en 2004 en el marco del programa HIPC. La excepción fue República Dominicana, pues la crisis bancaria derivó en aumentos importantes de la deuda pública y también del gasto.

Estos espacios fiscales permitieron reaccionar a la crisis financiera internacional en varios países de América Latina, dando lugar en algunos casos a aumentos de gasto importantes, como se ilustró en el cuadro 6, y en otros a un mayor endeudamiento derivado del déficit producido por la merma de ingresos, durante 2009 y con posterioridad. En el Caribe se observan incrementos en el peso relativo del gasto público y de la deuda pública, en algunos casos muy significativos.

El período 2010-2012 es más heterogéneo, como ya se mencionó, pues no se detectan pautas claras en la orientación de la política fiscal en función del ciclo macroeconómico, ni en América Latina ni en el Caribe.

\section{GRÁFICO 5 \\ AMÉRICA LATINA: CAMBIOS EN EL GASTO Y LA DEUDA PÚBLICA}

(En puntos del PIB)

a) Cambio entre 1991-1998

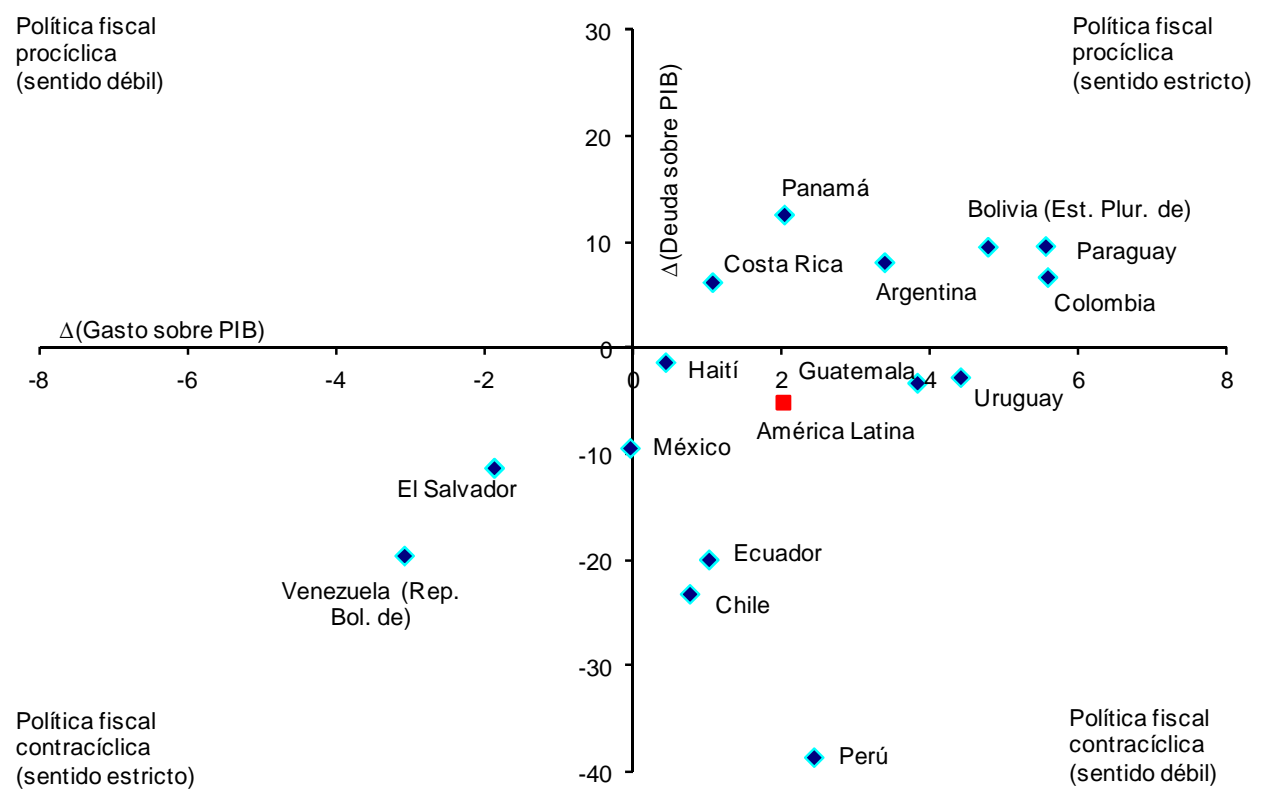


Gráfico 5 (continuación)

b) Cambio entre 2003-2007

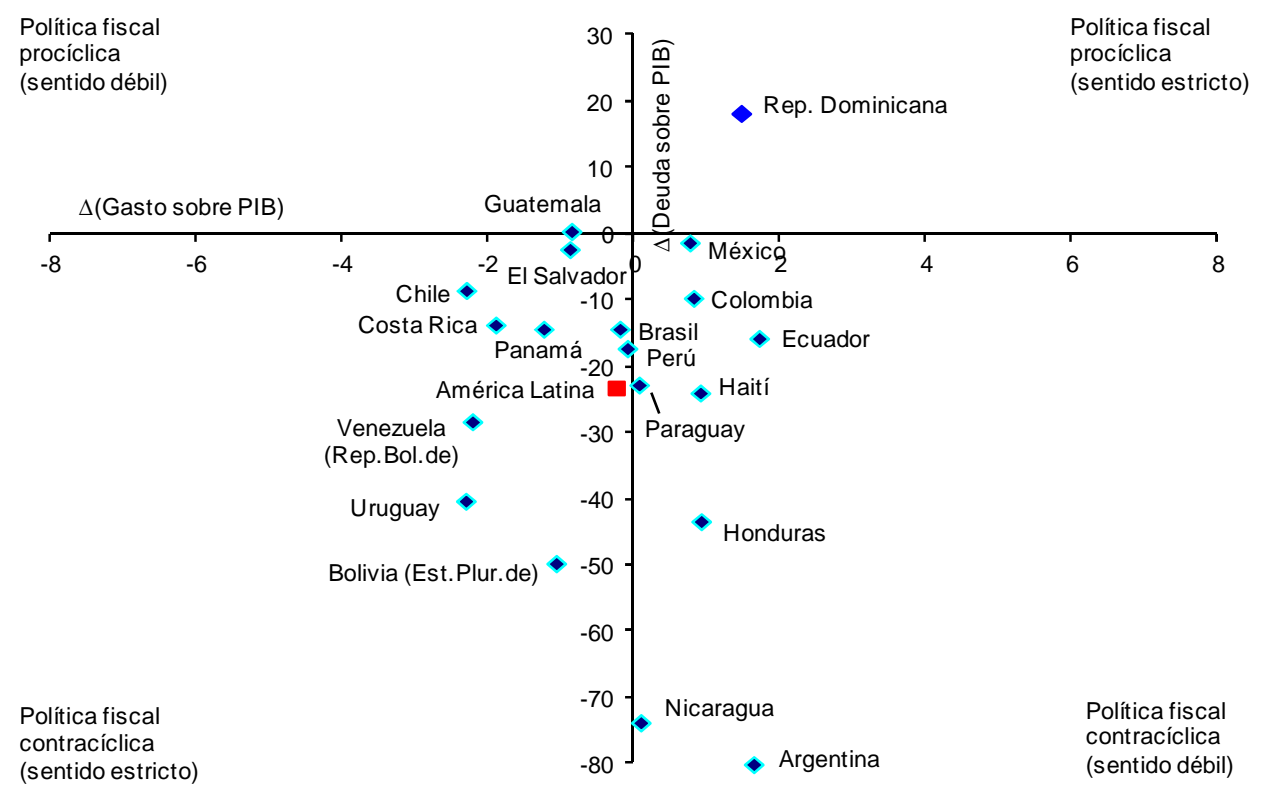

c) Cambio entre 2008-2009

$\begin{aligned} & \text { Política fiscal } \\ & \text { procíclica } \\ & \text { (sentido débil) }\end{aligned}$
Rep. Dominicana


Gráfico 5 (conclusión)

d) Cambio entre 2010-2012

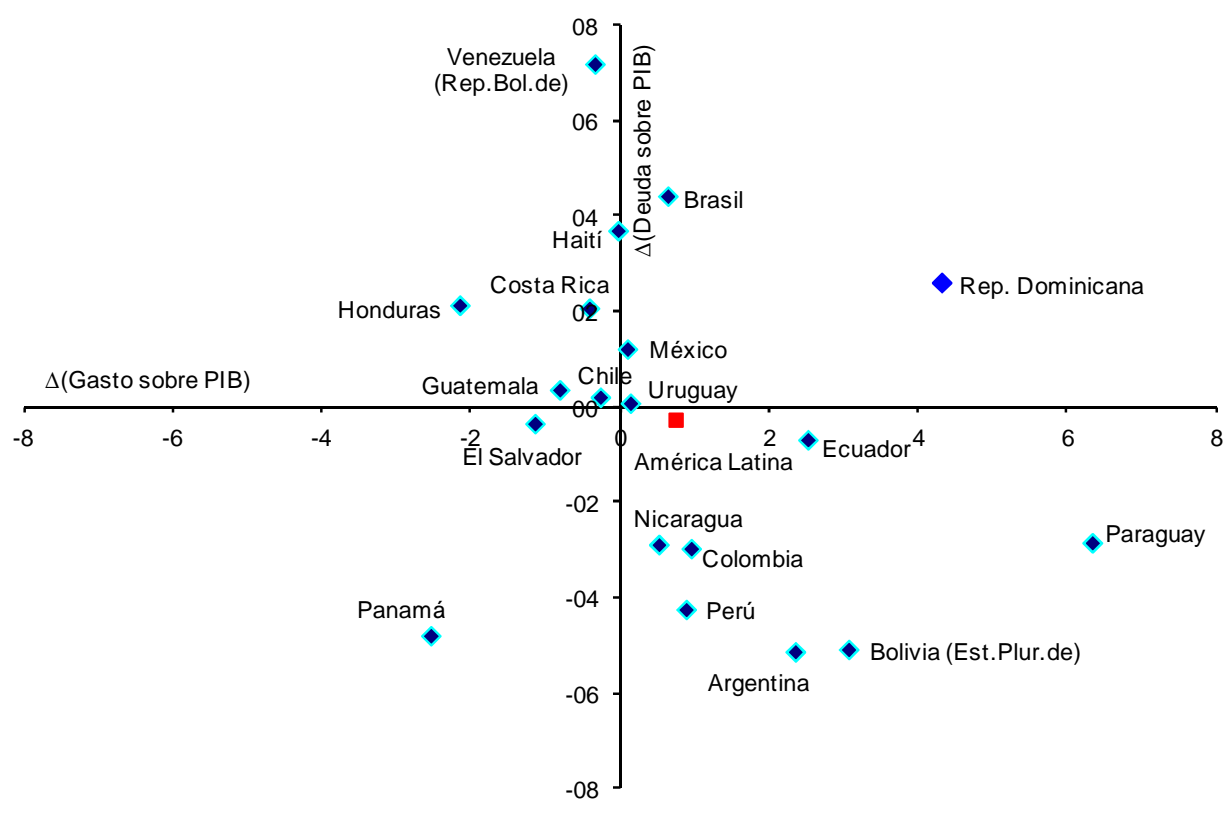

Fuente: Cálculos propios, sobre la base de cifras oficiales.

\section{GRÁFICO 6 \\ EL CARIBE: CAMBIOS EN EL GASTO Y LA DEUDA PÚBLICA}

(En puntos del PIB)

a) Cambio entre 2003-2007

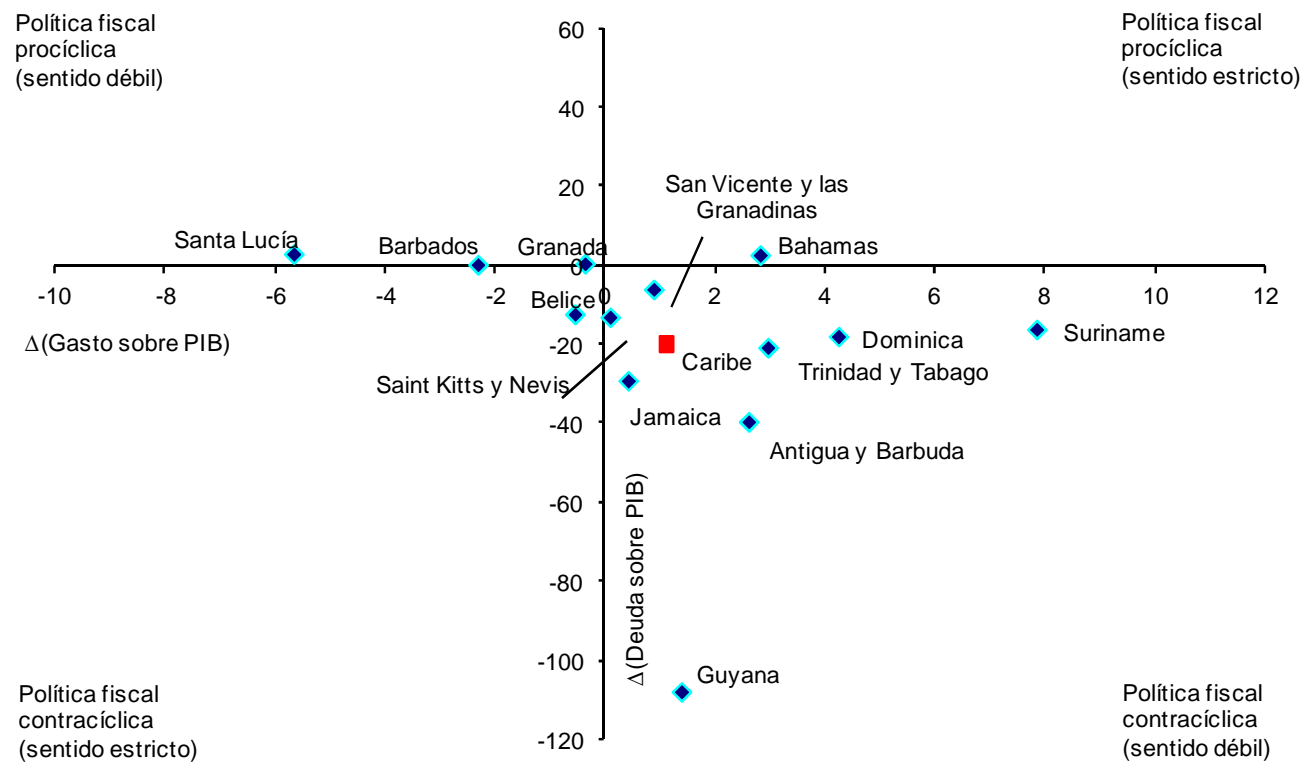




\section{Gráfico 6 (conclusión)}

b) Cambio entre 2008-2009

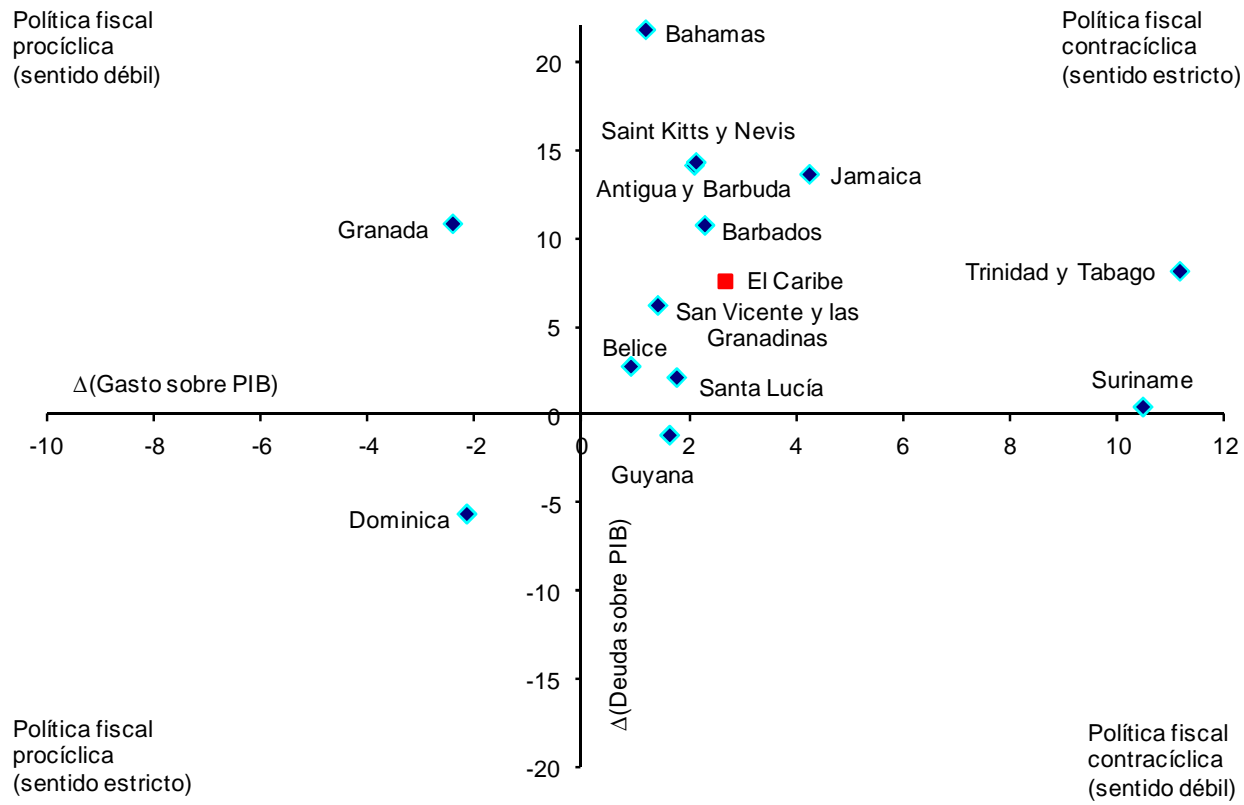

c) Cambio entre 2010-2012

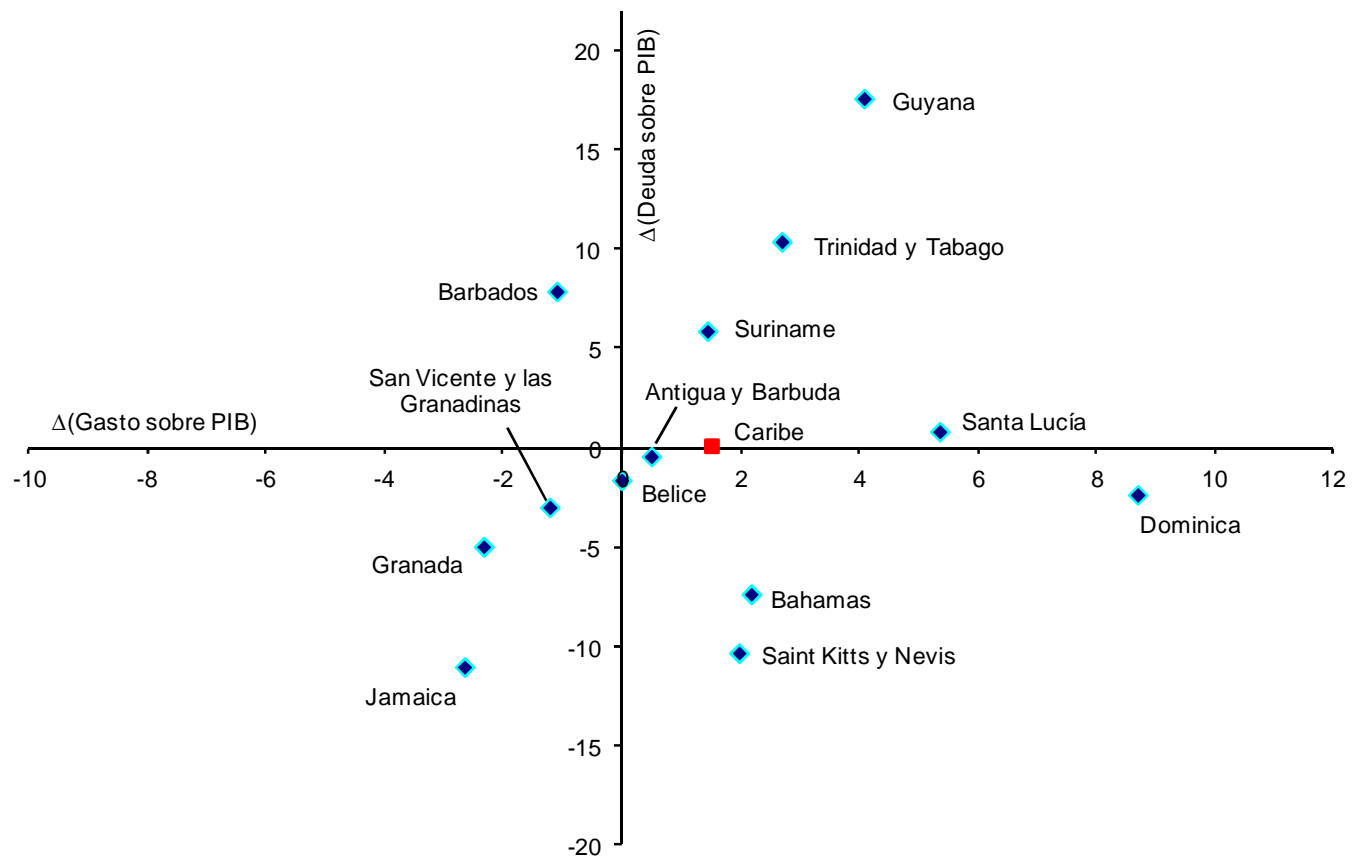

Fuente: Cálculos propios, sobre la base de cifras oficiales.

En el Estudio Económico de América Latina y el Caribe 2013, la CEPAL concluye que, salvo ciertas excepciones (los países del Caribe de habla inglesa y algunos de Centroamérica), los gobiernos de la región disponen de espacios para enfrentar escenarios adversos. De manera inédita, a partir de 2008 la 
política fiscal pasó a ser un potencial instrumento de estabilización macroeconómica. Durante la fase de contracción del gasto privado, los paquetes de estímulo fiscal contemplaron una combinación de aumentos de gasto, especialmente sociales y de inversión pública, y de reducción de impuestos a familias y empresas, permitiendo efectos multiplicadores que amortiguaron los impactos de la crisis (véase el recuadro 1$)^{13}$.

\section{RECUADRO 1 \\ MULTIPLICADORES DE POLÍTICA FISCAL}

La evidencia sugiere que el activismo fiscal puede estimular el nivel de actividad durante las recesiones, y que sus potenciales efectos negativos, sobre la inflación por ejemplo, son menores (Auerbach et al., 2012). Cuando las economías enfrentan un límite inferior en la fijación de las tasas de interés, los multiplicadores de política fiscal son de gran magnitud. Su tamaño depende del tipo de gastos o impuestos y de muchos factores propios del país y del momento. El grado de apertura y de integración financiera y el régimen de tipo de cambio condicionan el tamaño del multiplicador fiscal, y especialmente el multiplicador de las importaciones en economías abiertas.

Sin embargo, es generalmente aceptado que, en el corto plazo, ciertos gastos públicos tienen efectos significativos y superiores a las bajas de impuestos $y / 0$ al aumento de las transferencias, pues en el primer caso se estimula directamente a la demanda agregada y el empleo y en el segundo los mayores ingresos pueden ser ahorrados en vez de consumidos.

Las estimaciones del FMI para el G20 son de multiplicadores máximos de 0,6 para las transferencias y/o los impuestos, de 1 para los gastos en general y de 1,8 para los gastos de capital (Spilimbergo et al., 2010). La Unctad (2011), por su parte, estima valores de 0,71 en el caso de impuestos y de 1,87 para el gasto público general, aplicando un VAR a Estados Unidos en el período 1980-2010. Estos valores serían sensiblemente menores para países en desarrollo, aunque la escasa evidencia disponible indica efectos importantes en períodos recesivos (en torno a 1,25 para el gasto para el caso de Perú, ver Sánchez y Galindo, 2012). También se muestra que el impacto es superior cuando la posición fiscal es mejor (para la aplicación de estas metodologías al caso de Colombia, véase Vargas et al, 2012).

La experiencia reciente tiende a mostrar entonces que los estímulos fiscales tuvieron impactos positivos en América Latina. Cabe también recordar que los gastos sociales en educación, salud, vivienda y pensiones destinados a los grupos más pobres son una manera racional de promover la reactivación económica, a la par que mejora la distribución del ingreso.

Fuente: Elaboración propia.

\section{La necesidad de fortalecer las instituciones fiscales}

En muchos casos, sin embargo, estos paquetes no se aplicaron con la misma intensidad ni duración anunciada, pues dependieron de los espacios fiscales disponibles, del acceso al financiamiento y de la economía política del proceso. En efecto, la capacidad de reacción discrecional debe ser consistente con la credibilidad que otorga un manejo razonablemente simétrico de las finanzas públicas.

Como se sabe, a partir de inicios de la década del 2000 cobran importancia en la región las iniciativas legales tendientes a reforzar la responsabilidad y la transparencia en el ámbito de las finanzas públicas, denominadas genéricamente como reglas fiscales. Estas reglas de primera generación tuvieron un sesgo pro-cíclico, pues las metas que se basan en un presupuesto balanceado, o déficit cero, o en una reducción de la deuda pública independientemente de las condiciones macroeconómicas, impiden la consecución de objetivos de crecimiento. Para propósitos de estabilización, no es suficiente establecer simplemente límites anuales de déficit o de deuda pública.

Si el objetivo es asegurar consistencia dinámica impulsando la reducción de deuda en períodos de auge y aceptando un mayor déficit en períodos de menor crecimiento, las reglas macro-fiscales de "segunda generación" tienen que incorporar programación presupuestaria plurianual, cláusulas de excepción y algún tratamiento explícito de los ingresos transitorios. Las reglas macrofiscales de segunda generación requieren de un sustancial desarrollo de las instituciones, especialmente de aquellas

13 Para un análisis exhaustivo sobre la reacción de la política fiscal durante los tres episodios externos críticos que afectaron a la región entre 2008 y 2012, véase el Estudio Económico para América Latina y el Caribe (CEPAL, 2012b). 
capacidades que permitan transformar los análisis de sensibilidad y la construcción de escenarios prospectivos en procedimientos presupuestarios.

Aunque la mayor prudencia y la capacidad de reacción que se ha observado en los últimos años han estado basadas en un cierto consenso, éste no ha dado pie a instituciones fiscales. El desafío, entonces, es diseñar estrategias que permitan internalizar los efectos del ciclo sobre las finanzas públicas. Para reducir la amplitud y la duración del ciclo en América Latina, se podría avanzar con las siguientes medidas en el ámbito institucional.

\section{Mayores grados de coordinación de las políticas monetarias y fiscales}

Las políticas contra-cíclicas, para ser efectivas, abarcan acciones en múltiples ámbitos, como la fijación de la tasa de interés de política monetaria en función de la brecha de PIB (y no sólo en virtud de las expectativas de inflación), la consolidación de los mecanismos de transmisión de la política monetaria al sistema financiero, las regulaciones macroprudenciales, y otros tantos aspectos en los ámbitos laboral y productivo.

Podrán existir diversos grados de independencia en la definición de objetivos e instrumentos de los Bancos Centrales, pero lo que es realmente relevante es el grado de coordinación de las políticas monetaria y fiscal (por coordinación se entiende el proceso por el cual dos autoridades definen sus estrategias para mejorar los resultados de ambas). Por ejemplo, una política monetaria expansiva, acompañada por la plena operación de los estabilizadores automáticos (y por lo tanto una política fiscal neutra) puede representar una respuesta óptima para atenuar choques transitorios negativos, sin necesidad de un mayor activismo fiscal.

Por el contrario, al menos dos dinámicas perversas pueden conducir a una considerable amplificación de las fluctuaciones macroeconómicas. En la parte baja del ciclo, la ausencia de coordinación puede llevar a tasas de interés más altas de lo necesario, lo que a su vez amplifica los desequilibrios fiscales, tanto por el lado del saldo primario como del pago de intereses, y pone en peligro la solvencia del sector público, retroalimentando las expectativas de aumentos de la tasa de interés. La subsecuente corrección del desequilibrio de las cuentas públicas puede transformar la recesión en depresión. La secuencia es fatal en sus consecuencias sobre el desempleo, como se ha visto en la reciente experiencia de la Comunidad Europea.

Una organización institucional que otorgue incentivos a la coordinación de las políticas monetaria y fiscal es una reforma que sigue pendiente, que está presente en la discusión en varios países y que sin duda surgirá con mayor fuerza en la agenda futura.

\section{El dividendo fiscal}

La principal causa de fracaso de las experiencias de consolidación fiscal ha sido el excesivo optimismo respecto del crecimiento de mediano plazo. Más generalmente, las desviaciones respecto de los supuestos macroeconómicos claves constituyen el riesgo principal que debe enfrentar la autoridad fiscal. Tanto si las proyecciones son sistemáticamente superiores a la recaudación (dando lugar a un sesgo de optimismo que puede terminar en problemas agudos de sostenibilidad) como si ocurre lo contrario (dando lugar a un excedente presupuestario cuyo manejo suele ser discrecional), el proceso presupuestario se ve fuertemente afectado en su credibilidad y transparencia.

Un criterio utilizado en muchos países es clasificar como transitorios los ingresos no esperados en la Ley de Presupuestos (el denominado dividendo del crecimiento), separándolos por tanto del resto y definiendo con claridad el destino de estos recursos. La condición sine qua non para institucionalizar las políticas fiscales contracíclicas es hacer lo más prudente y transparente posible el proceso de proyección de los ingresos públicos.

\section{El fortalecimiento de la transparencia fiscal}

La transparencia fiscal es un elemento clave de la gestión pública, y supone un acceso inmediato a la información sobre las orientaciones, proyecciones, metas y contabilidad de las actividades del sector 
público. Dos actividades fundamentales son reducir las prácticas cuasifiscales, haciéndolas explícitas en los presupuestos, y mejorar la información fiscal. El Congreso debe discutir el conjunto de la política fiscal, lo que implica que el Gobierno debe presentar un análisis de todas las finanzas públicas, incluidas instituciones autónomas, empresas públicas y gobiernos locales.

En adición a los controles del Presupuesto y de los gastos por parte del Legislativo, de los Tribunales de cuentas y/o de las Contralorías, el control social ha de extenderse como instrumento de la participación de los ciudadanos en la formulación, fiscalización y seguimiento de las acciones de la Administración Pública. El control social es un importante instrumento de prevención de la corrupción y del fortalecimiento de la participación ciudadana en los asuntos fiscales. Las iniciativas en materia de transparencia, y sobre todo de control social, en la región han seguido distintos ritmos y alcances, con un desarrollo aún muy incipiente.

No obstante, a la luz de la experiencia reciente de la región, parece relevante también insistir en la creación de Consejos fiscales independientes o vinculados al Parlamento. En efecto, tanto la discusión de aspectos técnicos relativos a la formulación presupuestaria como el monitoreo de su ejecución y la evaluación sistemática de los programas públicos ameritan la consolidación de entidades que reflejen los dilemas de la política fiscal. Hay modelos interesantes de observatorios fiscales en la región, pero que requieren de una consolidación institucional similar a la existente en países desarrollados.

\section{La adopción de reglas estructurales de balance fiscal}

Las reglas macro-fiscales deben tener un objetivo de saldo estructural de mediano plazo, cláusulas de excepción y de transitoriedad y algún margen de maniobra para afrontar eventos catastróficos o situaciones recesivas persistentes. La regla de balance estructural permite dar continuidad a la acción fiscal mediante la ejecución plena del presupuesto, independientemente de cuál sea la etapa del ciclo económico y la evolución coyuntural de los ingresos, con evidentes ganancias de eficacia y eficiencia en la gestión pública.

En su aserción más amplia, es decir, incluyendo el efecto del precio de las materias primas, el componente cíclico del balance ha sido muy significativo en la región en los últimos años, por lo que la conducción de la política fiscal en función de un objetivo de mediano plazo está muy vinculado a la capacidad institucional de ahorrar en tiempos de bonanza. A su vez, "la libre operación de los estabilizadores automáticos" en períodos de estrechez puede llevar a déficit transitorios importantes. El corolario por tanto de las reglas estructurales es la constitución de fondos de estabilización.

\section{La constitución de fondos de estabilización de materias primas o de tributos}

Aunque la consolidación de mecanismos explícitos de ahorro en tiempo de bonanza ha resultado compleja en la región (pues muchos países han preferido pre-pagar deuda externa o mantener activos financieros bajo otras formas), algunos fondos de estabilización asociados a las leyes de responsabilidad fiscal (como en Chile o en Perú) se han transformado en instrumentos privilegiados de las políticas fiscales, al captar los ingresos transitorios asociados a la parte alta del ciclo de la minería y permitir una mayor capacidad de reacción a situaciones adversas o cambios imprevistos.

\section{El fortalecimiento de instancias de coordinación con los gobiernos subnacionales}

Es importante evitar asimismo comportamientos pro-cíclicos en las políticas fiscales sub-nacionales, sobre todo en un contexto de fuertes desequilibrios verticales, en que las entidades territoriales dependen casi exclusivamente de transferencias del Gobierno Central, a menudo amarradas a la recaudación nacional. De hecho, las fórmulas de co-participación de ingresos federales obligan a los Gobiernos subnacionales a frenar sus gastos en períodos de caída de ingresos, incitando a políticas expansivas en tiempos de bonanza.

Para remediar estos efectos de amplificación de las políticas pro-cíclicas, es recomendable desvincular las transferencias de la volatilidad de los ingresos públicos, por acuerdos multianuales de 
crecimiento por ejemplo, y sobre todo fortalecer el pacto fiscal vigente mediante una coordinación más efectiva de las decisiones de gasto.

Estas medidas o acciones pueden mejorar la economía política del proceso y la percepción de los mercados. Es conveniente para su perdurabilidad que estas innovaciones se instrumenten en la fase expansiva del ciclo. Para profundizar las políticas contra-cíclicas y lograr que sus efectos sean permanentes, un tema crucial de la agenda es perfeccionar la institucionalidad macroeconómica y los mecanismos que aseguren transparencia fiscal.

Pero los objetivos de sostenibilidad y de estabilización no son los únicos; importa también la contribución de las finanzas públicas al crecimiento de largo plazo de las economías y a la distribución del ingreso. 



\section{La incidencia de gastos e ingresos públicos sobre el crecimiento y la distribución del ingreso disponible}

Cuando se evalúa el desempeño económico simultáneamente por el crecimiento del ingreso disponible y por su distribución, los impactos de la política fiscal pueden ser positivos para ambos objetivos; la evidencia empírica reciente muestra la importancia de estas complementariedades (Hoeller et al. 2012).

Como se señaló, la mera distinción entre gastos corrientes y de capital, aunque muy importante, no es suficiente para establecer prioridades, ni tampoco lo es la separación entre el gasto social y el resto, cuando se sabe que el crecimiento y la generación de empleos tienen un papel importante en la reducción de la pobreza. A continuación se examina de manera más detallada la evolución de los componentes principales del gasto público.

\section{A. La clasificación económica: prioridad a la inversión}

Durante las décadas de 1980 y 1990, la consolidación fiscal en la región se logró con una fuerte reducción de la inversión pública, con el consiguiente impacto negativo sobre el crecimiento de las economías. En particular, la inversión en infraestructura disminuyó de 3,1 a 1,5 puntos del PIB en la década de los ochenta (véase Perroti y Sanchez, 2011), y mantuvo esos niveles hasta 2008. Especialmente como reacción a la crisis de dicho año, muchos países han gatillado un proceso de recuperación. En términos de composición, es notable el espacio que ha ganado la inversión pública si comparamos con 1990, aumentando a la par de la disminución del pago de intereses de la deuda pública (véase el gráfico 7). En América Latina, el promedio simple de los gastos públicos de capital para 20 países aumentó de 2 a 4,7 puntos del PIB entre 1990 y 2012. En el Caribe el promedio para 13 países pasó de 4,8 a 5,5 puntos del PIB en el mismo período. 


\section{GRÁFICO 7 \\ AMÉRICA LATINA (20 PAÍSES) Y EL CARIBE (13 PAÍSES): COMPOSICIÓN DEL GASTO PÚBLICO \\ (En porcentajes)}

a) América Latina
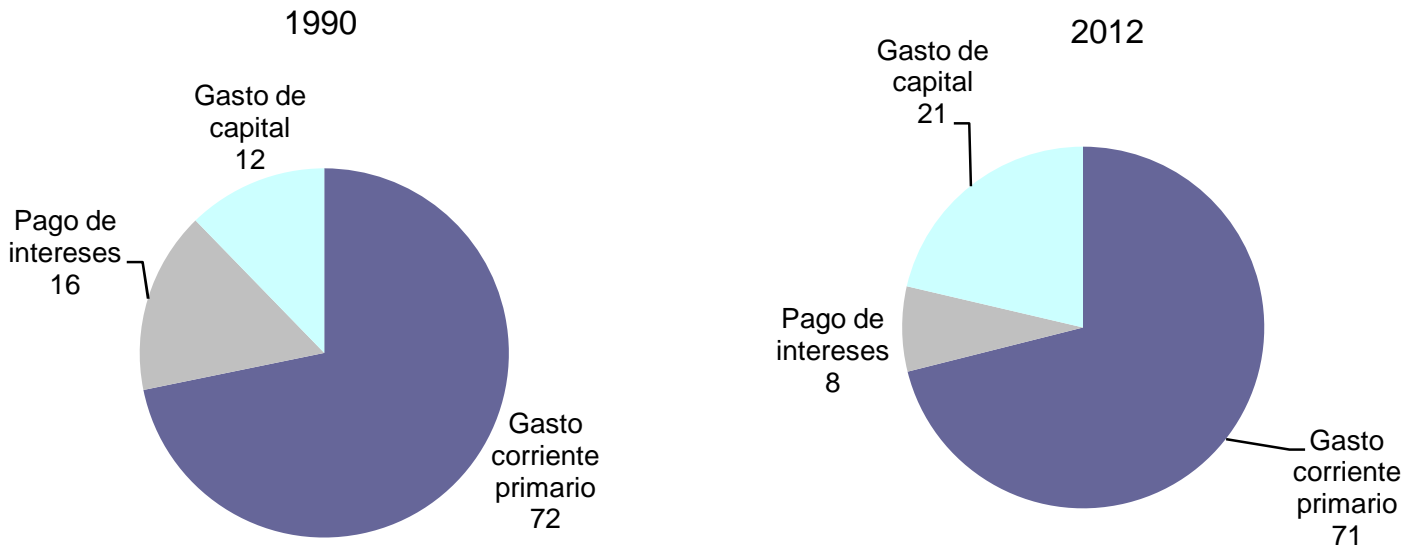

b) El Caribe

1990

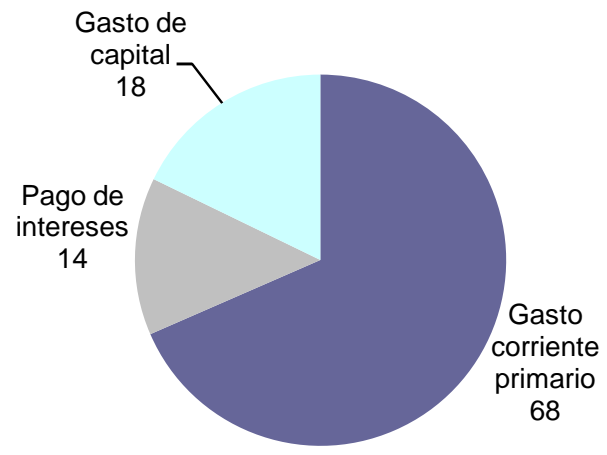

2012

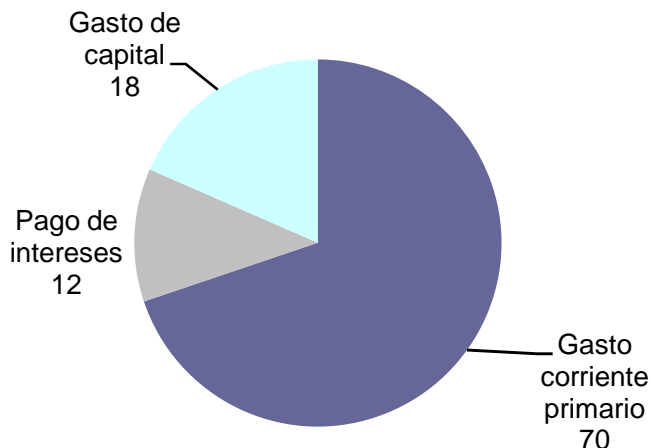

Fuente: Elaboración propia, sobre la base de datos oficiales.

De esta manera, varios países de América Latina han retomado un fuerte crecimiento de la inversión pública, incluso con anterioridad a la crisis financiera de 2009. Lo cierto es que el desmejorado punto de partida ayuda a explicar un comportamiento más dinámico de la inversión; se observa una vigorosa recuperación cuando se compara con 1990 en países como Argentina, Brasil, Bolivia (Estado Plurinacional de), Colombia, Dominica, Ecuador, Haití, México, Panamá, Paraguay, Trinidad y Tabago y Venezuela (véase el gráfico 8). Otros países, que tenían un alto coeficiente público de inversión en 1990, como Guyana, Cuba, Granada, Belice, Honduras, San Vicente y Barbados han tenido por el contrario una caída, en algunos casos acentuada, de sus gastos de capital.

Si bien la respuesta a la contracción de la demanda agregada no ha sido inmediata, se observa que la inversión pública ha tenido un papel contracíclico, especialmente en los países de América Latina en el período reciente, pero las brechas de infraestructura requieren un esfuerzo continuo de muchos años. 


\section{GRÁFICO 8 \\ GASTOS PÚBLICOS DE CAPITAL}

(En porcentajes del PIB)

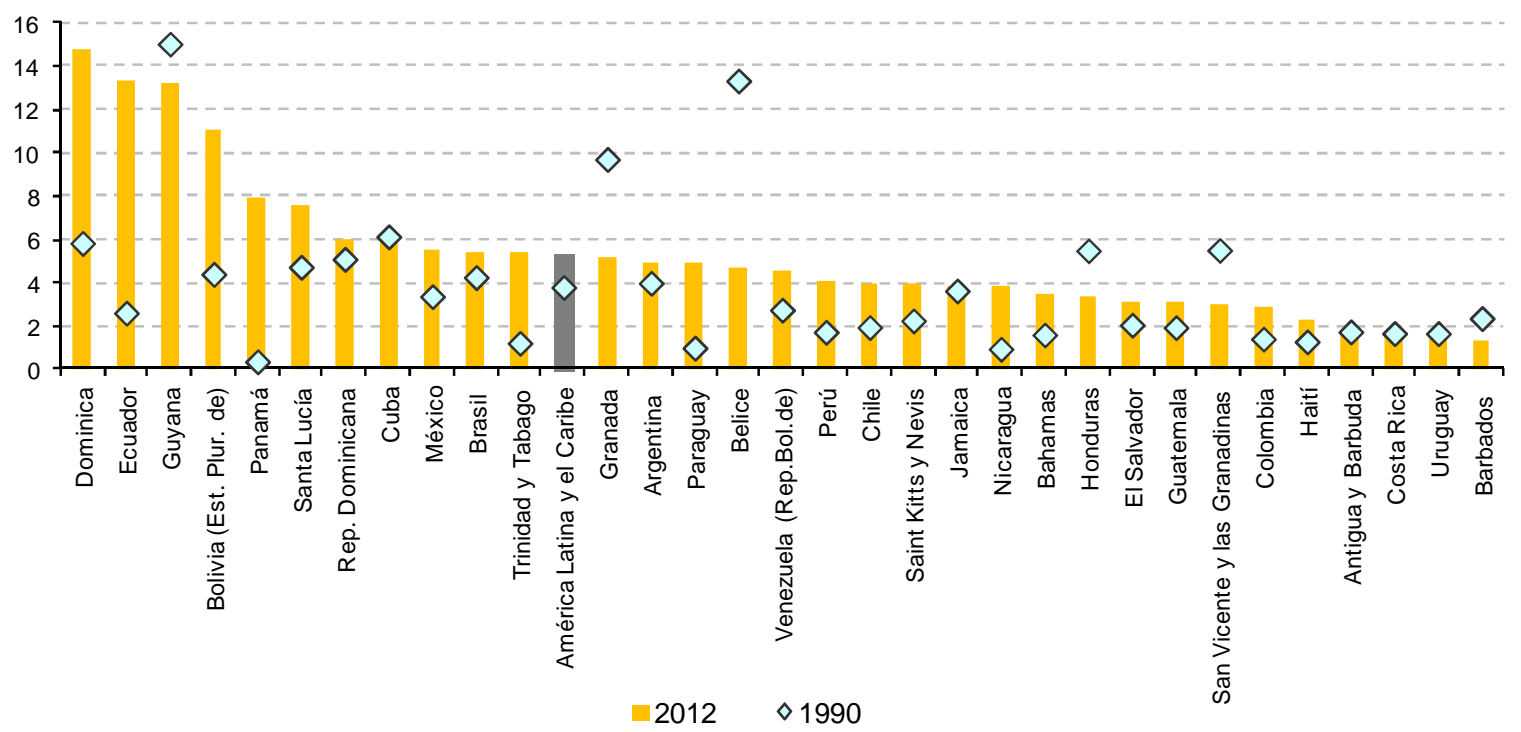

Fuente: Elaboración propia, sobre la base de datos oficiales.

Las alternativas para estimular a mediano plazo el proceso de inversión con características de bien público son diversas. La primera, más radical, es adoptar la regla de oro como norma de manejo de las finanzas públicas, que estipula que los gastos corrientes deben financiarse con ingresos corrientes, y los gastos de capital con deuda pública, pues éstos representan ingresos futuros, como cualquier inversión privada. La regla de oro estipula así que un equilibrio o un superávit en cuenta corriente es necesario, pero puede existir un déficit estructural en la cuenta de capital.

En el Manual de Estadísticas Fiscales del 2001 del FMI, el concepto de variación del patrimonio fiscal neto define como ingreso todas las transacciones que incrementan el patrimonio neto del gobierno, mientras el gasto se define como una disminución del mismo. La inversión se registra como un incremento en los activos no financieros, cuya contrapartida puede ser una disminución en los activos financieros. Por lo tanto, el patrimonio neto no se ve afectado y la inversión pública no se considera como un gasto.

Si los ajustes fiscales se han hecho principalmente reduciendo activos (entre los cuales están la inversión pública y los gastos de mantenimiento), la reducción de los pasivos del gobierno no se acompaña necesariamente de una mejoría del patrimonio neto del gobierno. Aunque muy atractivos, estos principios contables distan de aplicarse en la región, y tampoco van a reemplazar a las tradicionales metas de caja de saldo público.

A pesar de la claridad del concepto, la puesta en práctica generalizada de la regla de oro ha resultado compleja, pues subsisten tentaciones para opacar la contabilidad gubernamental. Existen problemas de definición que no son menores, en especial respecto del tratamiento de los costos de depreciación del capital. Por otra parte, al no recibir necesariamente el sector público la totalidad del retorno de sus inversiones, la analogía con el sector privado pierde consistencia. Las propias inversiones acarrean muchas veces gastos corrientes adicionales de operación, lo que hace que la separación contable no sea trivial.

Restan entonces alternativas parciales de mayor flexibilidad fiscal, que apuntan a incentivar cierto tipo de inversiones. En particular, parece necesario eximir la totalidad o a algunas empresas públicas de las metas consolidadas de balance fiscal. Si las empresas públicas no tienen funciones cuasifiscales, o si las transferencias desde el Gobierno Central están debidamente registradas en el presupuesto, no tiene 
mayor sentido incluirlas en los objetivos de déficit y de deuda pública, eliminándose de esta forma las restricciones artificiales a la inversión en infraestructura.

En tercer lugar, han surgido con mucha fuerza las iniciativas de asociación público-privada (APPs) en los países de América Latina. Sin embargo, el término resulta difícil de definir, confundiéndose en muchas ocasiones con privatizaciones parciales o con las tradicionales concesiones de infraestructura, que pueden dar lugar a pasivos contingentes, pero que no implican gastos corrientes futuros. En su aserción más amplia, las APPs se definen como "arreglos en que el sector privado ofrece infraestructura y servicios cuya provisión ha sido tradicionalmente realizada por el sector público". Ello incluye la construcción y operación de hospitales, escuelas, prisiones, agua y saneamiento, carreteras, túneles y puentes, redes ferroviarias, aeropuertos y sistemas de control de tráfico aéreo.

Como se observa, los proyectos que están en los primeros lugares de esta lista dan lugar a gastos públicos corrientes en el futuro. Como se trata en este caso de inversiones en bienes públicos "puros", esta práctica representa una alternativa real y potencialmente muy atractiva para reducir contablemente el sesgo anti-inversión, pero supone obligaciones fiscales futuras y no constituye por tanto una panacea.

Al final del camino, una adecuada combinación entre reglas adaptadas al entorno macroeconómico y algunas dosis de discrecionalidad puede ser la mejor receta para lograr los equilibrios apropiados entre gasto corriente e inversión, endeudamiento y saldo público.

\section{B. La clasificación funcional: preponderancia para el gasto social}

Es interesante reseñar que algunos componentes sociales del gasto público, que combinan en algunos casos gastos corrientes y gastos de capital, además de favorecer una mejor redistribución del ingreso, tienden a potenciar el crecimiento económico de largo plazo. El gasto público, en ciertos componentes claves, engloba o conlleva un doble dividendo, atendiendo simultáneamente los objetivos de crecimiento y de redistribución del ingreso disponible (Lindert, 2003).

Los gastos en educación, salud, exclusión social, vivienda, familia y niños, pensiones y desempleo aumentan la eficiencia macroeconómica, en la medida en que favorecen la formalidad, el empleo de calidad, las tasas de participación de mujeres y jóvenes en el mercado del trabajo y la inserción laboral de personas excluidas. Muchos tipos de transferencias sociales, además del gasto directo en educación y salud, tienen la característica de ser potencialmente progresivas y pro-crecimiento: seguridad alimentaria y nutricional, protección social y del medio ambiente, vivienda, cultura y recreación (véase el cuadro 8).

Es de notar que los países con altos coeficientes de gasto público también muestran en general los mayores avances en gasto social (véase el gráfico 9). En este sentido, la participación del gasto social en el presupuesto se ha visto incrementada de un 45\% en el periodo 1990-1991 a cerca del 63\% en 20102011 (véase CEPAL, 2012a). En los últimos años, las políticas fiscales han permitido dar sostenibilidad a un gasto público social creciente, pasando de 9,4 a 15,3 puntos del PIB como promedio de la región.

Destacan los fuertes aumentos en países que ya tenían un gasto social elevado en 1990, como Cuba, Argentina, Brasil, Uruguay y Costa Rica. Por otra parte, México, Paraguay, Honduras, Jamaica, Panamá, Perú, Ecuador, Guatemala, Trinidad y Tabago y República Dominicana destinan doce puntos de PIB o menos al gasto social, lo que representa un serio obstáculo al potencial de crecimiento de estas economías. Como lo consigna el Panorama Social de la CEPAL de 2012, en muchos de estos países se le ha otorgado reciente prioridad macroeconómica al gasto social, expandiendo especialmente los recursos destinados a educación. 


\section{EJEMPLOS DE IMPACTOS ECONÓMICOS DE LAS FUNCIONES SOCIALES}

\begin{tabular}{ll}
\hline Función social & Ejemplos de impacto económico \\
\hline Educación & La teoría de capital humano es el principal marco teórico bajo el cual se puede ver que la \\
educación tiene impacto económico. La educación fomenta la productividad de los \\
trabajadores, haciendo que estén más capacitados y habilitados para el mercado laboral, por \\
tanto tiene un impacto en el crecimiento económico. \\
La inversión en salud genera un incremento en la capacidad productiva, con beneficios para \\
las personas y para las unidades productivas.
\end{tabular}

Fuente: Martínez et al. 2013.

\section{GRÁFICO 9 \\ GASTO PÚBLICO SOCIAL, 1990-2011}

(En porcentaje del PIB)

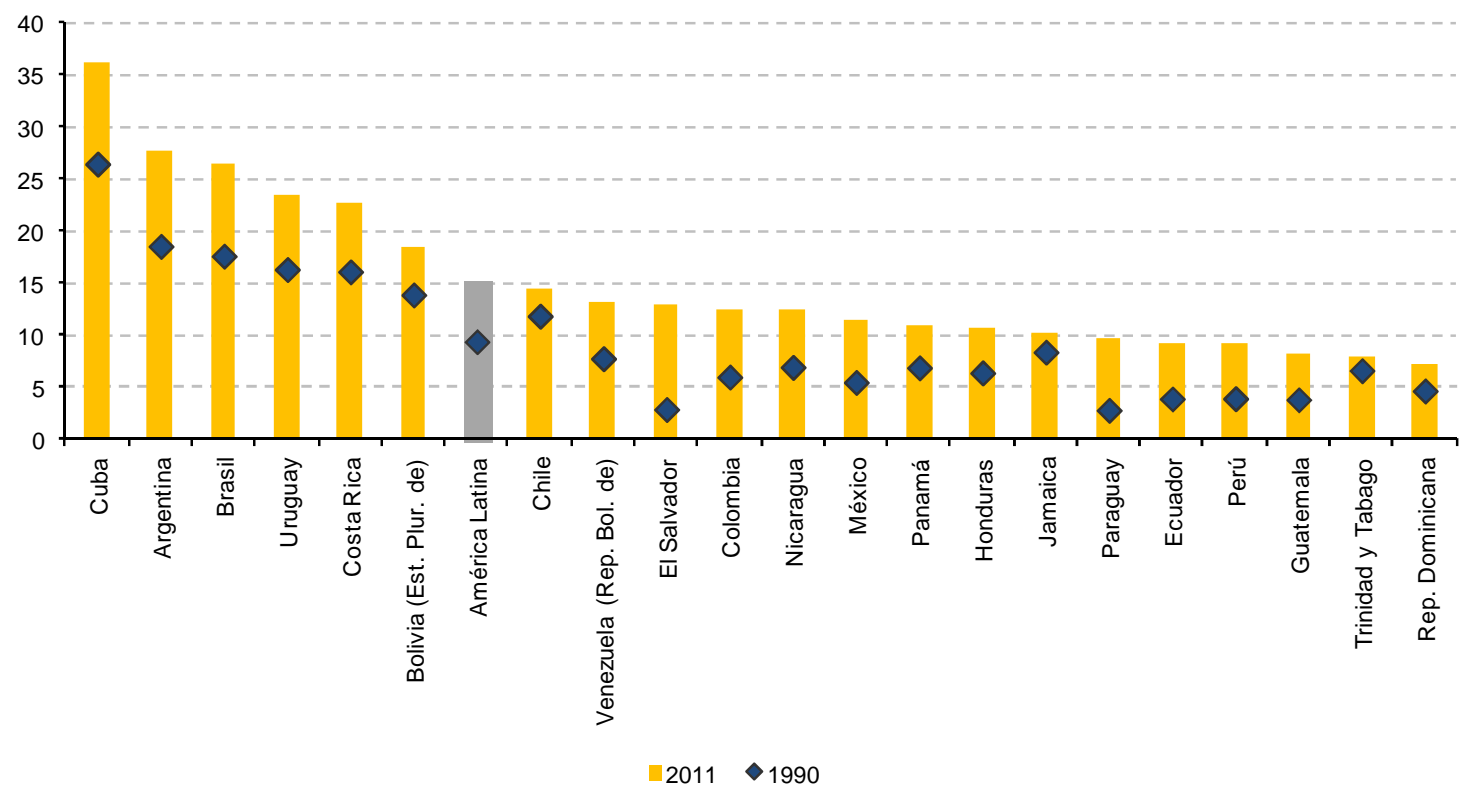

Fuente: Elaboración propia, sobre la base de cifras oficiales. 
También en cuanto a la composición de este gasto social se observa una elevada dispersión (véase el gráfico 10), que refleja la diversidad de modalidades de provisión de bienes y servicios públicos, especialmente en salud y pensiones. También ilustra el escaso grado de cobertura de la protección social en algunos países ${ }^{14}$.

Destaca la fuerte heterogeneidad del gasto en educación, la que se explica en parte por la variedad en la composición público/privada de la provisión de servicios de educación en sus diversos niveles, pero también por la insuficiente capacidad del Estado para generar los recursos necesarios. El impacto del gasto directo del sector público en educación, con los cambios en la cobertura pre-escolar y escolar primaria y secundaria, ha sido muy relevante en los países de la región (véase OCDE/CEPAL, 2012).

Basta una mirada a la clasificación cruzada del gasto público, económica y funcional, para darse cuenta de la tremenda dificultad para jerarquizar y asignar gastos sobre estas bases, sin tomar en cuenta las especificidades y situación de cada país, así como las prioridades programáticas. Por ejemplo, aunque es clara la importancia de asignar recursos a las diversas categorías de protección social, parece difícil hacerlo en desmedro de otras, igualmente claves en el desarrollo económico y social. En particular, parece un ejercicio vano separar los gastos entre "productivos" e "improductivos", según su clasificación económica (corriente o de capital) o funcional (gasto social u otro).

\section{GRÁFICO 10 \\ COMPOSICIÓN DEL GASTO PÚBLICO SOCIAL}

(En porcentaje del PIB)

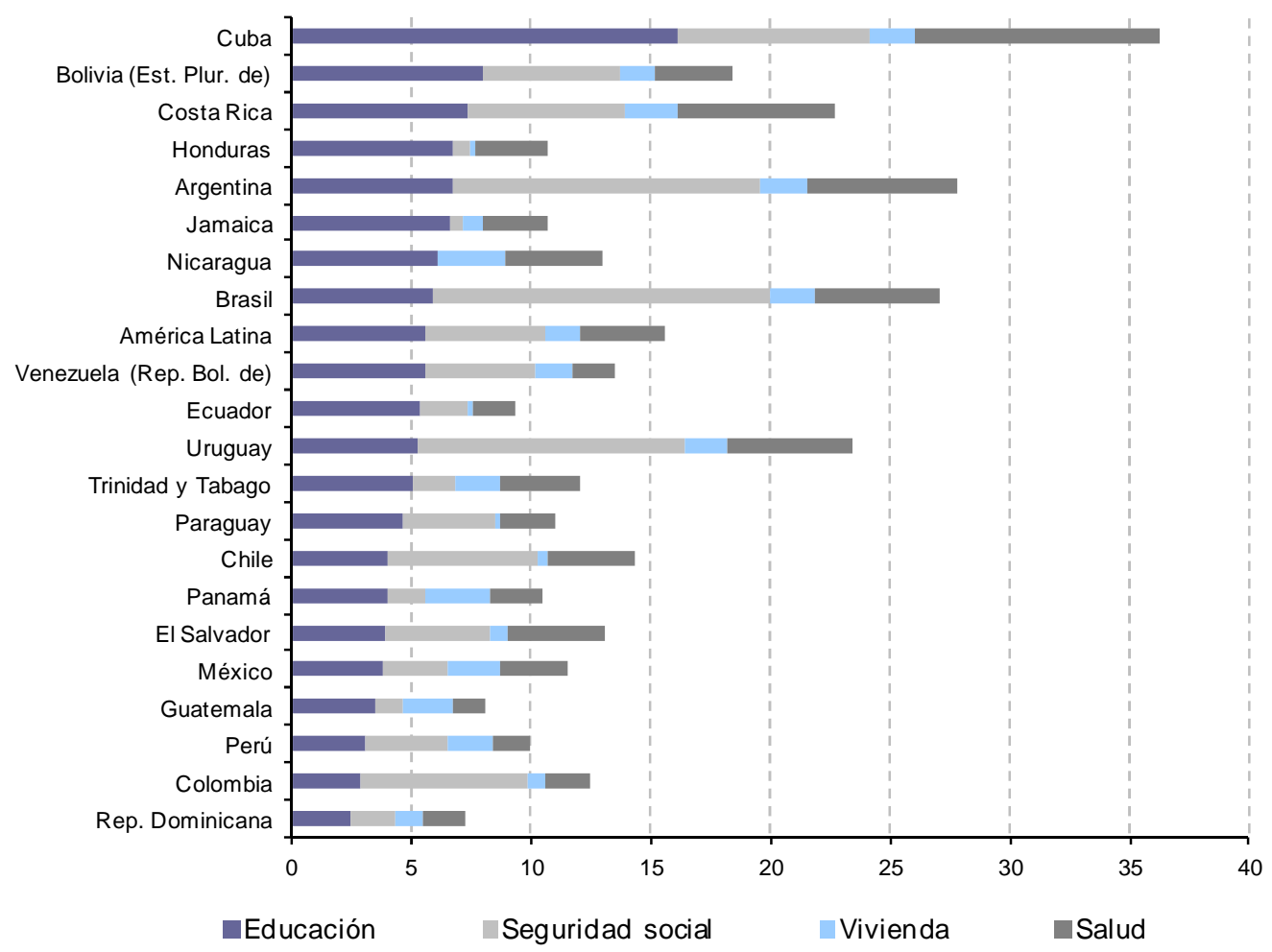

Fuente: Elaboración propia, sobre la base de cifras oficiales.

El cuadro 9 procura mostrar las tendencias recientes, que han ido en el sentido de mejoras en la asignación, tanto en monto como en composición. Así, a la par que disminuían los intereses pagados, ha

14 Véase CEPAL, 2010 y 2012c, para una clasificación de los países de la región según brechas de bienestar. 
aumentado el gasto total y el social, tanto en consumo de bienes y servicios como en inversión y transferencias, aunque en montos aún insuficientes en muchos países.

CUADRO 9

CLASIFICACIÓN CRUZADA DEL GASTO

\begin{tabular}{|c|c|c|c|c|c|}
\hline & Personal & $\begin{array}{l}\text { Bienes y } \\
\text { servicios de } \\
\text { consumo }\end{array}$ & Intereses & $\begin{array}{c}\text { Transferencias y } \\
\text { Subsidios }\end{array}$ & Inversión \\
\hline $\begin{array}{l}\text { Servicio públicos } \\
\text { generales }\end{array}$ & - & & -- & + & + \\
\hline Defensa & - & - & & & + \\
\hline $\begin{array}{l}\text { Orden público y } \\
\text { seguridad }\end{array}$ & + & + & & + & + \\
\hline Asuntos económicos & & & & - & \\
\hline Protección ambiental & + & & & + & + \\
\hline $\begin{array}{l}\text { Vivienda y servicios } \\
\text { comunitarios }\end{array}$ & & + & & + & + \\
\hline Salud & + & + & & + & + \\
\hline $\begin{array}{l}\text { Recreación, cultura y } \\
\text { religión }\end{array}$ & + & + & & + & + \\
\hline Educación & + & + & & + & + \\
\hline Protección social & + & & & ++ & \\
\hline
\end{tabular}

Fuente: Elaboración propia, sobre la base de Naciones Unidas.

Los dilemas dicotómicos entre crecimiento e igualdad, siempre latentes, pierden preponderancia cuando aumentan los gastos que tienen efectos positivos en el crecimiento económico, el empleo formal y el acceso a los bienes públicos. Para conseguir estos impactos, la tarea de mejorar la calidad del gasto público supone ampliar coberturas en muchos programas, continuar el esfuerzo de disminución de la carga de intereses, aumentar la inversión en capital humano y conocimiento y acelerar la inversión en infraestructura, todo lo cual requiere de una mayor movilización de recursos domésticos.

\section{Los sistemas tributarios}

Los impuestos surgen de la necesidad de financiar a los gobiernos, y resultan de un acuerdo social en el cual los agentes económicos acceden a ceder parte de sus ingresos para suministrar recursos para la administración, los gastos sociales y los bienes públicos necesarios para que los países funcionen adecuadamente.

Desde una perspectiva política, este pacto fiscal se basa en la existencia de reciprocidad entre el Estado y los ciudadanos, expresada en la voluntad de la mayoría de los hogares de pagar más impuestos en la medida en que mejore la calidad de los servicios públicos de salud, educación y seguridad, y haya menos corrupción y más control de la evasión (CEPAL, 2013a). El vínculo entre tributos y calidad del gasto público se hace por tanto indisoluble en sociedades democráticas. Por añadidura, el sistema tributario ha de contemplar con mayor preponderancia que antaño los objetivos de desarrollo sostenible.

En América Latina y el Caribe, más del 60\% de los ingresos tributarios (sin considerar la seguridad social) proviene de impuestos indirectos mientras que cerca del $37 \%$ de la carga tributaria grava la renta o la propiedad (gráfico 11). En la última década, los países de América Latina incrementaron la participación de los impuestos directos, principalmente debido al crecimiento de la imposición sobre la renta de las empresas ${ }^{15}$. Además, como consecuencia del fortalecimiento del IVA,

15 Diversos factores determinaron esta evolución, como por ejemplo, la ampliación parcial de algunas bases tributarias que gravan los servicios, la aplicación de impuestos mínimos o sustitutivos del impuesto sobre la renta, las mejoras en el control de contribuyentes y, en varios países, la apropiación de mayores recursos originados en la producción y exportación de bienes primarios. 
de los procesos de simplificación tributaria y de la liberalización del comercio, los impuestos generales sobre bienes y servicios aumentaron su importancia relativa mientras que tanto los impuestos específicos como los tributos sobre el comercio internacional continuaron perdiendo peso relativo en la composición de la recaudación. Sin embargo, en el Caribe estos últimos aún representan una porción importante de la estructura tributaria (casi un cuarto del total).

\section{GRÁFICO 11 \\ AMÉRICA LATINA (19 PAÍSES) Y EL CARIBE (13 PAÍSES): ESTRUCTURA TRIBUTARIA (SIN SEGURIDAD SOCIAL)}

(En porcentajes)

a) América Latina
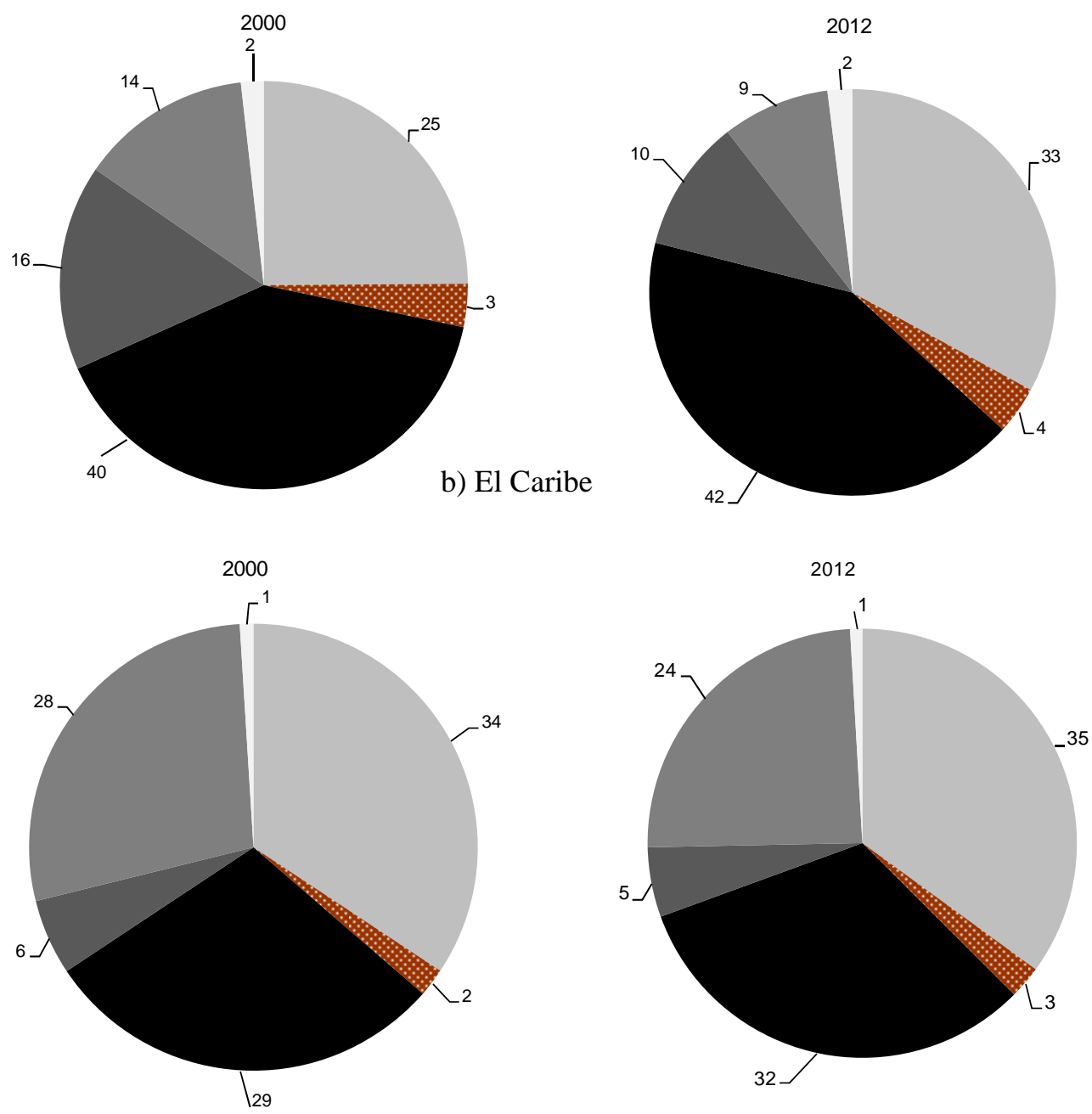

\footnotetext{
- Ingreso a las utilidades y a las ganancias de capital

-Generales sobre bienes y servicios

- Comercio y transacciones internacionales
}

$$
\begin{aligned}
& \text { Propiedades y otros directos } \\
& \text { Específicos sobre bienes y servicios } \\
& \text { Otros impuestos }
\end{aligned}
$$

Fuente: Elaboración propia, sobre la base de cifras oficiales.

Si potenciar el ahorro y la inversión, y por esta vía el crecimiento económico, es un objetivo adicional para los sistemas tributarios, la búsqueda de eficiencia y neutralidad ha de ser un principio que guie el diseño de los impuestos. El hecho de que los individuos adopten sus decisiones por razones 
fiscales, en vez de por razones de costos o productividad económica, causa pérdidas de bienestar que se proyectan de manera tangible en un deterioro del crecimiento económico. No obstante, la neutralidad impositiva absoluta es imposible (Sanz-Sanz y Sanz, 2013), e incluso indeseable, cuando se definen metas prioritarias como la suficiencia recaudatoria y la justicia distributiva. Los costos de la tributación pueden resumirse en cuatro categorías:

i) Los costos asociados a la transferencia de renta del sector privado al sector público, o efecto renta.

ii) Los costos de eficiencia vinculados a las distorsiones generadas en los procesos de elección de los agentes económicos, por los cambios en los precios relativos de bienes y/o factores productivos, o efecto sustitución.

iii) Los costos de administración en los que incurre la Administración Tributaria para asegurarse el cobro de los impuestos.

iv) Los costos de cumplimiento en los que debe incurrir el contribuyente para cumplir con sus obligaciones.

Ante lo inevitable del efecto renta, el diseño eficiente de los sistemas fiscales deberá ir encaminado a minimizar los excesos de gravamen y los costos de administración y cumplimiento que produce.

Un punto fundamental de la discusión entre impuestos, crecimiento y distribución del ingreso disponible tiene que ver con la definición conceptual de los sistemas tributarios, y si están orientados a gravar la renta o a gravar el gasto. Si se privilegia el segundo concepto, prevalecerán impuestos indirectos (como en el gráfico 11) y se eximirán los instrumentos de ahorro e inversión (caso típico en la región, lo que tiene amplias consecuencias sobre la equidad vertical de los sistemas).

Si se adopta el primero y se prioriza un objetivo de redistribución, se privilegiará el impuesto a la renta. Tradicionalmente se considera como base imponible el ingreso o renta de las personas (ISR), que de acuerdo a la definición de Haig-Simons, equivale a la variación que experimenta su patrimonio entre dos momentos del tiempo más el consumo durante ese mismo período (cubriendo entonces la totalidad de la renta). Sin embargo, en décadas recientes, la arquitectura del impuesto a la renta ha sido progresivamente desmantelada (Tanzi, 2013), distinguiendo entre diversos tipos de ingresos, y otorgando tratamientos especiales a aquellos que potencialmente estimulan el ahorro y la inversión privada.

El texto legal del impuesto a la renta, a lo largo de su historia, ha sufrido diversas modificaciones que apuntan en la dirección de gravar el gasto y no la renta, con la clara intención del legislador de desgravar el ahorro y la inversión, Por esta y otras razones, los países de América Latina en general han encontrado grandes dificultades para aplicar un impuesto sobre la renta personal global o sintético que alcance a todas las fuentes de ingresos de un mismo contribuyente de acuerdo a una estructura de tasas marginales progresivas. En la mayoría de los casos hay una larga serie de exoneraciones y tratamientos diferenciales según la fuente generadora de ingresos, que atenta contra la equidad horizontal y vertical del tributo y limitan su potencial recaudatorio y redistributivo (Gómez-Sabaíni y Morán, 2013).

En repetidas ocasiones, ante la eventualidad de crisis económicas, la autoridad fiscal ha respondido multiplicando incentivos y exenciones tributarias, con la esperanza (muchas veces vana) de estabilizar la demanda agregada y de controlar los efectos sobre el empleo de las recesiones. Como es sabido, sin embargo, estos instrumentos representan respuestas de oferta a problemas de demanda, por lo que son en general menos eficientes que las medidas monetarias y que los multiplicadores asociados al estímulo del gasto público.

En lo referido a los incentivos tributarios a la inversión, estos pueden ser generales (como la reducción de la tasa del IVA para los bienes de capital, la depreciación acelerada, las exenciones de aranceles a la importación de bienes de capital, la exención de dividendos), localizados en determinadas áreas geográficas (como en zonas extremas) o sectoriales, en determinadas industrias o actividades específicas.

De acuerdo al estudio de Agostini y Jorratt (2013) para diez países de la región, los incentivos generales a la inversión son utilizados en Ecuador y Chile; mientras que los sectoriales han sido 
intensamente aplicados en República Dominicana, Nicaragua, Argentina y Honduras. Respecto de los incentivos de localización, destacan Chile, República Dominicana, Argentina y Perú. Entre los incentivos sectoriales a la inversión, a nivel agregado, sobresalen los incentivos al turismo (22\% del total); los incentivos al sector exportador (19\%) y aquellos para actividades ligadas al sector de energía (15\% del total). Siete de los diez países analizados tienen incentivos para al sector energético (por ejemplo, al desarrollo de biocombustibles, créditos tributarios para la instalación de sistemas solares, exenciones del impuesto sobre la renta a la venta de energía generada con recursos renovables) y seis para minería y turismo.

En los países de la región analizados se observa un claro predominio de las exenciones impositivas a la inversión (un $76 \%$ del total), como la exención de aranceles para la importación de bienes de capital y la exoneración del impuesto a la renta para ciertas actividades o empresas. Las exenciones se aplican en mayor medida en el impuesto a la renta (40\%), pero también en aranceles (26\%) e IVA (23\%). También se recurre al uso de diferimientos del pago de impuestos (como la depreciación acelerada y la devolución anticipada del IVA por compras de bienes de capital) y de las deducciones (por ejemplo, la deducción de parte de la inversión en activos fijos).

En definitiva, aún cuando puedan encontrar justificación en algunos casos puntuales, los incentivos tributarios a la inversión pueden tener un impacto negativo tanto sobre la equidad como sobre la eficiencia de los sistemas. En términos de eficiencia, los incentivos han creado problemas de competencia tributaria interjurisdiccional (dando lugar a una "competencia al abismo" de los impuestos tanto a nivel nacional como regional) y otras distorsiones en las decisiones de localización y producción industrial.

De esta manera, instrumentos que pretenden incentivar las inversiones privadas, como los impuestos cedulares, las bajas tasas a las utilidades reinvertidas sin importar el tamaño de las empresas, la depreciación acelerada, los pactos tributarios o los regímenes sectoriales específicos, en realidad constituyen en muchos casos obstáculos insalvables para alcanzar objetivos de suficiencia recaudatoria y de equidad, dificultando por añadidura la administración tributaria.

\section{Informalidad y tributación ${ }^{16}$}

La informalidad en sentido amplio (productivo) está muy relacionada con la pobreza y la desigualdad de ingresos, dificultando la posibilidad de erradicar este sector en el corto plazo por la imposibilidad de crear empleos de calidad. A su vez, la informalidad está relacionada con la evasión de todos los impuestos, en tanto por su propia existencia no se registran actividades económicas potencialmente imponibles.

La informalidad encuentra vínculos cercanos con las raíces de la desigualdad en la incapacidad del sistema tributario en captar la actividad económica informal: la formalización de contribuyentes, en tanto reduce la evasión tributaria y promueva el cumplimiento voluntario, permite mejorar la equidad horizontal y vertical entre contribuyentes. Por lo tanto es esperable que toda política pública que apunte a reducir los niveles de informalidad produzca, directa o indirectamente, efectos positivos sobre la equidad entre los contribuyentes.

En años recientes, el crecimiento económico y la reducción de los niveles de desigualdad en América Latina han derivado en una moderada reducción del tamaño de la economía informal en todos los países de la región.

Como corolario de ello y dada la relación entre informalidad y evasión tributaria, los países han diseñado en los últimos años distintas estrategias para incrementar sus recursos tributarios y, a su vez aumentar el control sobre los contribuyentes, para lo cual han venido aplicando instrumentos heterodoxos como los regímenes simplificados para pequeños contribuyentes e impuestos mínimos o presuntivos del ISR empresarial, y se han introducido reformas en la administración tributaria tendientes a facilitar el pago de los impuestos y aumentar el nivel de cumplimiento tributario.

16 Esta sección es un extracto de Gómez-Sabaíni y Morán, 2012. 
En los últimos años se ha incrementado el interés de la política tributaria sobre las PYMES y los pequeños contribuyentes en general. Parece existir consenso en que la principal motivación para aplicar estos regímenes especiales en América Latina radica en la necesidad de garantizar el cumplimiento voluntario de sus obligaciones tributarias minimizando el costo implícito para las empresas más pequeñas y el costo que su administración representa para las Administraciones Tributarias, el cual se acrecienta en los países de menor grado de desarrollo.

El diseño de tratamientos especiales para gravar a los pequeños contribuyentes, ya sean estos personas físicas o empresas excluyéndolos de las normas generales del IVA y/o del ISR, estableciendo métodos presuntivos de determinación del impuesto y/o imponiéndoles tasas más reducidas, ha sido uno de los principales caminos que han adoptado los países de América Latina para "descomprimir" la carga de trabajo de las administraciones tributarias y mejorar así sus capacidades de fiscalización.

En la mayoría de los países la instrumentación de regímenes especiales de tributación para los pequeños contribuyentes no ha tenido como objeto primordial la recaudación tributaria, sino resolver una problemática de administración tributaria con la finalidad de incorporar a la formalidad a un amplio sector de contribuyentes de escasa significación económica.

Cabe aclarar que los esquemas simplificados de la región se aplican fundamentalmente sobre personas físicas que realizan actividades económicas, aunque en algún caso se extienden también a ciertos tipos de personas jurídicas tal como sucede en Brasil, Costa Rica, Chile, México y Perú. Además, prevén la adhesión voluntaria y la auto-categorización, y están dirigidos principalmente a los sectores de comercio y prestación de servicios.

No obstante, la experiencia muestra que su implementación debe ser cuidadosa puesto que también podrían generar resultados contrarios a los deseados, ya que estos regímenes especiales pueden crear una "trampa", especialmente en lo referido a los incentivos para el crecimiento de una empresa. En contextos de elevada informalidad y donde se percibe un bajo riesgo implícito para las acciones de evasión impositiva, el régimen simplificado debería constar de tasas impositivas reducidas y condiciones de conformidad realmente favorables como para atraer a los contribuyentes de menores ingresos. Pero esto, al mismo tiempo, actúa como incentivo para las empresas que se encuadran dentro de estos esquemas para permanecer dentro del régimen especial aún teniendo la capacidad de tributar bajo el régimen general de tributación.

De este modo, la aplicación de este tratamiento tributario especial podría ser contraproducente tanto en materia de ingresos tributarios (si permite disminuir la carga tributaria de los contribuyentes del régimen general), de eficiencia económica (si incentiva actitudes de "enanismo fiscal" en las empresas) y de equidad distributiva (si brinda ventajas legales a contribuyentes que se aprovechan de los beneficios brindados por el régimen simplificado).

Por lo tanto, se debe reconocer la existencia de sectores particulares (actividades primarias y terciarias especialmente), pero asimismo se debe evitar la "masificación" de los regímenes simplificados si se pretende elevar el cumplimiento voluntario y hacer más equitativo el sistema tributario.

\section{E. Un recuento de los determinantes de la distribución del ingreso}

En el período reciente, la gran mayoría de los países de América Latina combinó crecimiento económico con mejoras apreciables en sus índices de Gini. Sin duda, las mejoras del empleo formal y el consecuente aumento de los ingresos laborales explican buena parte de estos progresos. Como se detalla en CEPAL (2012c), la descomposición de las variaciones de la desigualdad revela que el ingreso por adulto aparece como el principal factor impulsor de la mejora distributiva. En diez países de la región la variación del ingreso laboral explica el $90 \%$ o más del total de estas mejoras; en otros cinco el cambio de los ingresos no laborales, esencialmente transferencias, contribuyó en un $40 \%$ o más en la reducción de la desigualdad. No cabe duda que futuras mejoras han de tener un componente fiscal significativo, al menos mientras la distribución primaria se mantenga tan desigual. 
El efecto redistributivo de la acción fiscal directa depende del nivel, composición y grado de progresividad de cada componente de impuestos y transferencias. Estas tres dimensiones definen las características de cada país (véase Joumard et al., 2012):

i) Impuestos y transferencias directas tienen un impacto redistributivo significativo en los países de la OCDE; la desigualdad en el ingreso disponible después de impuestos y transferencias es $30 \%$ menor que la desigualdad antes de impuestos y transferencias. Medida por el índice de Gini, la reducción es de 15 puntos en promedio en la OCDE.

ii) Los países de la OCDE que tienen una distribución más desigual del "ingreso de mercado" (previo a impuestos y transferencias) tienden a redistribuir más. Los casos extremos son Italia, Inglaterra y Finlandia, cuyos coeficientes de Gini pasan de 0,55 a 0,35, de 0,50 a 0,32 y de 0,48 a 0,25 , respectivamente. Un caso especial es Corea, que tiene un bajo coeficiente de Gini $(0,34)$ previo a la acción fiscal, y de 0,31 luego de ella. Aunque este país carece de transferencias directas significativas a los hogares y tiene una presión fiscal reducida, la igualitaria distribución primaria del ingreso puede asociarse al tremendo salto en educación de los últimos treinta años, pues más de un 65\% de la generación de 25-34 años posee educación terciaria, en contraste con algo más de 10\% de la generación de 55-64 años.

iii) En los países de la OCDE, las transferencias directas reducen más la dispersión del ingreso que los impuestos; tres cuartos de la reducción en la desigualdad entre el ingreso de mercado y el ingreso disponible pueden atribuirse a las transferencias, y el resto a los impuestos.

iv) $\mathrm{Al}$ tratarse esencialmente de pensiones en sistemas de reparto, en el promedio de países OCDE las transferencias reducen sobre todo la inequidad para los mayores de 65 años, pasando el coeficiente de Gini de 0,70 a 0,29 para este grupo etario. En cambio, para la población en edad de trabajar el coeficiente se reduce de 0,41 a 0,31. En países con sistemas públicos de pensiones maduros, los mayores de 65 años son pobres en términos de rentas de mercado y las pensiones públicas son su principal fuente de recursos.

En los países de América Latina la distribución del ingreso, muy desigual antes de impuestos y transferencias directas, mejora sólo levemente por la acción fiscal directa. Lustig et al. (2013) encuentran que la magnitud de la reducción de la desigualdad inducida por impuestos directos y transferencias en efectivo, aunque más significativa en Argentina, Brasil y Uruguay (del orden de 5\% del Gini), es muy acotada en el resto de la región ( $2 \%$ en promedio) ${ }^{17}$.

Esto se relaciona, por un lado, con un menor nivel relativo de transferencias en efectivo (sobre todo de las más progresivas) pero, además, con un impacto reducido de los impuestos directos, debido a que su limitada recaudación es de aproximadamente la mitad que los impuestos indirectos, los cuales tienen un efecto regresivo sobre la distribución del ingreso. La escasa contribución del ISR (especialmente personal), unida al pequeño monto recaudado por los impuestos a la propiedad y al patrimonio, hace que los sistemas tributarios contribuyan muy poco a mejorar los coeficientes de Gini; la redistribución vía impuestos es prácticamente inexistente en la región (véase CEPAL, 2013a).

En cuanto a los efectos redistributivos indirectos o de más largo plazo de las políticas fiscales, Tanzi et al. (2008) plantean que en un momento dado, en un país dado, la distribución del ingreso "primaria" (previa a la intervención del Estado) estaría determinada, en términos generales, por diversas herencias, de la riqueza tangible y material, del capital humano, incluyendo una infinidad de activos que determinan el capital social de una persona, y de las políticas públicas pasadas.

Importa así destacar la preponderancia de factores hereditarios, que no se pueden cambiar en el corto plazo, y que tienen que ver esencialmente con la posición social inicial de los individuos en la sociedad; es claro que la distribución previa del ingreso es un importante factor explicativo del valor actual del coeficiente de Gini. La persistencia presentada por los indicadores de desigualdad de ingresos

17 Sin embargo, de acuerdo con este estudio, las transferencias en especie, tanto en educación como en salud, logran redistribuir más que las transferencias en efectivo en los seis países. La disminución final de la desigualdad cuando se agrega este concepto supera el $20 \%$ en Argentina, Brasil y Uruguay mientras que en México, Bolivia y Perú el efecto es menor (16\%, 11\% y 8\%, respectivamente). 
ciertamente refleja heterogeneidad estructural y la inexistencia de políticas capaces de modificar esta situación, pero también proviene de una desigual distribución de los activos, tanto físicos como humanos.

Como lo recuerdan Infante y Sunkel (2009), "la heterogeneidad estructural de América Latina se manifiesta en niveles diferentes de productividad de los ocupados en los distintos estratos productivos, lo que es el factor originario de la desigual distribución del ingreso". Por tanto reducir dichas brechas de productividad supone políticas distributivas, además de redistributivas, de modo a mejorar el ingreso primario (autónomo) de los sectores menos favorecidos. Si bien este tipo de intervenciones son necesarias, no se pueden cuantificar fácilmente ${ }^{18}$, y no parece necesario plantear un dilema entre este tipo de fomento productivo y las políticas sociales.

Otro factor explicativo se relaciona directamente al mercado del trabajo, en su capacidad de agregar movilidad social, lo que se vincula también a la demanda por empleo, a la evolución de los salarios y por tanto al nivel de actividad. Sin pretender exhaustividad en cuanto a los factores explicativos de la desigualdad de ingresos, el objeto de esta sección es resaltar la importancia de la política fiscal en los objetivos conjuntos de crecimiento y distribución.

En tal sentido, la provisión de bienes públicos tiene efectos indirectos y de más largo plazo, pues las políticas que inciden en la productividad de los más pobres tienen grandes retornos en materia de equidad. Los gastos públicos en justicia, seguridad ciudadana, infraestructura y transporte público, salud, capacitación laboral, inclusión social, y tantos otros, benefician más que proporcionalmente a los más pobres, al insertarlos a la fuerza laboral en mejores condiciones.

El nivel de impuestos y su progresividad impacta también indirectamente sobre la distribución del ingreso. La capacidad del sistema tributario para corregir distribuciones desiguales dependerá del volumen recaudado y de la estructura de tasas según niveles de ingresos, pero también de la evasión del impuesto a la renta y del número de exenciones. A mediano plazo, el sistema tributario puede también tener influencia sobre la oferta de trabajo (por ejemplo si existen muchas cargas asociadas al empleador), el esfuerzo individual y el tamaño de las familias, todos asuntos que inciden en la evolución del coeficiente de Gini.

En la región, la evidencia empírica reciente (González y Martner, 2012) muestra que las políticas fiscales han afectado significativamente la distribución del ingreso, directamente por el gasto social y la progresividad tributaria, e indirectamente por la calidad de la educación y de las instituciones. Asimismo se subraya el papel primordial de los ingresos laborales en las mejoras recientes.

Resulta interesante, sobre la base de la ecuación de panel estimada para 18 países en el artículo recién citado, descomponer las variaciones del índice de Gini entre 2000 y 2011 (véase el cuadro 10). Se observa que la mejora de 4,4 puntos de Gini obedeció esencialmente al cambio en tres variables: el gasto social, el indicador de capital humano y la tasa de desempleo.

18 Muchas políticas de fomento productivo tienen un componente financiero (Banca de Desarrollo, préstamos subsidiados a ciertas actividades,) más que presupuestario, como es generalmente el caso de las políticas sociales, por lo que no resulta fácil contrastar ambas formas de redistribución. 


\section{CAMBIOS EN EL COEFICIENTE GINI Y EN SUS VARIABLES EXPLICATIVAS, 2000-2011}

\begin{tabular}{|c|c|c|c|c|}
\hline Variables & 2000 & 2011 & $\begin{array}{l}\text { Cambio variables entre } \\
2000-2011 \text { (en puntos) }^{a}\end{array}$ & $\begin{array}{l}\text { Cambio en el coeficiente de } \\
\text { Gini (en puntos, por cien) }\end{array}$ \\
\hline \multicolumn{5}{|l|}{ Fiscales } \\
\hline Gasto social sobre el PIB & 11,70 & 14,50 & 2,80 & $-1,16$ \\
\hline Gasto público de capital sobre el PIB & 3,40 & 4,50 & 1,10 & $-0,25$ \\
\hline $\begin{array}{l}\text { Índice de progresividad tributaria (razón } \\
\text { de impuestos directos sobre impuestos } \\
\text { indirectos) }\end{array}$ & 43,00 & 58,70 & 15,70 & $-0,22$ \\
\hline \multicolumn{5}{|l|}{ Institucionales } \\
\hline Índice de estabilidad política & 40,55 & 40,47 & $-0,08$ & 0,00 \\
\hline \multicolumn{5}{|l|}{ Logros en educación } \\
\hline $\begin{array}{l}\text { Gasto público en educación } \\
\text { sobre PIB }\end{array}$ & 3,90 & 5,00 & 1,20 & $-0,02$ \\
\hline $\begin{array}{l}\text { Indicador de capital humano } \\
\text { (razón número de personas con educación } \\
\text { terciaria y secundaria sobre personas con } \\
\text { educación primaria) }\end{array}$ & 72,50 & 86,90 & 14,40 & $-1,44$ \\
\hline \multicolumn{5}{|l|}{ Macroeconómicas } \\
\hline Tasa de desempleo & 10,20 & 7,20 & $-3,00$ & $-1,31$ \\
\hline Coeficiente de Gini & 0,54 & 0,50 & $-4,30$ & $-4,40$ \\
\hline
\end{tabular}

Fuente: Cálculos propios, en base a resultados de González y Martner (2012).

a En las variables expresadas sobre PIB, se calculan los cambios en puntos del PIB; en el Gini, en puntos de Gini por cien; en las demás variables las variaciones son absolutas.

Particular atención merecen los indicadores de capital humano, que en cualquiera de sus mediciones resultan altamente significativos en la determinación de la distribución del ingreso disponible, tanto en un corte temporal como en una visión transversal (gráfico 12).

\section{GRÁFICO 12 \\ ÍNDICE DE GINI Y AÑOS DE EDUCACIÓN DE LA POBLACIÓN ENTRE 25 Y 64 AÑOS, 2011}

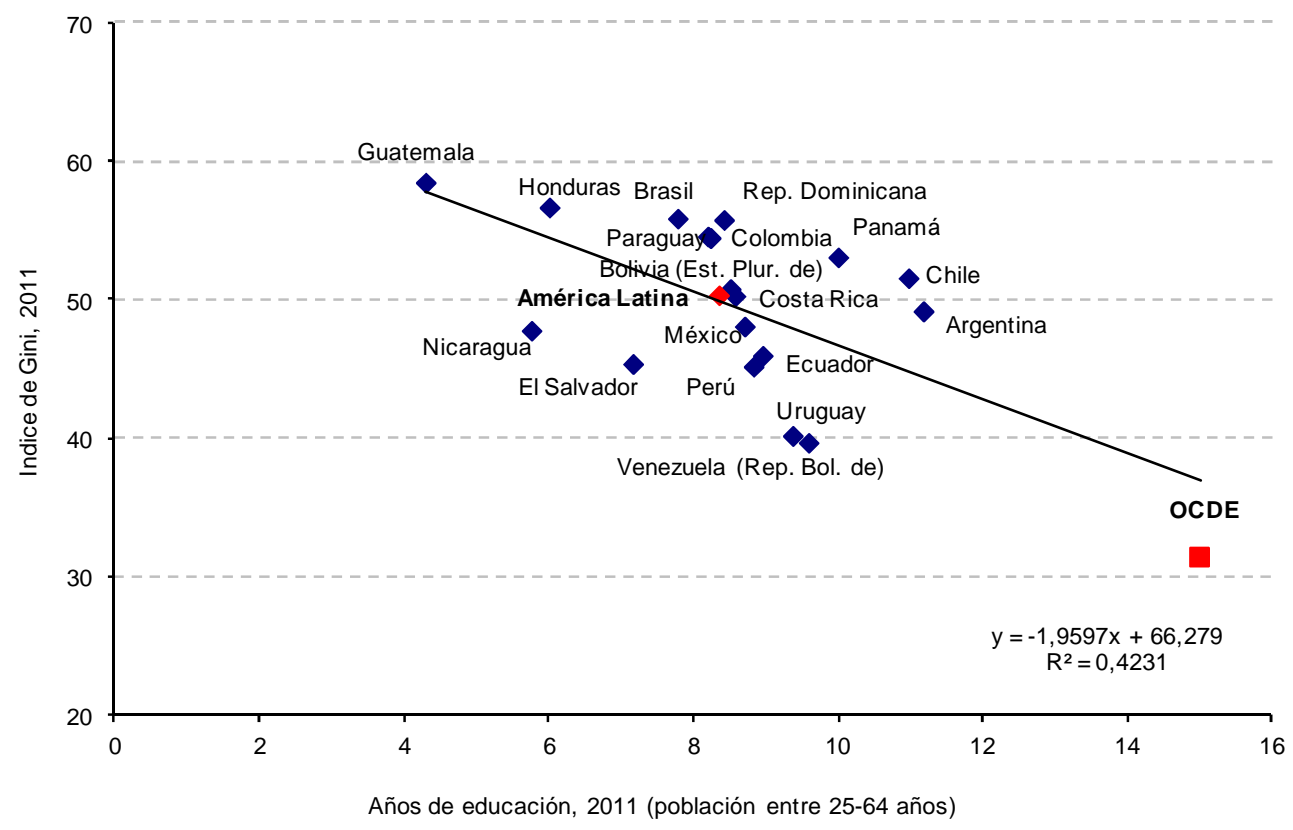

Fuente: Elaboración propia, sobre la base de datos oficiales. 


\section{Comentarios finales}

Como consecuencia de la crisis financiera internacional, la discusión sobre la política fiscal ha estado muy marcada en los últimos años (y seguirá estándolo en el futuro cercano) por el dilema entre estabilización macroeconómica y sostenibilidad de la deuda pública. Así como los eventos recientes en Europa han demostrado que no basta con políticas de austeridad fiscal para reducir la incertidumbre y dinamizar el crecimiento (en especial porque los multiplicadores fiscales son mucho más elevados de lo anticipado, veáse Blanchard y Leigh, 2013), la propia dinámica perversa de la deuda pública, en condiciones de estancamiento, ha ilustrado la dificultad de llevar a cabo políticas fiscales contracíclicas cuando el origen de la crisis es financiera. Más allá de los matices, importa encauzar este dilema hacia una perspectiva de mediano plazo; no sólo se trata de aplicar paquetes de estímulo fiscal en condiciones cíclicas adversas, sino de delinear estrategias que apunten a potenciar el crecimiento de las economías.

En palabras (aproximadas) de Jeffrey Sachs (2011), "No basta con gastar y reducir impuestos para que la economía se recupere y vuelva a la normalidad; creo fuertemente en el papel de la inversión pública para satisfacer las necesidades de la sociedad (...). Necesitamos modernizar nuestra infraestructura, renovar nuestro sistema eléctrico, mejorar nuestras ciudades, y entrenar a una nueva fuerza laboral. Ello requiere programas de gobierno bien diseñados, y una buena coordinación con los gobiernos locales. Estas políticas deben incluir aumentos de ingresos provenientes de la imposición a la riqueza y a los ingresos altos, a las transacciones financieras, a las ganancias de capital y a las emisiones de carbono".

Aunque, afortunadamente, América Latina ha podido crecer y controlar su deuda pública en los últimos años, los desafíos de mediano plazo son muy similares a los reseñados; sólo un gasto público de mayor calidad, debidamente respaldado por un sistema tributario eficiente y equitativo, podrá permitir transitar hacia esquemas de desarrollo sostenible y con grados crecientes de igualdad e inclusión social.

Superar los dilemas de corto plazo entre estabilidad macroeconómica, crecimiento de largo plazo, protección social y tributación supone la creación o consolidación de Instituciones orientadas a construir políticas fiscales transparentes y con objetivos claros. El consenso social y la legitimidad del gobierno y del Estado se construyen sobre la base de la confianza que los ciudadanos tienen sobre la acción estatal.

Como se plantea en la Hora de la Igualdad (CEPAL, 2010), "es necesario crear una nueva arquitectura estatal que permita posicionar al Estado en el lugar que le corresponde en la conducción de las estrategias de desarrollo de los países de la región, articulando acciones al menos en cinco grandes 
ejes: dinamizando el crecimiento económico; promoviendo la convergencia en la productividad sectorial, fomentando una mayor articulación territorial; impulsando mejores condiciones de empleo e institucionalidad laboral y proveyendo bienes públicos y protección social con clara vocación universalista y redistributiva".

En este marco la CEPAL viene planteando desde hace ya quince años la relevancia de este pacto fiscal (CEPAL, 1998, 2013; Fuentes Knight, 2012). Así, la idea de pacto fiscal se asocia estrechamente al diseño explícito y consensuado de una ruta de navegación de mediano y largo plazo, y a la necesidad de un diseño integral de políticas y programas públicos. 


\section{Bibliografía}

Adam, C. S. y D. L. Bevan (2005), "Fiscal Deficits and Growth in Developing Countries", Journal of Public Economics 89: 571-97.

Aghion, P., E. Caroli y C. Garcia-Penalosa (1999), "Inequality and Economic Growth: The Perspective of the New Growth Theories", Journal of Economic Literature, 37: 1615-60.

Agostini, C. y M. Jorrat (2013): "Política tributaria para mejorar la inversión y el crecimiento en América Latina", Serie Macroeconomía del Desarrollo, 130, CEPAL

Alesina, A., Perotti, R. (1995): "Fiscal Expansions and Adjustments in OECD Countries", Economic Policy, 1995, 207-248, 21, October.

Alesina, A. y D. Rodrik (1994), "Distributive Politics and Economic Growth", Quarterly Journal of Economics, 109: 465-90.

Angelopoulos, K., Economides, G y Kammas, P. (2007), "Tax-spending policies and economic growth: theoretical predictions and evidence from the OECD”, European Journal of Political Economy, 23, 885-902.

Arnold, J., Brys, B., Heady, C., Johansson, Å., Schwellnus, C. y Vartia, L. (2011), “Tax policy for economic recovery and growth. " Economic Journal, 121, February, 2011, F59-F80.

Auerbach A. y Gorodnichenko, Y. (2012), "Measuring the Output Responses to Fiscal Policy", American Economic Journal: Economic Policy, 4(2), 1-27.

Barro, R. (1990), "Government Spending in a Simple Model of Exogenous Growth", Journal of Political Economy, 98: 103-125.

Bayraktar, N. y B. Moreno-Dodson (2010), "How Can Public Spending Help You Grow? An Empirical Analysis for Developing Countries", Policy Research Working Paper 5367, World Bank, Washington, DC.

Bennmarker, H, Mellander, E y Öckert, B. (2009), "Do Regional Payroll Tax Reduction Boost Employment?", Labor Economics, 16, 480-489.

Bils, M. y Klenow, P. (2008), "Fiscal Stimulus in the Form of Lower Payroll Taxes", Stanford, CA: SIEPR Policy Brief.

Blanchard O. y Leigh D. (2013): "Growth Forecast Errors and Fiscal Multipliers", International Monetary Fund, WP/13/1.

Bose, N., M. E. Haque y D. R. Osborn (2007), "Public Expenditure and Economic Growth: A Disaggregated Analysis for Developing Countries", Manchester School 75 (5): 533-56.

Bourguignon, F. (1998), "Distribution, Redistribution and Development: Where Do We Stand?", DELTA Working Papers 98-11. 
CEPAL (1998), El Pacto Fiscal. Fortalezas, debilidades, desafíos. Síntesis (LC/G.2024) Santiago, Chile. (2010), La hora de la igualdad. Brechas por cerrar, caminos por abrir. Documento del trigésimo tercer período de sesiones, Brasilia.

CEPAL-Secretaría General Iberoamericana (2011), Espacios Iberoamericanos. Hacia una nueva arquitectura del Estado para el desarrollo, Santiago, Chile.

CEPAL (2012a): "Cambio estructural para la igualdad: Una visión integrada del desarrollo (LC/G.2524 (SES.34/3)), Santiago, Chile. , (2012b), Estudio Económico de América Latina y el Caribe 2012 (LC/G.2546-P), Santiago de Chile. (2012c), "Panorama Social de América Latina 2012", LC/G.2557-P, Santiago de Chile. (2013a), "Panorama fiscal de América Latina y el Caribe. Reformas tributarias y renovación del pacto fiscal", LC/G.3580, Santiago, Chile.

(2013b), "Estudio Económico de América Latina y el Caribe. Tres décadas de crecimiento inestable", documento informativo, 2013-384, Santiago de Chile.

Cornia, G. A., Gómez-Sabaini, J.C. y Martorano, B. (2011), "A New Fiscal Pact, Tax Policy Changes and Income Inequality. Latin America during the last decade", Working Paper No. 2011/70, UNUWIDER.

Cornia, G.A. (2005), "Inequality, Growth and Poverty in an Era of Liberalisation and Globalisation". Oxford: Oxford University Press.

De la Fuente A. (1997), "Fiscal Policy and Growth in the OECD", CEPR Discussion Paper No. 1755.

Devarajan, S., Swaroop, V. y Zou, H. (1996). "The Composition of Public Expenditure and Economic Growth" Journal of Monetary Economics, vol. 37, 313-344.

Fuentes Knight, J.A. (2012): "Hacia Pactos fiscales en América latina: entre la reciprocidad y la confrontación, in Barcena, Serra (eds), CEPAL/SEGIB/CIDOB.

Futagami, K., Morita, H. y Shibata, A. (1993). "Dynamic analysis of an endogenous growth model with public capital" Scandinavian Journal of Economics, 95, pp. 607-25.

Gemmell, N. (2010) "Public expenditure and economic growth. What do we know?", Presentación al Banco Mundial, Workshop on Fiscal Policy for Growth and Development, Washington, D.C.

Gemmell, N., Kneller, R. y Sanz, I. (2009), "The Composition of Government Expenditure and Economic Growth," en S. Barrios, L. Pench, y A Schaechter (eds.) European Economy: The Quality of Public Finances and Economic Growth. Bruselas: Comisión Europea, 17-45.

(2011a), "The growth effects of corporate and personal tax rates in the OECD" Bond University Working Paper Series; No. 49, May 2011.

(2011b), "The timing and persistence of fiscal policy impacts on growth: evidence from OECD countries", Economic Journal, 121, February, 2011, F33-F58.

Gemmell, N., Misch, F. y Moreno-Dodson, B. (2012) "Public Spending and Long-Run Growth in Practice: Concepts, Tools, and Evidence" en Moreno-Dodson, B. (ed.), Is Fiscal Policy the Answer? A Developing Country Perspective Washington, D.C., World Bank.

Ghosh, S. y A. Gregoriou (2008), "The Composition of Government Spending and Growth: Is Current or Capital Spending Better?" Oxford Economic Papers 60 (3): 484-516.

Giavazzi F. y McMahon, M. (2012), "The Household effects of Government Spending”, en Alesina, A. y Giavazzi, F. (eds.), Fiscal Policy After the Great Recession, University of Chicago Press y NBER.

Gómez-Sabaíni, J.C. y D. Morán (2012): "Informalidad y tributación en América Latina: Explorando los nexos para mejorar la equidad", serie Macroeconomía del desarrollo, 124, CEPAL. (2013): Política tributaria en América Latina: agenda para una segunda generación de reformas", serie Macroeconomía del Desarrollo, 133, CEPAL.

González, I., y R. Martner (2012): Superando el "síndrome del casillero vacío". Determinantes de la distribución del ingreso en América Latina, Revista de la CEPAL, 108.

Gupta, S., B. Clements, E. Baldacci y C. Mulas-Granados (2005), "Fiscal Policy, Expenditure Composition, and Growth in Low-Income Countries", Journal of International Money and Finance 24 (3): 441-63.

Haque, M. E. (2004), "The Composition of Public Expenditures and Economic Growth in Developing Countries." Global Journal of Finance and Economics 1 (1): 97-117.

Harju, J. y Kosonen, T. (2012) "The Impact of Tax Incentives on the Economic Activity of Entrepreneurs", NBER Working Paper No. 18442.

Hoeller, P. Joumard I., Pisu M., Blochy D. (2012), "Less income inequality and more growth. Are they compatible? Part 1. Mapping income inequality across the OECD", OECD Economics Department Working Papers, N 924, OECD Publishing. 
Hong, H. y S. Ahmed (2009), "Government Spending on Public Goods: Evidence on Growth and Poverty." Economic and Political Weekly 44 (31): 102-08.

Infante, R, y Sunkel, O. (2009), Chile: Hacia un desarrollo inclusivo, Revista de la CEPAL, 98, abril, pp. 135-154.

Jaimovich, D. y Panizza, U. (2007): "Procyclicality or Reverse Causality?, IDB Working Paper No. 501

Johannson, A., Heady, C. Arnold, J., Brys, B. y Vartia, L. (2008) "Taxation and Economic Growth," Paris: OECD Economics Department Working Paper 620.

Jorgenson, D. y Yun, K. (2001), "Investment Volume 3: Lifting the Burden: Tax Reform, the Cost of Capital, and U.S. Economic Growth", Cambridge: MIT Press.

Joumard, I., M. Pisu and D. Bloch (2012), "Tackling income inequality: The role of taxes and transfers", OECD Journal: Economic Studies,

Keane, M. (2011), "Labor Supply and Taxes: A Survey," Journal of Economic Literature, XLIX(4): 9611075 .

Loayza, N. (1996). "The Economics of the Informal Sector: A Simple Model and Some Empirical Evidence from Latin America". Carnegie-Rochester Conference Series on Public Policy, 45(1): 129-62.

López, R. y S. Miller (2007), "The Structure of Public Expenditure: A Robust Predictor of Economic Development? College Park, MD: University of Maryland.

Lozano, I. (2009): "Caracterización de la Política Fiscal en Colombia y Análisis de su Postura Frente a la Crisis Internacional", Borradores de Economía, 566.

Lindert, P. (2003): "Why The Welfare State Looks Like a Free Lunch," Working Papers 27, University of California, Davis, Department of Economics.

Lustig, Nora, Carola Pessino, and John Scott. 2013. "The Impact of Taxes and Social Spending on Inequality and Poverty in Argentina, Bolivia, Brazil, Mexico and Peru: An Overview.” Public Finance Review, forthcoming.

M'Amanja, D. y O. Morrissey (2005), "Fiscal Policy and Economic Growth in Kenya", CREDIT (Centre for Research in Economic Development and International Trade) Research Paper 05/06, University of Nottingham, U.K.

Manski, C. (2012) "Identification of Income-Leisure Preferences and Evaluation of Income Tax Policy", Cemmap Working Paper 07/12, Institute for Fiscal Studies.

Martner, R. (2007): "La política fiscal en tiempos de bonanza”, Serie Gestión Pública, 66, CEPAL. (2000), "Estrategias de política económica en un mundo Incierto. Reglas, indicadores, criterios", Serie cuadernos del ILPES No 45, CEPAL, Naciones Unidas.

Martinez, R., A.Palma, L.Flores y M.P.Collinao (2013): EL impacto económico de las políticas sociales", Serie Documentos de proyecto, CEPAL.

Meghir C. and Phillips D. (2010), "Labour Supply and Taxes" in Dimensions of Tax Design, The Mirrlees Review, Sir James Mirrlees (editor): 202-274. Oxford: Oxford University Press.

Mendoza, E., Milesi-Ferretti G. y Asea P. (1997) "On the ineffectiveness of tax policy in altering long-run growth: Harberger's superneutrality hypothesis", Journal of Public Economics, 66, 99-126.

Miller S., y Russek F. (1997), "Fiscal structures and economic growth: international evidence", Economic Inquiry, 35, 603-613.

Moreno-Dodson, B. (2012): "Is Fiscal Policy the Answer? A Development Country Perspective", The World Bank.

Muinelo-Gallo L. y Roca-Sagalés, O. (2011), "Economic Growth and Inequality: The Role of Fiscal Policies", Australian Economic Papers 50 (2-3), pp. 74

Musgrave, R. y J. Buchanan (1999), Public Finance and Public Choice: Two Contrasting Visions of the State, MIT Press Books, The MIT Press, edition 1, volume 1, number 0262024624, December.

Nijkamp, P. y Poot, J (2004), "Meta-analysis of the effects of fiscal policies on long-run growth", European Journal of Political Economy, 20, 91-124.

OCDE/CEPAL (2011): "Perspectivas Económicas de América Latina 2012: Transformación del Estado para el Desarrollo", OECD Publishing.

Panizza, U. y A. Presbitero (2012), "Public debt and economic growth: is there a causal effect?", MoFiR Working Paper, $\mathrm{N}^{\mathrm{o}} 65$.

Perrotti, D. y Sánchez, R. (2011). La brecha de infraestructura en América Latina y el Caribe”. Serie Recursos Naturales e Infraestructura; 153, CEPAL.

Piketty, T., Saez, E. y Stantcheva, S. (2011), "Optimal Taxation of Top Labor Incomes: A Tale of Three Elasticities", CEPR Discussion Paper 8675.

Rocha, F. y A. C. Giuberti (2007), "Composição do gasto público e crescimento econômico: uma avaliação macroeconômica da qualidade dos gastos dos Estados brasileiros." Economia Aplicada 11 (4): 463-85. 
Rodrik, D. (2008), "The real exchange rate and economic growth", Brookings Papers on Economic Activity, vol. $2008, \mathrm{~N}^{\mathrm{o}} 2$.

Roeger, W. y in't Veld, J. (2012), “On the appropriate fiscal stance in the current crisis”, mimeo, Directorate General for Economic and Financial Affairs, Comisión Europea.

Romero-Avila, D. y Strauch, R. (2008), "Public finances and long-term growth in Europe: Evidence from a panel data analysis", European Journal of Political Economy, 24, 172-191.

Sachs, J. (2011): "The Price of Civilization", Random House.

Salinas Jiménez, J. y Delgado Rivero, F. (2012), "Impuestos, crecimiento económico y bienestar: una visión panorámica", Documento presentado en el XXIV Seminario Regional de Política Fiscal, Santiago de Chile, 24-26 de enero.

Sanchez, W. y H.Galindo (2013): "Multiplicadores Asimétricos del Gasto Público y de los Impuestos en el Perú", Documento de trabajo, Ministerio de Economía y Finanzas.

Sanz-Sanz, J.F. y Sanz Labrador, I. (2013), "Política fiscal y crecimiento económico: Consideraciones microeconómicas y relaciones macroeconómicas", CEPAL, Santiago de Chile.

Schuknecht, L. y Tanzi, V. (2005), "Reforming Public Expenditure in Industrialised Countries. Are there Trade-Offs?" European Central Bank, Working Paper No. 435.

Tanzi, V. (2009): "The Role of the State and Public Finance in the Next Generation" in Martner Ricardo (editor) "Las finanzas públicas y el pacto fiscal en América Latina" CEPAL - Serie Seminarios y Conferencias No 54.

Tanzi, V. (2013): "Tax Reform In Latin America: A long term assessment", paper presented at the XXV Regional Seminar on Fiscal Policy, ECLAC, Santiago (Chile).

Tanzi, V., A. Afonso and L. Schuknecht (2008), Income Distribution Determinants and Public Spending Efficiency, Working Paper No. 861, European Central Bank.

Unctad (2011): Trade and Development Report, United Nations.

Venieris, Y.P. y D.K. Gupta (1986), "Income Distribution and Sociopolitical Instability as Determinants of Savings: A Cross-sectional Model”, Journal of Political Economy, 94(4): 873-83.

Vargas H., A. González y Lozano I. (2012): "Macroeconomic Effects of Structural Fiscal Policy Changes in Colombia", Borradores de Economía, 691.

Yan, C. y L. Gong (2009), "Government Expenditure, Taxation and Long-Run Growth." Frontiers of Economics in China 4 (4): 505-25. 


\section{Serie}

\section{E P A L Macroeconomía del Desarrollo}

\section{Números publicados}

\section{Un listado completo así como los archivos pdf están disponibles en www.cepal.org/publicaciones}

138. Políticas fiscales para el crecimiento y la igualdad, Ricardo Martner, Andrea Podestá e Ivonne González, (LC/L.3716), 2013.

137. Desarrollo minero y conflictos socioambientales. Los casos de Colombia, México y Perú, Miryam Saade, (LC/L.3706), 2013.

136. Rasgos estilizados de la relación entre inversión y crecimiento en América Latina y el Caribe, 1980-2012, Luis Felipe Jiménez y Sandra Manuelito, (LC/L.3704), 2013.

135. Impactos de las reformas recientes de política fiscal sobre la distribución de ingresos. El caso del Perú, Andrés A. Escalante (LC/L.3699), 2013.

134. Política fiscal y crecimiento económico. Consideraciones microeconómicas y relaciones macroeconómicas, José Félix Sanz-Sanz e Ismael Sanz Labrador (LC/L.3638), 2013.

133 Política tributaria en América Latina: agenda para una segunda generación de reformas, Juan Carlos Gómez Sabaíni y Dalmiro Morán (LC/L.3632), 2013.

132. Descentralización, inversión pública y consolidación fiscal: hacia una nueva geometría del triángulo, Roberto Fernández Llera (LC/L.3622), 2013.

131. La arquitectura financiera mundial y regional a la luz de la crisis, José Antonio Ocampo (LC/L.3584), 2013.

130. Política tributaria para mejorar la inversión en América Latina, Claudio Agostini y Michel Jorratt (LC/L.3589), 2013.

129. La inversión y el ahorro en América Latina: nuevos rasgos estilizados, requerimientos para el crecimiento y elementos de una estrategia para fortalecer su financiamiento, Sandra Manuelito y Luis Felipe Jiménez (LC/L.3603), 2013.

128. Interacciones intergubernamentales entre los impuestos sobre el petróleo y el gas y la protección ambiental, Giorgio Brosio (LC/L.3583), 2013.

127. Política fiscal e inversión: Un enfoque sistémico y de crecimiento inclusivo, José María Fanelli (LC/L.3556), 2013.

126. Elites económicas, desigualdad y tributación, Juan Pablo Jiménez y Andrés Solimano (LC/L.3552), 2012.

125. La reforma tributaria uruguaya de 2006: algunas consideraciones de economía política y comportamental, Andrés Rius (LC/L.3550), 2012.

124. Informalidad y tributación en América Latina: Explorando los nexos para mejorar la equidad, Juan Carlos Gómez Sabaíni y Dalmiro Morán (LC/L.3534), 2012.

123. Clase media y política fiscal en América Latina, Diego Avanzini (LC/L.3527), 2012.

122. Crecimiento, empleo y distribución de ingresos en América Latina, Jürgen Weller (LC/L.3516), 2012.

121. Revenue sharing: the case of Brazil's ICMS, José Manuel Arroyo, Juan Pablo Jiménez and Carlos Mussi (LC/L.3489), 2012.

120. Estimación de la recaudación potencial del impuesto a la renta en América Latina, Darío Rossignolo (LC/L.3484), 2012.

119. Imposición a la renta personal y equidad en América Latina: Nuevos desafíos, J. C. Gómez Sabaíni, J. Pablo Jiménez y Darío Rossignolo (LC/L.3477), 2012.

118. Tax structure and tax evasion in Latin America, Juan Carlos Gómez Sabaíni and Juan Pablo Jiménez (LC/L.3455), 2012. 